\author{
苯并三氮唑类有机光伏材料研究进展 \\ 白阳 $a$ 薛灵伟 $*, a$ 王海侨 $a, b$ 张志国*,a \\ ( ${ }^{a}$ 北京化工大学 材料科学与工程学院 北京 100029) \\ ( ${ }^{b}$ 北京化工大学 北京市水性聚合物合成与应用工程技术研究中心 北京 100029)
}

\begin{abstract}
摘要 数十年来, 有机太阳能电池(organic solar cells, OSCs)的相关研究进展迅速, 其能量转换效率从 2000 年的不足 $5 \%$, 发展至今已经超过 $18 \%$, 而这主要得益于给体和非富勒烯受体有机光伏材料的不断推陈出新. 苯并三氮唑 (benzotriazoles, BTA)作为一种经典的缺电子型杂环单元, 伴随着有机光伏领域的兴起与发展, 由 BTA 单元构筑的聚合 物给体、小分子给体、非富勒烯小分子受体以及聚合物受体材料被不断地设计合成出来, 特别是 $\mathrm{J}$ 系列聚合物给体材 料和 Y 系列非富勒烯受体材料. 伴随着材料体系的不断优化, 相关的分子设计策略也得到更新与完善, 以期从多角度 对 OSCs 的性能有针对性的进行调控. 本综述旨在通过介绍基于 BTA 单元的有机光伏材料的相关研究进展以及与之相 关的分子设计策略, 回顾 BTA 类光伏材料数十年来的发展历程, 并展望其未来的发展前景.
\end{abstract}

关键词 有机光伏材料; 苯并三氮唑; 给体; 受体

\title{
Research Advances on Benzotriazole-based Organic Photovoltaic Materials
}

\author{
Yang Bai $^{a}$ Ling-Wei Xue*, Hai-Qiao Wang ${ }^{a, b}$ Zhi-Guo Zhang* \\ ( ${ }^{a}$ College of Material Science and Engineering, Beijing University of Chemical Technology, Beijing 100029, China) \\ ${ }^{b}$ Beijing Engineering Research Center for the Synthesis and Applications of Waterborne Polymers, \\ Beijing University of Chemical Technology, Beijing 100029, China)
}

\begin{abstract}
Over the past two decades, organic solar cells (OSCs) have been developed rapidly with the power conversion efficiency rapidly rising from less than $5 \%$ to over $18 \%$, which is mainly promoted by the development of various new donor and acceptor materials. As a typical electron-deficient penta-heterocycle, benzotriazoles (BTAs) derivates a variety of high-performance photovoltaic materials, including polymer donor, small-molecule donor materials, as well as non-fullerenes acceptor and polymer acceptor. Among them, the J series of polymer donors and Y series of non-fullerenes acceptors are typical examples, and thus are specially highlighted in this review. Meanwhile, molecular design strategies of those BTA-based photovoltaic materials have also been discussed. It shows that donor-acceptor (D-A) conjugated strategy is still the most efficient thus far, where A units is the BTA unit or its derivatives, and D units commonly used in BTA-based photovoltaic materials are benzodithiophene, benzodifuran, dithienosilole, indacenodithiophene, thiophene, etc. The D-A strategy is both applied for donor molecules (with the molecular structure of D-A, D- $\pi-A-\pi, D-A-D-A-D$, etc.), and for acceptor molecules (with the molecular structure of A-D-A, A- $\pi-D-\pi-A, A-D A D-A$, etc.). By adjusting their molecular structures and/or pairing of differential D and A units, various properties such as absorption band and energy levels of molecules, as well as the morphology and charge carrier mobilities in OSCs can be well controlled. Furthermore, through side-chain engineering, such as flexible side-chains (alkyl, alkoxy, alkylthiol, alkylsilyl, etc.), conjugated side-chains (substituted-thiophene or benzene, etc.), electron-withdrawing groups ( $\mathrm{F}$ atoms, $\mathrm{Cl}$ atoms, dicyanomethylene, etc.), their photovoltaic properties can be further regulated. Here, this review focuses on the research progress on BTA-based photovoltaic materials and related molecular design strategies developed in recent years, and also presents perspective on its future development.
\end{abstract}

Keywords organic photovoltaic material; benzotriazole; donor; acceptor

\section{1 引言}

从工业革命至今的二百多年以来, 对各种能源的开 发和利用一直是推动人类文明进步的关键. 而目前作为
主要能源的化石能源, 其开发利用过程中的碳排放等危 害, 是导致全球气候和环境恶化的最主要原因, 因此,

\footnotetext{
*E-mail: xlingwei@mail.buct.edu.cn; zgzhang@mail.buct.edu.cn

Received May 5, 2021; published June 21, 2021.

Project supported by the National Natural Science Foundation of China (No. 51722308), Fundamental Research Funds for the Central Universities (Nos. Buctrc201822, XK1802-2), Beijing Natural Science Foundation (No. 2192043) and State Key Laboratory of Chemical Resource Engineering.

项目受国家自然科学基金(No. 51722308)、中央高校基本科研业务费专项资金(Nos. Buctrc201822, XK1802-2)、北京自然科学基金(No. 2192043)和化 工资源有效利用国家重点实验室开发基金资助。
} 
如何更好地处理能源和环境问题关乎全体人类的命运. 在 2020 年 9 月份的第 75 届联合国大会上, 中国国家主 席习近平提出了两个历史性的碳减排目标, 即“碳达峰” 和 “碳中和” 。为了实现这两大 “碳目标” ，建成以可 再生能源为主体的可持续能源结构, 完成能源结构转 型, 从根本上减少碳排放才是重中之重. 相比于其它可 再生能源, 太阳能光伏发电几乎不受限于地理环境, 充 分利用太阳能是公认的实现能源与环境的协调可持续 发展的最佳方案. 太阳能光伏发电是一种依靠光伏效应 将太阳能转换成电能的技术, 所使用的设备为太阳能电 池( solar cells, SCs), 其最为重要的性能指标为能量转换 效率(power conversion efficiency, PCE). 与传统硅基太 阳能电池相比, 以有机半导体作为光电转换活性材料的 有机太阳能电池具有轻质、柔性、可溶液加工等优点, 具 有广阔的发展和应用前景, 是新能源领域的研究热点之 一.

图 1 中展示了从 1976 年以来各种太阳能电池的 PCE 的发展趋势 ${ }^{[1]}$. 可以看出, 有机太阳能电池的研究 (organic solar cells, OSCs, 图 1, 红色线条)虽起步较晚, 但其 PCE 从 2000 年的不足 $5 \%$, 发展至今已经超过 $18 \%$, 展示出美好的应用前景. OSCs 相比于硅基太阳能电池, 具有诸多突出的优势. 首先从材料的角度来讲, 可通过 多样化的策略设计分子结构, 调控其光伏性能, 极大地 拓宽其性能潜力, 且可通过优化合成路线, 显著降低生 产成本; 再者从器件的角度来讲, 可通过溶液加工、卷 对卷印刷等方式, 制备轻质、柔性、可穿戴器件等, 弥 补硅基太阳能电池在诸多应用场景上的不足, 在能源结 构转型过程中提高可再生能源的利用率 ${ }^{[2]}$.

\section{2 有机太阳能工作机理}

在 OSCs 的发展历程中, 其器件结构得到了不断地 优化, 从最早期的单组分的肖特基型(Schottky-type)单 层 (single-layer) 器 件 结 构 ${ }^{[3]}$, 到 基于 异质 结 (heterojunction)的双层(two-layer)器件结构 [4], 再到目前 广泛应用于绝大多数 OSCs 的本体异质结 (bulk-heterojunction, BHJ) 器件结构 ${ }^{[5]}$. BHJ-OSCs 器件结 构的特征是其活性层中的电子给体(electron donor)材料 和电子受体(electron acceptor)材料均匀共混, 形成了纳 米尺度的双连续的互穿网络结构, 其界面面积相对于双 层活性层呈现出数量级的提升, 更有利于激子的扩散和 有效解离 ${ }^{[6]}$. 在 BHJ-OSCs 中, 光电转换过程如下, 给体 和受体材料在吸收光子后，使其前线电子从其最高占有 轨道(highest occupied molecular orbital, HOMO)能级向 最低未占有轨道(lowest unoccupied molecular orbital, LUMO) 能级跃迁, 形成具有一定束缚能(约 $0.3 \sim 0.5 \mathrm{eV}$ ) 的电子(electron)-空穴(hole)对, 即光生激子(exciton), 也 被称为 Frankel 激子. 在激子浓度梯度的驱动下, Frankel 激子扩散至给体和受体材料(D/A) 的界面处, 转变为束 缚能相对较弱的 CT 态激子(charge-transfer exciton), 并 在能级差 $\left(\Delta E_{1} 、 \Delta E_{3}\right)$ 的驱动下, 克服束缚能, 解离成为 载流子, 即自由电子和空穴, 解离过程仅约几百飞秒. 随后，载流子(即位于给体材料的空穴、位于受体材料的 电子)在功函数不同的阳极和阴极之间的内建电场的驱 动下, 分别沿着给体材料和受体材料所形成的连续通 道, 传输至阳极和阴极, 即完成了整个光电转换过程, 如图 2 所示 ${ }^{[7]}$.

Best Research-Cell Efficiencies

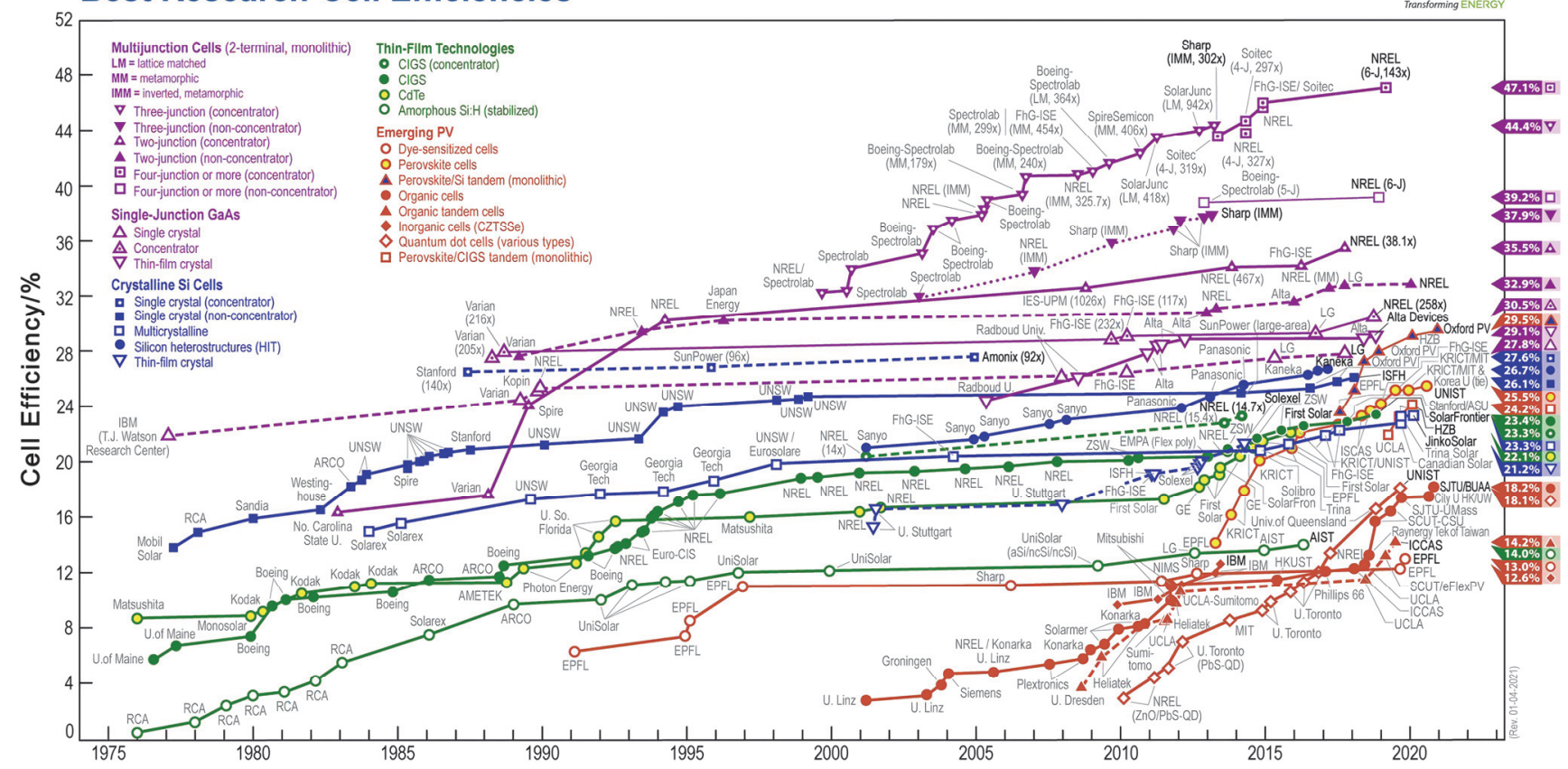

图 1 美国国家可再生能源实验室(NREL)认证的太阳能电池最高能量转换效率

Figure 1 The best research-cell efficiencies certificated by national renewable energy laboratories (NREL) 


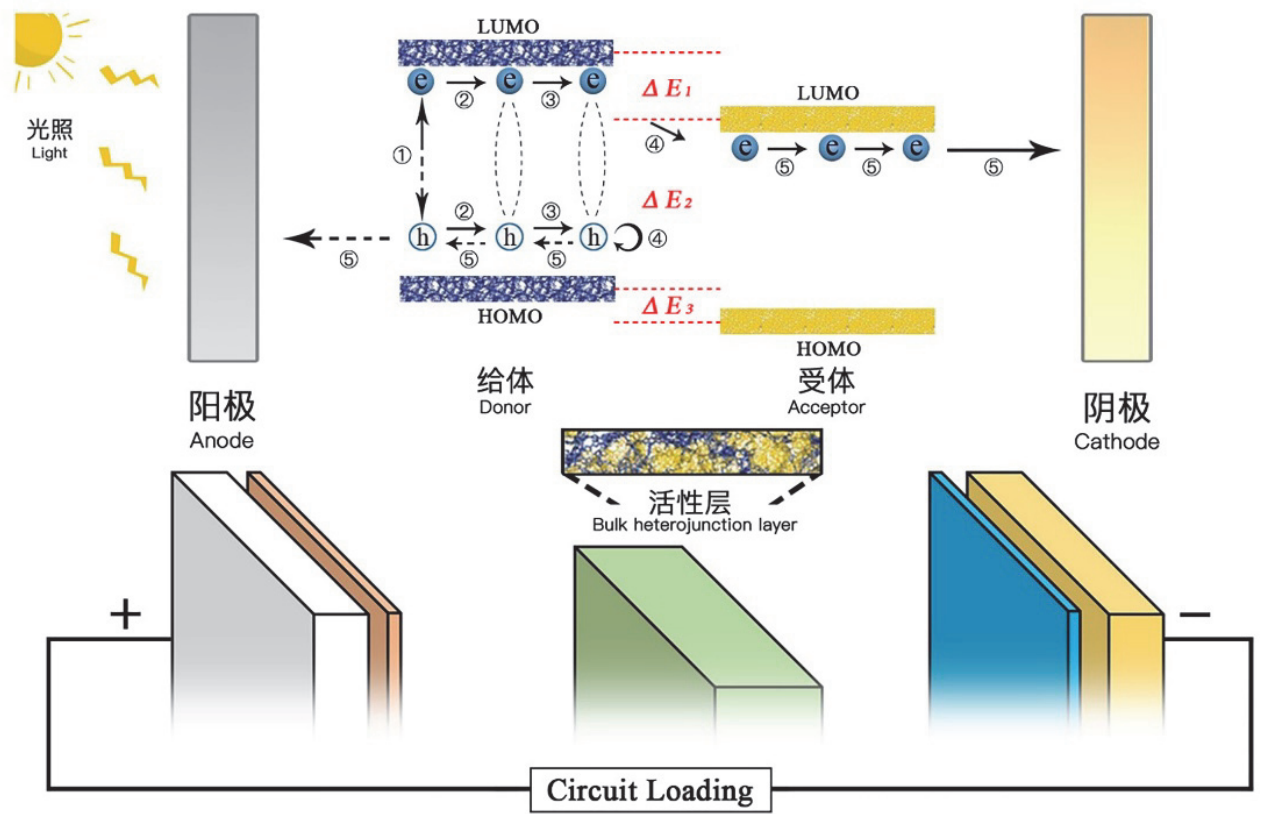

图 2 本体异质结有机太阳能电池器件工作原理示意图: (1)光生激子的产生; (2)光生激子的扩散; (3) CT 激子的形成; (4) CT 激子的解离、载流子 的产生; (5)载流子的传输和收集

Figure 2 Diagram of working mechanism of bulk heterojunction OSCs: (1) light-generated exciton formation; (2) light-generated exciton diffusion; (3) charge-transfer exciton formation; (4) charge-transfer exciton dissociation/carrier formation; (5) carrier transportation and collection

OSCs 器件的性能指标的表征通常采用由美国材料 与试验协会(american society for testing and materials, ASTM) 规定的 AM1.5G 模拟标准太阳光谱作为入射光 源, 功率为 $100 \mathrm{~mW} / \mathrm{cm}^{2}$, 得到伏安特性曲线 $(J-V$ 曲线), 如图 3 所示, 主要性能指标为以下四个:

(1)短路电流密度( short circuit current density, $J_{\mathrm{sc}}$ ): 定义为 OSCs 上施加电压为零时外电路上的电流密度, 即最高输出电流, 对应 $J-V$ 曲线在纵坐标(current density)上的截距, 取决于有效吸收光子的数量、激子解离以 及载流子的传输和收集效率.

(2)开路电压(open circuit voltage, $V_{\mathrm{oc}}$ ): 定义为 OSCs 的外电路断开或电流为零时的电压, 即最大输出电压, 对应 $J-V$ 曲线在横坐标(voltage)上的截距, 取决于给体 的 $E_{\mathrm{HOMO}}$ 与受体的 $E_{\mathrm{LUMO}}$ 的差值(即图 2 中的 $\Delta E_{2}$ ).

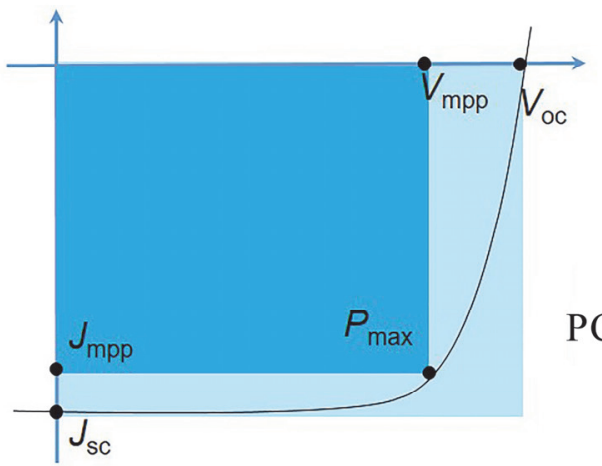

(3)填充因子(fill factor, FF): 定义为 OSCs 的最大输 出功率(maximum putout power, mpp)时(如图 3 中深蓝色 矩形所示, $J-V$ 曲线与坐标轴所能围成的最大矩形的面 积时 $)$ 电流密度 $\left(J_{\mathrm{mpp}}\right)$ 和电压 $\left(V_{\mathrm{mpp}}\right)$ 的乘积与短路电流密 度 $\left(J_{\mathrm{sc}}\right)$ 和开路电压 $\left(V_{\mathrm{oc}}\right)$ 的乘积(如图 3 中浅蓝色矩形所 示)的比值, 因此 $J-V$ 曲线越趋近于矩形, 其数值越大, 对于理想的 OSCs, 其填充因子理论上为 $1 . \mathrm{FF}$ 是一个影 响因素较为复杂的参数, 与给受体材料的迁移率、共混 薄膜的形貌密切相关，例如分子的结晶性、排列取向、 相分离状态等.

(4)能量转换效率(power conversion efficiency, PCE): 定义为 OSCs 的最高输出功率与模拟入射光源功率 $\left(P_{\text {in }}\right)$ 的比值, 可由短路电流密度 $J_{\mathrm{sc}}$ 、开路电压 $V_{\mathrm{oc}}$ 和填充因 子 FF 计算所得, 是最为重要的性能指标.

图 3 有机太阳能电池的电流密度-电压 $(J-V)$ 曲线图

Figure 3 Current-voltage $(J-V)$ characteristics of OSCs 
其它性能指标, 例如, 能量损失 $E_{\mathrm{loss}}\left(E_{\mathrm{g}} \mathrm{opt}-e V_{\mathrm{oc}}\right)$ 可 以分为两部分, 即电荷形成过程中的能量损失 $\left(E_{\mathrm{g}} \mathrm{opt}-\right.$ $\left.E_{\mathrm{CT}}\right)$, 和电荷复合过程中的能量损失 $\left(E_{\mathrm{CT}}-e V_{\mathrm{oc}}\right), E_{\mathrm{CT}}$ 约 等于图 2 中的 $\Delta E_{2}$, 即通过适当调节 $\Delta E_{1}$ 或者 $\Delta E_{3}$ 即可 有效地降低 $E_{\mathrm{loss}}$, 而第二部分的能量损失则是辐射/非辐 射造成的 $\mathrm{CT}$ 态激子的损失, 辐射损失是不可避免的, 而非辐射损失可以通过设计具有较高的场致发光量子 效率的有机光伏分子来降低 ${ }^{[8]}$; 外量子效率 (external quantum efficiency, EQE) 定义为吸收特定波长的光后, 产生的电子数与所有入射的光子数之比, 等等.

整个光电转换过程围绕着活性层中激子的产生、扩 散和解离, 因此, 光伏材料的设计和选择显得至关重要. 而如何选择合适的给体和受体材料则需要同时考虑到 以下几点: (1)具有互补的强吸收谱带, 尽可能宽的覆盖 太阳光谱, 以提升 $J_{\mathrm{sc}}$, 例如将宽带隙给体材料与窄带隙 的受体材料匹配; 具有匹配的 $E_{\mathrm{LUMO}}$ 与 $E_{\mathrm{HOMO}}$, 保证足 够的 $\Delta E_{1} 、 \Delta E_{3}$ 来提供激子解离的驱动力 ${ }^{[2 b, 6 i, 8 c, 9]}$, 以及 足够大的 $\Delta E_{2}$ 来确保较高的 $V_{\mathrm{oc}} ;(2)$ 具有较高的载流子 迁移率, 以提高 $J_{\mathrm{sc}}$ 和 $\mathrm{FF}$; (3) 具有良好的溶解性和结晶 性; (4)良好的共混薄膜形貌, 以形成纳米级别的互穿网 络结构, 增加给受体接触面积的同时降低激子的双分子 复合损失等 $[2 \mathrm{a}, 2 \mathrm{~b}, 2 \mathrm{f}, 10]$. 值得注意的是, 这些因素之间相 互制衡, 例如, 调节分子的 $E_{\mathrm{LUMO}}$ 与 $E_{\mathrm{HOMO}}$ 也会影响其 带隙; 拓宽吸收谱带可以提高 $J_{\mathrm{sc}}$, 但带隙的降低又会导 致 $V_{\mathrm{oc}}$ 的损失; 增加烷基链可以改善其溶解性, 但过多 的烷基链会改变其载流子迁移率及共混形貌 ${ }^{[10 a, 11]}$.

在过去的数十年间, 有机太阳能电池器件的 PCE 逐步提高, 但仍与商业化的硅基太阳能电池存在一定的 差距, 在商业化应用的道路上仍存在着诸多亟待克服的 挑战. 例如, 如何进一步提高 PCE、器件的环境稳定性, 如何降低大面积制备过程中 PCE 的损失, 如何更好地 发展柔性器件和实现器件的半透明化等. 因此, 为了推 动有机光伏领域的进一步发展, 设计合成更为高效的有 机光伏材料显得尤为重要.

苯并三氮唑(benzotriazoles, BTA)作为一种经典的 缺电子型杂环单元, 伴随着有机光伏领域的兴起与发 展, 基于 BTA 单元的小分子和聚合物给体材料、非富勒 烯小分子和聚合物受体材料被不断地设计合成出来, 相 关的分子设计策略也得到了不断的更新与完善, 以期从 多角度对 OSCs 的性能进行优化. 本综述旨在通过介绍 基于 BTA 单元的有机光伏材料的相关研究进展以及与 之相关的分子设计策略, 回顾其数十年来的发展历程, 并展望其未来的发展前景.

\section{3 苯并三氮唑类光伏材料}

三氮唑(triazole, TA)是一类重要的含三个氮原子的 五元杂环化合物, 可以在铜催化下通过叠氮和炔烃的 1,3-偶极环合的点击反应等合成 ${ }^{[12]}$, 其衍生物在有机化
学 ${ }^{[13]}$ 、配位化学 ${ }^{[14]}$ 、材料化学 ${ }^{[15]}$ 、医药 ${ }^{[16]}$ 领域具有重 要的应用和潜力. 在有机光伏领域, 应用最为广泛的为 2,4,5-三取代-1,2,3-苯并三氮唑(benzotriazole, BTA), 合 成路线如图 4 所示 ${ }^{[10 b, 17]}$. 三氮唑单元属于缺电子单元 (electron-deficient unit), 其结构中的两个亚胺键 $(\mathrm{C}=\mathrm{N})$ 上的氮原子(即 1,3 号位)具有强电负性, 2 号位的氮原子 易于修饰取代基，孤对电子具有较强的给电子特性，这 些特性使其成为一种溶解度可调的电子受体单元 ${ }^{[18]}$. 近年来 BTA 衍生物在光伏材料中的设计与合成也得到 了广泛关注，典型的结构有酰亚胺并苯并三氮唑 (pyrrolo[3,4-f $]$ benzotriazole-5,7-dione)、噻吩并苯并三氮 唑 (thiophene[2,3-f]benzotriazole) 、萗并双三氮唑 (naphtho[1,2-c:5,6-c]bis-[1,2,3]triazole)、吡啶并三氮唑 ([1,2,3]triazolo[3,4-c]pyridine) 、哒嗪并三氮唑 ([1,2,3] triazolo[4,5- $d]$ pyridazine)等(如图 4 所示).

近二十年来, 基于 BTA 单元构筑给体光伏材料和 受体材料的研究始终处在有机光伏领域的最前沿, 并不 断取得新的突破. 基于 BTA 单元及其衍生物的给体材 料和受体材料主要分为小分子类材料和聚合物类材料.

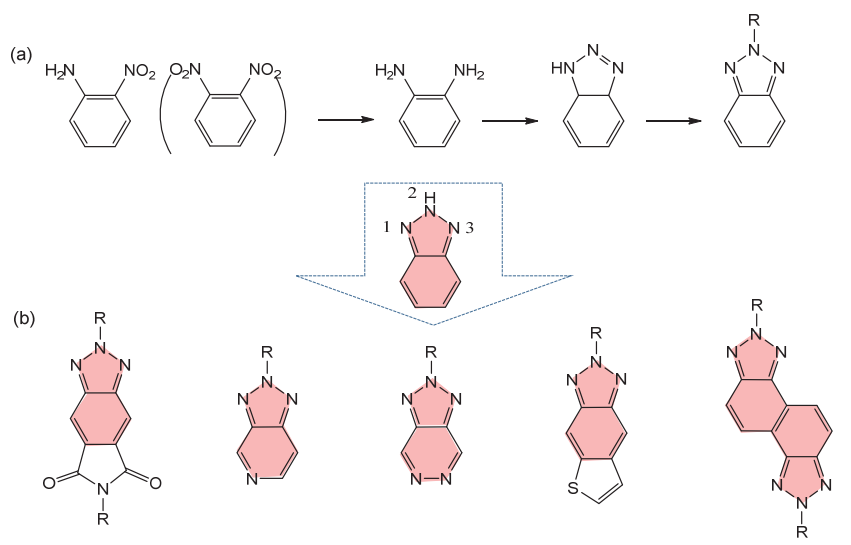

图 4 BTA 单元合成路线及部分 BTA 衍生物分子结构示意图

Figure 4 Synthetic route of the BTA unit and molecule structures of BTA derivatives

\section{1 基于苯并三氮唑单元的给体材料}

在给体材料的分子结构设计上，一般采用 D-A 或 $D-\pi-A-\pi$ 型设计策略, 即由给体单元 (electron-donating units, D)和受体单元(electron-accepting units，A)构成分 子主链. 通过选择具有不同分子结构的 “ $D$ ” 单元和 “ $A$ ” 单元, 调控给体分子的吸收谱带、能级以及空穴迁移率. 在这里，常见的 “ $\mathrm{A}$ ” 单元通常有苯并三氮唑 (benzotriazole, BTA)及其衍生物, 如酰亚胺并苯并三氮 唑 (pyrrolo[3,4-f]benzotriazole-5,7-dione, TzBI) 等. 常见 的 “ $\mathrm{D}$ ” 单元通常有苯并二噻吩(benzodithiophene, BDT)、 苯并二呋喃(benzodifuran, BDF)、噻吩(thiophene, T)、并 噻吩 (thieno[3,2- $b]$ thiophene, TT) 等. 进一步地, 可以通 过功能性侧链进行调控, 也就是侧链工程(side-chain engineering), 常用的侧链包括: 烷基侧链、烷氧基侧链、 烷硫基侧链、硅烷基侧链等柔性侧链; 取代噻吩、取代 
苯环、取代并噻吩等共轭侧链; 以及氟原子、氯原子、 丙二腈基等吸电子基团等 $[11 \mathrm{~b}, 11 \mathrm{c}, 18 \mathrm{~b}, 19]$.

基于三氮唑单元的给体材料主要分为聚合物类和 小分子类材料两大类. 对于聚合物类材料, 根据其分子 主链结构以及研究的广度的不同, 分成如下五类进行讨 论: 根据与 BTA 单元共聚的给体单元的不同, 分为基于 柔性侧链取代的 BDT 单元(或其衍生物单元)、共轭侧链 取代的 BDT 单元(或其衍生物单元)、噻吩给体单元、其 它类型给体单元四类聚合物类给体材料; 另外, 考虑到 对 BTA 单元进行结构调整或化学修饰也是调控其性能 的有效方式, 相关 BTA 衍生物的聚合物类给体也单独 列为一类进行介绍.

以下根据上述分类分别进行讨论.

3.1.1 基于柔性侧链取代的 BDT 单元或其衍生物构筑 的给体材料

该体系为最早受到关注的基于 BTA 单元的给体材 料, 其分子主链结构以及所涉及的分子设计策略为其后 的给体分子设计提供了重要的设计思路.

2010 年, 邹应萍等 ${ }^{[20]}$ 以具有柔性烷基侧链的苯并 二噻吩(BDT)为给体单元, BTA 受体单元作为主链, 设 计合成了交替共聚物给体材料 PBDTBTz. 并在此基础 上, 引入噻吩 $\pi$ 桥, 合成了 PBDTDTBTz(图 5a). 噻吩 $\pi$ 桥的引入, 降低了 BDT 单元与 BTA 单元之间的空间位 阻, 改善了分子堆叠, 延长了主链的共轭长度, 有效地 调控了材料的光电性质. 基于 $\mathrm{PBDTDTBTz} / \mathrm{PC}_{71} \mathrm{BM}$ $(w / w, 1: 4,58 \mathrm{~nm})$ 器件的 $\mathrm{FF}(62.0 \%)$ 明显高于基于 PBDTBTz $/ \mathrm{PC}_{71} \mathrm{BM}(w / w, 1: 4,57 \mathrm{~nm})$ 器件 $(\mathrm{FF}=47.0 \%)$. 因此, 其 PCE 值也相应从 $1.40 \%$ 提升至 $1.70 \%$. 该研究 是首例以 BTA 和 BDT 为共轭主链的给体聚合物, 也表 明基于 BTA 单元构筑聚合物给体材料具有良好的研究 潜力.

2011 年, 尤为等 ${ }^{[21]}$ 以 BTA 和其氟化衍生物为受体 单元, 分别设计合成了 PBnDT-HTAZ 和 PBnDT-FTAZ (图 5b), 其 BDT 单元和 BTA 单元上均为支化烷基链(3丁基壬基和 2-丁基辛基). 相比于 PBnDT-HTAZ, 具有氟 化 BTA 单元的 PBnDT-FTAZ 的 $E_{\mathrm{HOMO}}$ 和 $E_{\mathrm{LUMO}}$ 有所下 降, 相应的吸收系数也有所提高, 空穴迁移率更是提高 了一个数量级 $\left(3.34 \times 10^{-6} \mathrm{~cm}^{2} \cdot \mathrm{V}^{-1} \cdot \mathrm{s}^{-1}\right.$ 至 $6.76 \times 10^{-5}$ $\left.\mathrm{cm}^{2} \cdot \mathrm{V}^{-1} \cdot \mathrm{s}^{-1}\right)$, 并直观地表现为器件整体性能的提升. 基 于 PBnDT-HTAZ/PC ${ }_{61} \mathrm{BM}(w / w, 1: 2,230 \mathrm{~nm})$ 器件的 $V_{\mathrm{oc}}$ 为 $0.70 \mathrm{~V}, J_{\mathrm{sc}}$ 为 $11.1 \mathrm{~mA} / \mathrm{cm}^{2}, \mathrm{FF}$ 为 $55.2 \%$, $\mathrm{PCE}$ 为 $4.36 \%$; 而基于 PBnDT-FTAZ $/ \mathrm{PC}_{61} \mathrm{BM}(w / w, 1: 2,250 \mathrm{~nm})$ 器件 的 $V_{\mathrm{oc}}$ 为 $0.79 \mathrm{~V}, J_{\mathrm{sc}}$ 为 $11.8 \mathrm{~mA} / \mathrm{cm}^{2}, \mathrm{FF}$ 为 $72.9 \%, \mathrm{PCE}$ 为 $7.10 \%$. 该研究初步表明, 引入氟原子可以在保持 $E_{\mathrm{g}}$ 基 本不变的同时, 能够降低分子的 $E_{\mathrm{LUMO}}$ 与 $E_{\mathrm{HOMO}}$, 改善 材料的空穴迁移率, 提高器件的整体性能指标.

一般来讲, OSCs 器件的 PCE 很大程度上受到活性 层膜厚的影响. 值得注意的是, 基于 PBnDT-FTAZ/
$\mathrm{PC}_{61} \mathrm{BM}$ 器件具有较弱的膜厚依赖性, 活性层膜厚为 1 $\mu \mathrm{m}$ 器件的 PCE 仍可达到约 $6 \%{ }^{[21]} .2013$ 年, 尤为等 ${ }^{[22]}$ 对该奇特现象进行了深入研究，阐述了氟化效应：具有 氟取代主链的 PBnDT-FTAZ 与 $\mathrm{PC}_{61} \mathrm{BM}$ 分子间确实存在 一定的排斥作用力，使其分子间保持适当的链间距，显 著降低了空穴-电子对发生双分子复合的概率 ${ }^{[23]}$. 2014 年, 尤为等 ${ }^{24]}$ 通过将 PBnDT-FTAZ 和 PBnDT-HTAZ 进 行无规共聚得到一系列不同氟取代量的 PBnDT-(X)TAZ, 进一步探究了氟化效应对空穴迁移率 的影响. 结果表明, 氟原子取代程度与其空穴迁移率呈 现出显著的正相关性.

进一步地，随着非富勒烯受体的兴起，2017 年尤为 等 ${ }^{[25]}$ 在非富勒烯体系中, 研究了器件性能与给体材料 的氟化效应的关系. 与富勒烯体系类似, 相比于 PBnDT-HTAZ/ITIC $(w / w, 1: 1.5,90 \mathrm{~nm})$ 器件, 器件 PBnDT-FTAZ/ITIC $(w / w, 1: 1.5,90 \mathrm{~nm})$ 的 $V_{\mathrm{oc}}$ 由 $0.85 \mathrm{~V}$ 提升至 $0.91 \mathrm{~V}$. 另外, 氟化效应也改善了该非富勒烯体 系的载流子传输和收集效率，使得器件的 $J_{\mathrm{sc}}$ 得到了大 幅提高 $\left(12.5 \mathrm{~mA} / \mathrm{cm}^{2}\right.$ 至 $\left.16.3 \mathrm{~mA} / \mathrm{cm}^{2}\right)$, 综合表现为器件 的 PCE 接近翻倍提升(4.26\%至 8.37\%). 2019 年，尤为 等 ${ }^{[26]}$ 将 PBnDT-HTAZ 的噻吩 $\pi$ 桥进行双氟化, 设计合成 了 dFT-HTAZ(图 5c), 在 $E_{\mathrm{g}}$ 维持不变的同时, 其 $E_{\mathrm{LUMO}}$ 与 $E_{\mathrm{HOMO}}$ 相较于共轭 $\pi$ 桥不含氟取代基的聚合物均降低 约 $0.4 \mathrm{eV}$. 相比于 HTAZ/ITIC-Th1(w/w, 1: 1, 75 100 $\mathrm{nm}$ )器件, 基于 dFT-HTAZ/ITIC-Th1( $w / w, 1: 1,75 \sim 100$ $\mathrm{nm}$ )器件的 $V_{\mathrm{oc}}$ 由 $0.75 \mathrm{~V}$ 提升至 $0.99 \mathrm{~V}, J_{\mathrm{sc}}$ 由 $11.8 \mathrm{~mA} / \mathrm{cm}^{2}$ 提升至 $16.1 \mathrm{~mA} / \mathrm{cm}^{2}, \mathrm{FF}$ 由 $35.8 \%$ 提升至 $57.1 \%, \mathrm{PCE}$ 则 提升接近三倍 $(3.16 \%$ 至 $9.12 \%)$. 可以看出, 氟化策略不 仅可以应用在 BTA 受体单元上，该体系中噻吩 $\pi$ 桥单元 上引入氟原子同样可以对分子的光伏性能进行有效地 调控.

以上研究结果明确了在给体分子的设计中, 无论对 于富勒烯体系还是随后兴起的非富勒烯体系，氟化都是 一种行之有效的策略. 这是由于氟原子不仅是体积最小 的吸电子基团，而且是电负性最强的元素 ${ }^{[27]}$. 其空间位 阻极小, 通过非共价键如 $F \cdots H 、 F \cdots S 、 F \cdots \pi$ 等, 改善 了分子内和分子链间的相互作用，降低了给体材料的分 子能级, 提高了其空穴迁移率, 增强的 $\pi-\pi$ 相互作用使 其分子更趋于平面化.

关于该体系的给体材料的分子设计中, 其它课题组 也尝试在主链结构以及 BDT 单元的侧链工程上进行调 控.

2012 年，李永舫等 ${ }^{[28]}$ 以苯并二呋喃(benzodifuran, $\mathrm{BDF})^{[29]}$ 为给体单元，设计合成了 PBDFDTBTz(图 5d). 由于氧原子的电负性稍高于硫原子 ${ }^{[30]}$, 呋喃环的引入 一定程度上降低了共轭主链的电子云密度 ${ }^{[31]}$. 基于 PBDFDTBTz/PC ${ }_{71} \mathrm{BM}(w / w, 1: 2,70 \sim 100 \mathrm{~nm})$ 器件的 $V_{\mathrm{oc}}$ 为 $0.44 \mathrm{~V}, J_{\mathrm{sc}}$ 为 $4.9 \mathrm{~mA} / \mathrm{cm}^{2}, \mathrm{FF}$ 为 $57.5 \%, \mathrm{PCE}$ 为 
$1.24 \%$.

2013 年, 彭强等 ${ }^{[32]}$ 以烷硫基 ${ }^{[33]}$ 作为 BDT 单元的侧 链, 以呋喃环作为共轭 $\pi$ 桥, 设计合成了 PBDTFBZS 和 $\operatorname{PBDTFBZO}$ (图 5e), 其中 BTA 单元均为单氟化. 相比于 PBnDT-FTAZ，二者的带隙明显下降，基于 PBDTFBZS/ $\mathrm{PC}_{71} \mathrm{BM}(w / w, 1: 2,110 \mathrm{~nm})$ 或 PBDTFBZO/PC ${ }_{71} \mathrm{BM}$ $(w / w, 1: 2,95 \mathrm{~nm})$ 器件的 PCE 仅为 $4.10 \%$ 和 $3.18 \%$. 在 该体系中添加 $3 \mathrm{wt} \%$ 的 1,8-二碘辛烷(1,8-diiodooctane, DIO)对活性层形貌进行调控后 ${ }^{[6 f, 34]}$, 可使两种器件的 $\mathrm{PCE}$ 明显提升至 $7.74 \%$ 和 $6.25 \%$. 值得注意的是, 基于 PBDTFBZS:PC 71 BM/PNDTDPP: $\operatorname{PC}_{71} \mathrm{BM}(w / w, 1: 2,150$ $\mathrm{nm} ; w / w, 1: 1.5,120 \mathrm{~nm}$ )叠层器件的 PCE 可以达到 $9.40 \%$.

2013 年, Hwang 等 [35] 以三异丙基硅烷乙炔基 (triisopropylsilylethynyl, TIPS) 作为 BDT 单元的侧链, 设 计合成了 PTIPSBDT-DTBTz(图 5f), 并以 BDT 单元上无 侧链取代的 PBDT-DTBTz 作为对照, 研究了 TIPS 侧链 对光伏性能的影响. TIPS 单元可以改善共轭分子的溶解 性、结晶性、抗氧化性等, 也能促进分子间共轭 $\pi$ 主链 的堆叠 ${ }^{[36]}$. 相比于基于 PBDT-DTBTz/PC $\mathrm{PC}_{71} \mathrm{BM}(w / w, 1$ :

1,3 vol $\%$ DIO) 器件, 基于 PTIPSBDT-DTBTz/ $\mathrm{PC}_{71} \mathrm{BM}(w / w, 1: 1,3 \mathrm{vol} \% \mathrm{DIO})$ 器件的 $V_{\mathrm{oc}}$ 和 $\mathrm{FF}$ 略有提 升 $(0.77 \mathrm{~V}$ 至 $0.80 \mathrm{~V}, 48.0 \%$ 至 $55.0 \%), J_{\mathrm{sc}}$ 和 $\mathrm{PCE}$ 均大幅 提升 $\left(7.9 \mathrm{~mA} \cdot \mathrm{cm}^{-2}\right.$ 至 $12.7 \mathrm{~mA} \cdot \mathrm{cm}^{-2}, 2.88 \%$ 至 $\left.5.53 \%\right)$, 表 明引入硅烷基侧链可以有效地提升材料的光伏性能.

2014 年, 尤为等 ${ }^{[37]}$ 通过在 BDT 单元上引入烷硫基

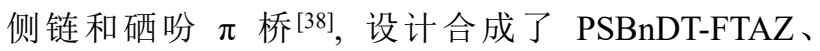

PBnDT-SeFTAZ 和 PSBnDT-SeFTAZ(图 5g). 相比于 PBnDT-FTAZ, 烷硫基侧链的引入使其器件的 $V_{\mathrm{oc}}$ 略微 提升, $J_{\mathrm{sc}}$ 明显降低; 而硒吩 $\pi$ 桥的引入则降低了材料的 $E_{\mathrm{g}} \mathrm{opt}$, 略微提升了器件的 $J_{\mathrm{sc}}$, 且这三种材料的空穴迁移 率(分别为 $2.90 \times 10^{-4} \mathrm{~cm}^{2} \cdot \mathrm{V}^{-1} \bullet \mathrm{s}^{-1} 、 3.46 \times 10^{-4} \mathrm{~cm}^{2} \bullet \mathrm{V}^{-1}$. $\left.\mathrm{s}^{-1} 、 1.72 \times 10^{-4} \mathrm{~cm}^{2} \cdot \mathrm{V}^{-1} \cdot \mathrm{s}^{-1}\right)$ 与 PBnDT-FTAZ $\left(1.19 \times 10^{-3}\right.$ $\left.\mathrm{cm}^{2} \cdot \mathrm{V}^{-1} \cdot \mathrm{s}^{-1}\right)$ 相比均降低一个数量级. 三者与 $\mathrm{PC}_{61} \mathrm{BM}$ 的 共混活性层的表面粗糙度、相聚集程度也相应增加，以 上因素综合导致器件的 PCE 值分别为 4.06\%、5.72\% 和 $1.87 \%$, 较 PBnDT-FTAZ 器件(PCE 为 $6.81 \%$ ) 有所降低.

2015 年, Kim 等 ${ }^{[39]}$ 设计合成了 S-PBDTBTz、 A-PBDTBTz 和 F-PBDTBTz(图 5h), 研究了 BTA 单元上 对称或非对称烷基侧链以及氟化效应对材料光伏性能 的影响. 相比于具有非对称的烷基侧链(2-已基癸基)的 A-PBDTBTz, S-PBDTBTz 上对称的烷基侧链(2-辛基癸 基)降低了 $\mathrm{BDT}$ 单元与共轭 $\pi$ 桥噻吩单元之间的二面角, 改善了分子堆积, 将空穴迁移率提高了一个数量级 $\left(1.0 \times 10^{-4} \mathrm{~cm}^{2} \bullet \mathrm{V}^{-1} \cdot \mathrm{s}^{-1}\right.$ 至 $\left.3.8 \times 10^{-3} \mathrm{~cm}^{2} \cdot \mathrm{V}^{-1} \bullet \mathrm{s}^{-1}\right)$, 并提高 了基于 $\mathrm{S}-\mathrm{PBDTBTz} / \mathrm{PC}_{71} \mathrm{BM}$ 器件的整体性能指标( $\mathrm{PCE}$ 为 $5.39 \%$, 而 $\mathrm{A}-\mathrm{PBDTBTz} / \mathrm{PC}_{71} \mathrm{BM}$ 器件 $\mathrm{PCE}$ 为 $3.05 \%$ ). 值得注意的是, 在该体系中, 具有氟化 BTA 单元的 F-PBDTBTz 与 $\mathrm{PC}_{71} \mathrm{BM}$ 匹配的器件却表现出最差的器 件性能(PCE 仅为 $1.80 \%$ ). 分析结果表明，相比于 S-PBDTBTz, F-PBDTBTz 分子结构中的 BTA 单元与共 轭 $\pi$ 桥噻吩单元之间的二面角降低的同时, BDT 单元与 噻吩 $\pi$ 桥之间的二面角反而增大了, 增大了 $\pi$ - $\pi$ 堆积面 间距.
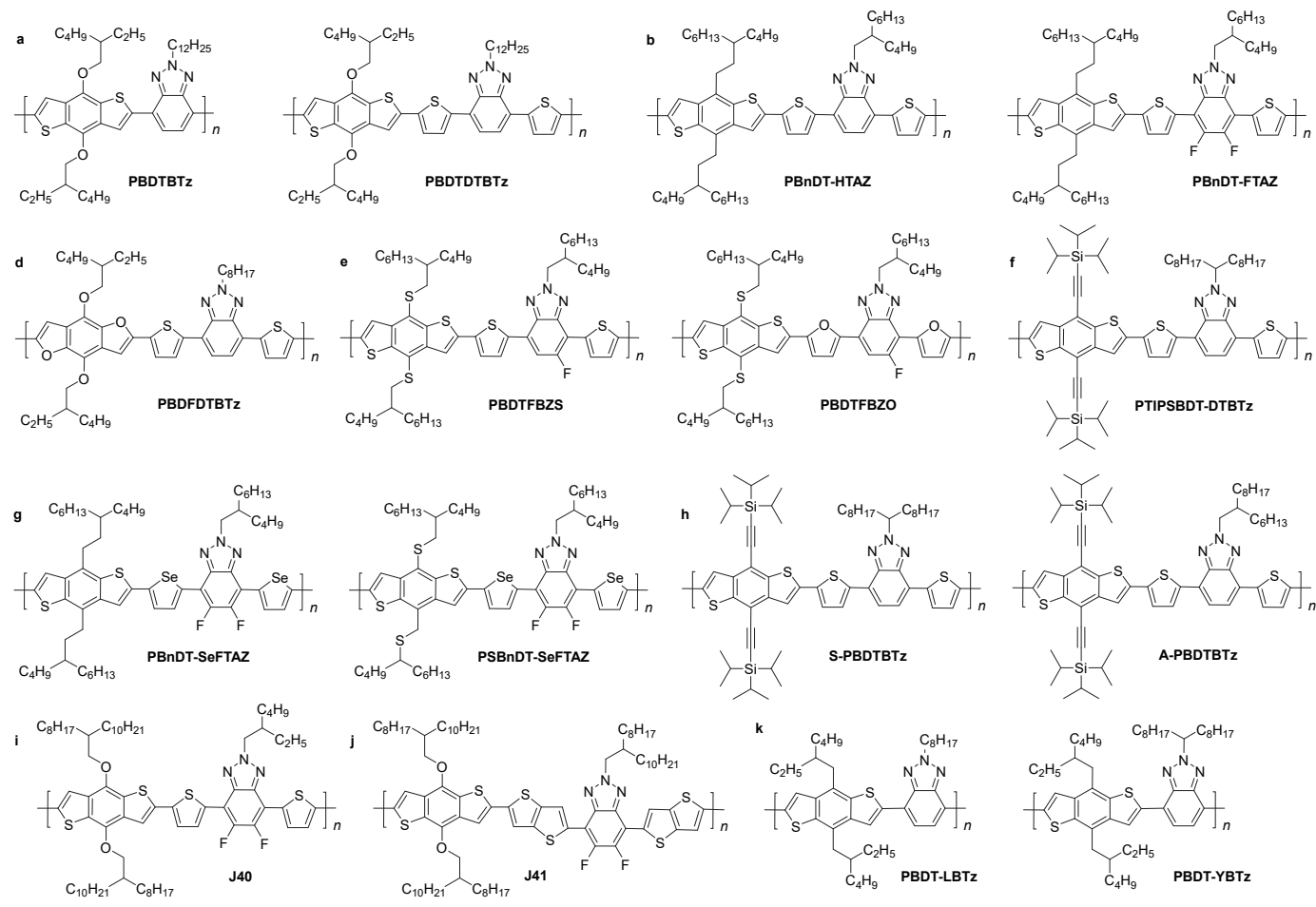

图 5 基于柔性侧链取代的 BDT 单元(或其衍生物)构筑的给体材料

Figure 5 Donor materials based on the BDT or its derivatives with flexible side-chains
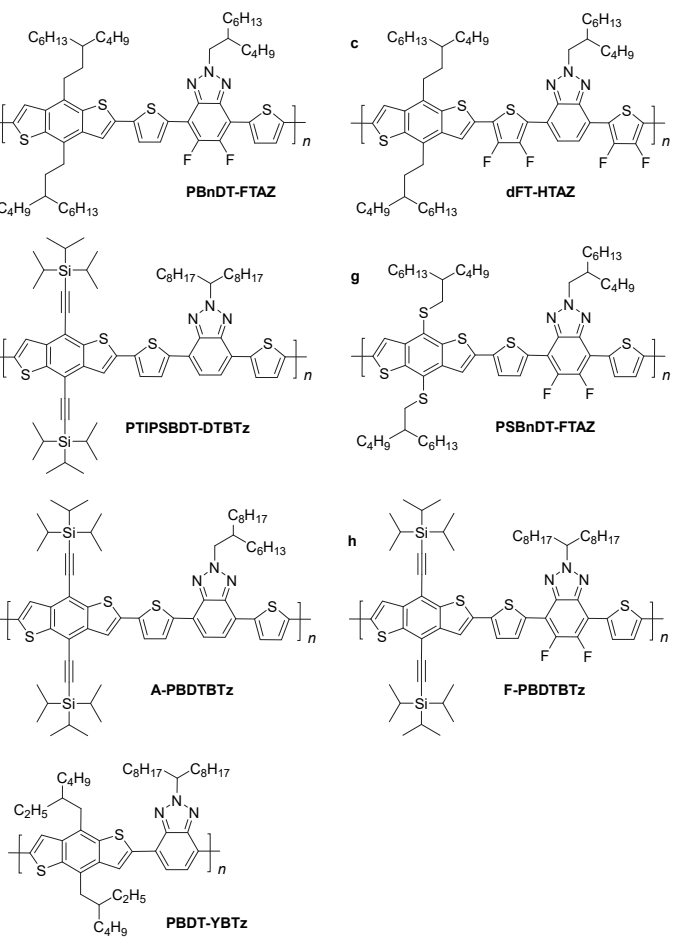
总体而言, 从分子设计策略上, 共轭 $\pi$ 桥(噻吩、硒 吩、呋喃、并噻吩等)的引入, 主链结构的调整(引入 $\mathrm{BDF}$ 单元、 $\mathrm{TT}$ 单元等), 以及 $\mathrm{BDT}$ 单元上的侧链工程(烷基 链替换为烷硫链、烷氧链、硅烷链等), 均可以有效地调 控材料的光伏性能, 这些调控策略也成为了给体分子设 计中通用的设计策略, 得到了广泛的应用.

2016 年, 李永舫、张志国等 ${ }^{[40]}$ 以具有柔性烷氧基侧 链取代的 BDT 单元作为给体单元, 设计合成了 J40(图 $5 i)$. 基于 $\mathrm{J} 40 / \operatorname{ITIC}(w / w, 1: 1)$ 器件的 $V_{\mathrm{oc}}$ 为 $0.89 \mathrm{~V}, J_{\mathrm{sc}}$ 为 $12.2 \mathrm{~mA} / \mathrm{cm}^{2}, \mathrm{FF}$ 为 $60.1 \%, \mathrm{PCE}$ 为 $6.48 \%$. 在此基础上, 后继研究中 [41]以并噻吩(TT)作为共轭 $\pi$ 桥, 设计合成了 $\mathrm{J} 41$ (图 $5 \mathrm{j}$ ), 其 $E_{\mathrm{LUMO}}$ 明显降低, 吸收边界轻微蓝移约 10 $\mathrm{nm}$. 基于 $\mathrm{J} 41 / \mathrm{ITIC}(w / w, 1: 1)$ 器件的 $V_{\mathrm{oc}}$ 为 $0.93 \mathrm{~V}, J_{\mathrm{sc}}$ 为 $13.7 \mathrm{~mA} / \mathrm{cm}^{2}, \mathrm{FF}$ 为 $68.6 \%, \mathrm{PCE}$ 为 $8.74 \%$. 与具有噻吩共
轭侧链取代的 BDT 单元的 J60、J61(图 7b)对比发现，共 轭侧链对于调控光伏性能上具有独特的优势，以下部分 将详细介绍.

为了更直观地表现分子结构的改变对材料的 $E_{\mathrm{LUMO}}$ 和 $E_{\mathrm{HOMO}}$ 的影响, 我们将以上材料的分子能级图进行对 比，如图 6 所示. 相关给体材料的电化学性质及相应的 有机太阳能电池器件性能指标如表 1 所示.

\section{1 .2 基于共轭侧链取代的 BDT 单元或其衍生物构筑 的给体材料}

李永舫课题组对该体系聚合物给体材料的研究最 早也最为深入, 这也是他们所提出 “二维共轭的聚合物 给体材料” 概念在三氮唑类聚合物上的拓展. 他们习惯 将该体系聚合物给体材料以 $\mathrm{J}$ 开头进行命名，也俗称 $\mathrm{J}$ 系列聚合物.

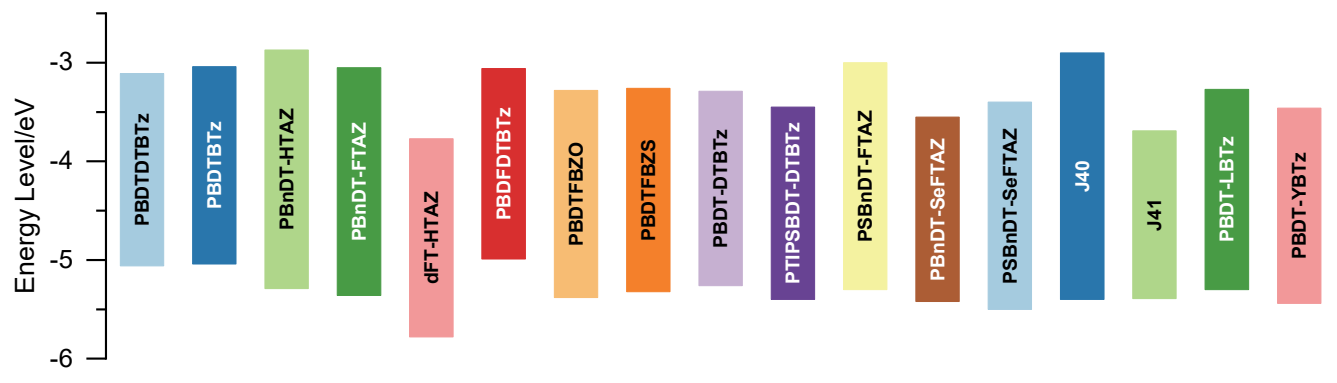

图 6 基于柔性侧链取代的 $\mathrm{BDT}$ 单元或其衍生物构筑的给体材料的能级示意图

Figure 6 Energy level diagram of donor materials based on the BDT or its derivatives with flexible side-chains

表 1 基于柔性侧链取代的 BDT 单元或其衍生物构筑的给体材料的电化学性质及相应的有机太阳能电池器件性能指标

Table 1 The electrochemical properties of donor materials based on the BDT or its derivatives with flexible side-chains and the photovoltaic characteristics of the corresponding solar cells

\begin{tabular}{|c|c|c|c|c|c|c|c|c|c|c|}
\hline \multirow[b]{2}{*}{ Donor } & \multicolumn{4}{|c|}{ Optical and electrochemical property } & \multicolumn{5}{|c|}{ Photovoltaic characteristics of corresponding OSCs device } & \multirow[b]{2}{*}{ Ref. } \\
\hline & $E_{\mathrm{g}}{ }^{\text {opt } a} / \mathrm{eV}$ & $\mathrm{HOMO} / \mathrm{eV}$ & $\mathrm{LUMO} / \mathrm{eV}$ & $\begin{array}{c}E_{\mathrm{g}}{ }^{\text {ec } b /} \\
\mathrm{eV}\end{array}$ & Acceptor & $V_{\mathrm{oc}} / \mathrm{V}$ & $\begin{array}{c}J_{\mathrm{sc}} / \\
\left(\mathrm{mA} \cdot \mathrm{cm}^{-2}\right) \\
\end{array}$ & $\mathrm{FF} / \%$ & $\mathrm{PCE} / \%$ & \\
\hline PBDTDTBTz & 1.95 & -5.06 & -3.11 & 1.95 & $\mathrm{PC}_{71} \mathrm{BM}$ & 0.61 & 4.5 & 62.0 & 1.70 & {$[20]$} \\
\hline \multirow[t]{2}{*}{ PBDTBTz } & 2.00 & -5.04 & -3.04 & 2.00 & $\mathrm{PC}_{71} \mathrm{BM}$ & 0.61 & 4.8 & 47.0 & 1.40 & [20] \\
\hline & & & & & $\mathrm{PC}_{61} \mathrm{BM}$ & 0.70 & 11.1 & 55.2 & 4.36 & [21] \\
\hline \multirow[t]{3}{*}{ PBnDT-HTAZ } & 1.98 & -5.29 & -2.87 & 2.42 & ITIC & 0.85 & 12.5 & 39.9 & 4.26 & [25] \\
\hline & & & & & ITIC-Th1 & 0.75 & 11.8 & 35.8 & 3.16 & [26] \\
\hline & & & & & $\mathrm{PC}_{61} \mathrm{BM}$ & 0.79 & 11.8 & 72.9 & 7.10 & [21] \\
\hline \multirow[t]{2}{*}{ PBnDT-FTAZ } & 2.00 & -5.36 & -3.05 & 2.31 & ITIC & 0.91 & 16.3 & 56.5 & 8.37 & [25] \\
\hline & & & & & IT-M & 0.97 & 17.9 & 69.1 & 12.0 & {$[42]$} \\
\hline dFT-HTAZ & 2.01 & -5.78 & -3.77 & 2.01 & ITIC-Th1 & 0.99 & 16.1 & 57.1 & 9.12 & [26] \\
\hline PBDFDTBTz & 1.93 & -4.99 & -3.06 & 1.93 & $\mathrm{PC}_{71} \mathrm{BM}$ & 0.44 & 4.9 & 57.5 & 1.24 & {$[28]$} \\
\hline PBDTFBZO & 1.83 & -5.38 & -3.28 & 2.10 & $\mathrm{PC}_{71} \mathrm{BM}$ & 0.82 & 7.2 & 53.6 & 3.18 & [32] \\
\hline PBDTFBZS & 1.81 & -5.32 & -3.26 & 2.06 & $\mathrm{PC}_{71} \mathrm{BM}$ & 0.78 & 9.1 & 57.6 & 4.10 & [32] \\
\hline PBDT-DTBTz & 1.97 & -5.26 & -3.29 & 1.97 & $\mathrm{PC}_{71} \mathrm{BM}$ & 0.77 & 7.9 & 48.0 & 2.88 & [35] \\
\hline PTIPSBDT-DTBTz & 1.95 & -5.40 & -3.45 & 1.95 & $\mathrm{PC}_{71} \mathrm{BM}$ & 0.80 & 12.7 & 55.0 & 5.53 & [35] \\
\hline PSBnDT-FTAZ & 1.85 & -5.30 & -3.00 & 1.85 & $\mathrm{PC}_{61} \mathrm{BM}$ & 0.85 & 7.5 & 63.8 & 4.06 & [37] \\
\hline PBnDT-SeFTAZ & 1.79 & -5.42 & -3.55 & 1.79 & $\mathrm{PC}_{61} \mathrm{BM}$ & 0.78 & 13.4 & 54.6 & 5.72 & [37] \\
\hline PSBnDT-SeFTAZ & 1.78 & -5.50 & -3.40 & 1.78 & $\mathrm{PC}_{61} \mathrm{BM}$ & 0.78 & 5.2 & 45.9 & 1.87 & [37] \\
\hline S-PBDTBTz & $\sim 2.00$ & N/A & N/A & $\mathrm{N} / \mathrm{A}$ & $\mathrm{PC}_{71} \mathrm{BM}$ & 0.80 & 12.7 & 55.0 & 5.39 & [39] \\
\hline A-PBDTBTz & $\sim 2.00$ & N/A & N/A & N/A & $\mathrm{PC}_{71} \mathrm{BM}$ & 0.72 & 10.3 & 43.0 & 3.05 & [39] \\
\hline F-PBDTBTz & $\sim 2.00$ & N/A & N/A & N/A & $\mathrm{PC}_{71} \mathrm{BM}$ & 0.89 & 8.2 & 36.0 & 1.80 & [39] \\
\hline $\mathrm{J} 40$ & 1.95 & -5.40 & -2.90 & 2.50 & ITIC & 0.89 & 12.2 & 60.1 & 6.48 & {$[40]$} \\
\hline J41 & 2.00 & -5.39 & -3.69 & 1.70 & ITIC & 0.93 & 13.7 & 68.6 & 8.74 & {$[41]$} \\
\hline PBDT-LBTz & 2.03 & -5.30 & -3.27 & 2.03 & $\mathrm{PC}_{71} \mathrm{BM}$ & 0.66 & 3.8 & 43.0 & 1.07 & [43] \\
\hline PBDT-YBTz & 1.98 & -5.44 & -3.46 & 1.98 & $\mathrm{PC}_{71} \mathrm{BM}$ & 0.80 & 5.8 & 42.0 & 1.95 & [43] \\
\hline
\end{tabular}

${ }^{a}$ Optical bandgap calculated from the absorption edge (onset) of the polymer films: $E_{\mathrm{g}}{ }^{\text {opt }}=1240 / \lambda_{\text {edge. }}{ }^{b}$ Electrochemical bandgap obtained from: $E_{\mathrm{g}}{ }^{\mathrm{ec}}=E_{\mathrm{LUMO}}-$ E 
2012 年, 李永舫、张志国等 ${ }^{[10 b]}$ 在 BDT 单元上引入 噻吩共轭侧链, 设计合成了 PBDT-HBTA(J50) 和 PBDT-FBTA(J51)(图 7a). 相比于 PBnDT-HTAZ 和 PBnDT-FTAZ(图 5b) ${ }^{[21]}$, BDT 单元上噻吩共轭侧链的引 入使其吸收谱带红移了约 $15 \mathrm{~nm}$. 同样的, 氟化效应使 得基于 $\mathrm{J} 51$ 器件性能明显优于基于 $\mathrm{J} 50$ 器件. 基于 PBDT-FBTA $/ \mathrm{PC}_{71} \mathrm{BM}(w / w, 1: 2,120 \mathrm{~nm}, 5 \mathrm{wt} \% \mathrm{DIO})$ 器 件的 $V_{\mathrm{oc}}$ 为 $0.75 \mathrm{~V}, J_{\mathrm{sc}}$ 为 $11.9 \mathrm{~mA} / \mathrm{cm}^{2}, \mathrm{FF}$ 为 $67.2 \%$, PCE 为 $6.00 \%$, 且膜厚为 $400 \mathrm{~nm}$ 器件的 PCE 仍可达到 $4.74 \%$. 该研究为 $\mathrm{J}$ 系列给体材料的开端, 为该系列聚合物的进 一步研究奠定了基础.

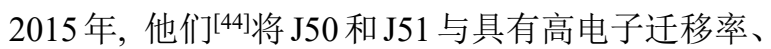
高电子亲和能的 $n$-型聚合物受体材料 $\mathrm{N} 2200$ 匹配, 基于 $\mathrm{J} 51 / \mathrm{N} 2200(w / w, 2: 1,120 \mathrm{~nm}, 1 \mathrm{wt} \%$ DIO)的全聚合物太 阳能电池(All-PSCs) 器件的 $V_{\mathrm{oc}}$ 为 $0.83 \mathrm{~V}, J_{\mathrm{sc}}$ 为 14.2 $\mathrm{mA} / \mathrm{cm}^{2}, \mathrm{FF}$ 为 $70.2 \%, \mathrm{PCE}$ 为 $8.27 \%$, 且表现出较低的膜 厚依赖性. 优异的光伏性能得益于给受体具有互补的吸 收谱带, 以及共混活性层具有半结晶性质、良好的纳米 尺度相分离互穿网络、较高且均衡的载流子迁移率等. 紧接着, 他们又将 J50 和 J51 与窄带隙的非富勒烯型小 分子受体材料 ITIC 匹配 ${ }^{[45]}$, 进一步增强了器件在长波 长范围 $(600 \sim 800 \mathrm{~nm})$ 对太阳光的吸收, 基于 $\mathrm{J} 51 / \mathrm{ITIC}(w / w, 1: 2,1 \mathrm{wt} \% \mathrm{DIO})$ 器件的 $V_{\mathrm{oc}}$ 为 $0.82 \mathrm{~V}, J_{\mathrm{sc}}$ 为 $16.5 \mathrm{~mA} / \mathrm{cm}^{2}, \mathrm{FF}$ 为 $69.0 \%$, PCE 为 $9.26 \%$. 根据以往 的经验, 给受体要形成交错的能级, 也就是给体的 $E_{\mathrm{LUMO}}$ 和 $E_{\mathrm{HOMO}}$ 要高于受体, 且相应的能级差 $\left(\Delta E_{\mathrm{LUMO}}\right.$ 、 $\left.\Delta E_{\mathrm{HOMO}}\right)$ 必须大于激子结合能 $(0.3 \sim 0.5 \mathrm{eV})$, 才能确保 有效的激子解离和载流子传输 ${ }^{[2 b, 6 a, 8 c, 9]}$. 该体系中, $\mathrm{J} 51 / \mathrm{ITIC}$ 的 $\Delta E_{\mathrm{LUMO}}$ 为 $0.75 \mathrm{eV}$, 可以确保给体相中激子 的有效解离及电子的高效传输(J51 至 ITIC), 而 $\Delta E_{\mathrm{HOMO}}$ 仅为 $0.22 \mathrm{eV}$. 光致发光猝灭分析结果表明, 受体相中产 生的激子的解离仍然是高效的. 以上成果不仅开启了 $\mathrm{J}$ 系列聚合物的后续研究, 也开启了 BTA 类材料在非富 勒烯体系中应用的热潮.

2016年, 他们 ${ }^{[46]}$ 在 J51 的基础上, 将 BTA 单元上的 直链烷基链 (辛基)替换为支化烷基链(2-己基癸基, 其后 的绝大多数 $\mathrm{J}$ 系列给体材料均采用该烷基侧链), 将 BDT 单元上侧链噻吩单元的支化烷基链(2-己基癸基)分 别替换为更短的支化烷基链以及支化烷硫基和直链烷 硫基链, 设计合成了 J52、J60、J61(图 7b). 引入烷硫基 侧链有利于提升材料的光伏性能, J60 和 J61 表现出轻微 红移的吸收谱带、降低的分子能级以及更好的结晶度, 且 J61 薄膜及其与 ITIC 的共混薄膜均表现出更强的分 子链间相互作用和缩短的 $\pi-\pi$ 堆积面间距. 同样的, 光 致发光光谱表明 $\mathrm{J} 61 / \mathrm{ITIC}$ 之间在较低的 $\Delta E_{\mathrm{HOMO}}(0.16$ $\mathrm{eV}$ ) 的情况下可以保证在 ITIC 相中产生的激子的高效解 离, 有利于降低器件的 $E_{\mathrm{loss}}(0.68 \sim 0.65 \mathrm{eV})$, 进而得到 更高的 $V_{\mathrm{oc}}$ 和 PCE, 基于 $\mathrm{J} 61 / \mathrm{ITIC}(w / w, 1: 1)$ 器件的 $V_{\mathrm{oc}}$ 为 $0.89 \mathrm{~V}, J_{\mathrm{sc}}$ 为 $17.4 \mathrm{~mA} / \mathrm{cm}^{2}, \mathrm{FF}$ 为 $61.5 \%$, $\mathrm{PCE}$ 为 $9.53 \%$.
进一步地, 他们 ${ }^{[47]}$ 将 J61 与 $m$-ITIC 匹配后, 器件整体性 能得到进一步提升, 基于 $\mathrm{J} 61 / m-\operatorname{ITIC}(w / w, 1: 1,120$ $\mathrm{nm}$ ) 器件的 $V_{\mathrm{oc}}$ 为 $0.92 \mathrm{~V}, J_{\mathrm{sc}}$ 为 $18.3 \mathrm{~mA} / \mathrm{cm}^{2}, \mathrm{FF}$ 为 $70.6 \%$, PCE 提升至 $11.77 \%$.

为了验证在较低的 $\Delta E_{\mathrm{HOMO}}$ 下, 能否进一步提升器 件的性能, 2016 年, 他们 ${ }^{[48]}$ 将 BDT 单元上侧链噻吩单元 的烷基链替换为三丙基硅烷基, 设计合成了 $\mathrm{J} 71$ (图 7c). 得益于 $\mathrm{Si}\left(\delta^{*}\right)-\mathrm{C}\left(\pi^{*}\right)$ 键的相互作用, J71 表现出更强的 $\pi-\pi$ 相互作用, 吸收系数也有所提升, $E_{\mathrm{HOMO}}$ 均下降 0.2 $\mathrm{eV}, \mathrm{J} 71 / \mathrm{ITIC}$ 的 $\Delta E_{\text {Hомо }}$ 进一步降低至 $0.11 \mathrm{eV}$. 基于 $\mathrm{J} 71 / \mathrm{ITIC}(w / w, 1: 1,100 \mathrm{~nm})$ 器件的 $V_{\mathrm{oc}}$ 为 $0.94 \mathrm{~V}, J_{\mathrm{sc}}$ 为 $17.3 \mathrm{~mA} / \mathrm{cm}^{2}, \mathrm{FF}$ 为 $69.8 \%$, PCE 则达到了 $11.41 \%$, 明显 高于基于前述的 $\mathrm{J}$ 系列聚合物给体材料(J52、J60 至 J64) 的器件的 PCE. 该研究表明在给体分子设计中引入硅烷 基是一种非常有效的策略, 且再次验证了在 $\Delta E_{\mathrm{HOMO}}$ 远 低于经验值 $(0.3 \mathrm{eV})$ 的情况下实现受体相中产生的激子 高效解离的可行性，这极大地拓宽了给受体分子的设计 思路. 例如可以通过降低给体材料的 $E_{\mathrm{HOMO}}$ 提高器件的 $V_{\mathrm{oc}}$ ，同时又能兼顾 $J_{\mathrm{sc}}$ 及 PCE.

后续研究中的绝大多数 $\mathrm{J}$ 系列聚合物给体材料均基 于 J52、J60、J61 和 J71 的分子结构.

在 J61 的基础上, 2017 年他们 ${ }^{[49]}$ 以呋喃环作为共轭 $\pi$ 桥, 设计合成了 $\mathrm{J} 61-\mathrm{F}$ (图 7d), 其 $E_{\mathrm{HOMO}}$ 有所降低 $(-5.32 \mathrm{eV}$ 至 $-5.45 \mathrm{eV})$, 基于 $\mathrm{J} 61-\mathrm{F} / \mathrm{ITIC}(w / w, 1: 1.5$, $100 \mathrm{~nm}$ )器件的 $\mathrm{PCE}(8.24 \%)$ 相对于基于 J61/ITIC 器件 $(\mathrm{PCE}=9.53 \%)^{[46]}$ 有所下降.

在 J61 的基础上, 2018 年, 李永舫、张占军等 ${ }^{[50]}$ 通 过改变 BDT 单元的噻吩共轭侧链上的烷硫基侧链类型, 设计合成了 $\mathrm{J} 62$ (直链烷硫基)、J63(不饱和双键烷硫基) 和 J64(环烷烃硫基)(图 7e), 进一步探讨侧链取代对物化 性质和光伏性能的影响. 从与 ITIC 的共混薄膜形貌上 看, 具有双键烷硫基侧链的 J63 分子因不饱和键的存在 而表现出更强的层状堆叠，具有环烷烃硫基的 J64 分子 因环己烷较大的空间位阻而表现出较弱的层状堆叠, 具 有硫辛基侧链的 $\mathrm{J} 62$ 分子的活性层薄膜的粗精度则居于 二者之间. 基于 $\mathrm{J} 62 / \mathrm{ITIC}(w / w, 1.5: 1)$ 器件表现出最为 优异的光伏性能, $V_{\mathrm{oc}}$ 为 $0.92 \mathrm{~V}, J_{\mathrm{sc}}$ 为 $16.9 \mathrm{~mA} / \mathrm{cm}^{2}, \mathrm{FF}$ 为 $70.1 \%$, PCE 为 $10.81 \%$, 明显高于基于 J63/ITIC 器件 $(\mathrm{PCE}=8.13 \%)$ 和 $\mathrm{J} 64 / \mathrm{ITIC}$ 器件 $(\mathrm{PCE}=8.59 \%)$.

在 J71 的基础上, 2017 年, 李永舫等 ${ }^{[51]}$ 通过改变硅 烷基侧链的类型，设计合成了 J70、J72、J73 和 J74(图 $7 \mathrm{f})$. 研究结果表明, 具有较短且为直链的硅烷基侧链的 分子具有更为规整的分子堆叠，更强的 $\pi-\pi$ 相互作用， 更强的吸收系数, 以及更高的载流子迁移率, 从而有利 于提高器件的 $J_{\mathrm{sc}}$ 和 $\mathrm{FF}$; 而具有较长或支链型硅烷基侧 链的分子则表现出更低的 $E_{\mathrm{HOMO}}$, 有利于提高 $V_{\mathrm{oc}}$. 因 此, 得益于较高的 $J_{\mathrm{sc}}$ 和 $\mathrm{FF}$, 基于 $\mathrm{J} 70 / m-\mathrm{ITIC}(w / w, 1$ : 1.5)器件表现出最高的 PCE(11.62\%), 而基于 J74/m-ITIC 器件则表现出最高的 $V_{\mathrm{oc}}(0.99 \mathrm{~V})$. 
在 J71 的基础上, 2017 年，李永舫等 ${ }^{[29 b]}$ 以 BDF 作为 给体单元，设计合成了 $\mathrm{J} 81$ (图 $7 \mathrm{~g}$ ), $E_{\mathrm{HOMO}}$ 有所降低，进 而提高了器件的 $V_{\mathrm{oc}}$. 相比于 J71/ITIC 和 J71/m-ITIC 器 件 ${ }^{[48]}$, 基于 $\mathrm{J} 81 / \mathrm{ITIC}$ 和 $\mathrm{J} 81 / m-\operatorname{ITIC}(w / w, 1: 1)$ 器件的 PCE 均有所下降(11.41\%至 10.60\%, 12.05\%至 $11.05 \%$ ).

在 J52 的基础上, 2017 年, 张茂杰等 ${ }^{[52]}$ 将 BDT 单元 上侧链噻吩单元的 $\beta$ 位进行氟取代, 设计合成了 PFBZ(即 J52-F, 图 7h). 同样的, 氟化效应使其 $E_{\mathrm{LUMO}}$ 和 $E_{\mathrm{HOMO}}$ 降低, 吸收系数提高, 所得聚合物具有更强的分 子链间相互作用和缩短的 $\pi-\pi$ 堆积面间距. 相比于 J52/ITIC 器件 ${ }^{[46]}$, 未经热退火处理的 PFBZ/ITIC $(w / w$, $1: 2,1 \mathrm{wt} \% \mathrm{DIO})$ 器件的整体性能均有所提升, PCE 由 $5.51 \%$ 提升至 $10.40 \%$. 且 PCE 具有较低的膜厚依赖性, 膜厚为 $200 \mathrm{~nm}$ 器件的 PCE 仍可达到 $8.9 \%$. 另外, 器件 表现出较高的热退火耐候性, 在 $150{ }^{\circ} \mathrm{C}$ 下热退火 $1 \mathrm{~h}$ 后, PCE 仍可达到 $9.3 \%$, 使得基于 PFBZ 体系的器件在大面 积制备及实际应用中具有良好的潜力. 将 PFBZ 与 $\mathrm{N} 2200$ 匹配 ${ }^{[53]}$, 无额外添加剂的情况下, 基于 $\mathrm{PFBZ} / \mathrm{N} 2200(w / w, 1: 2)$ 器件的 $V_{\mathrm{oc}}$ 为 $0.90 \mathrm{~V}, J_{\mathrm{sc}}$ 为 13.5 $\mathrm{mA} / \mathrm{cm}^{2}, \mathrm{FF}$ 为 $67.0 \%, \mathrm{PCE}$ 为 $8.10 \%$, 且同样具有良好的 热退火耐候性.

进一步地, 2017 年, 他们 ${ }^{[54]}$ 将 BDT 单元上侧链噻吩 单元进行双氟化, 以期与主链上 BTA 单元的氟化产生 协同效应, 设计合成了 J91(图 7i). J91 表现出增强的吸 收系数, 降低的 $E_{\mathrm{HOMO}}$ 以及更高的空穴迁移率. $\mathrm{J} 91 / m$-ITIC $(w / w, 1: 1.5,100 \mathrm{~nm})$ 器件的整体性能相比于 J52/ITIC 器件 [46] 也大幅度提高, $V_{\mathrm{oc}}$ 为 $0.98 \mathrm{~V}, J_{\mathrm{sc}}$ 为 18.0 $\mathrm{mA} / \mathrm{cm}^{2}, \mathrm{FF}$ 为 $65.5 \%, \mathrm{PCE}$ 进一步提升至 $11.63 \%$. 而瞬 态吸收光谱分析表明，这得益于 J91 有效地抑制了 J91/m-ITIC 活性层中三线态的形成, 减少了 CT 态激子 的双分子复合损失.

在 $\mathrm{J} 52$ 和 $\mathrm{J} 71$ 的基础上, 2018 年, 张茂杰等 ${ }^{[55]}$ 将 $\mathrm{BDT}$ 单元上侧链塞吩单元的 $\beta$ 位进行氯取代, 设计合成 了 PBZ-Cl(即 J52-Cl)和 PBZ-ClSi(图 7j). 和氟取代类似, 引入氯原子同样可以增加分子链间的非共价键相互作 用如 $\mathrm{Cl} \cdots \mathrm{H} 、 \mathrm{Cl} \cdots \mathrm{S} 、 \mathrm{Cl} \cdots \mathrm{C}$ 等, 从而得到更有序的分子 堆叠以及更高的载流子迁移率, 且由于氯原子拥有价层 空轨道(3d), 可以诱导共轭 $\pi$ 电子, 进而降低分子的 $E_{\mathrm{HOMO}}{ }^{[56]}$, 因此相比于 PBZ(即 J52), PBZ-Cl 和 PBZ-ClSi 表现出逐渐降低的 $E_{\mathrm{HOMO}}$ 和 $E_{\mathrm{LUMO}}$, 增强的吸收系数以 及改善的载流子迁移率. 相比于 $\mathrm{PBZ} / \mathrm{IT}-4 \mathrm{~F}(w / w, 1: 1$, $100 \mathrm{~nm}, 1 \mathrm{wt} \% \mathrm{PN})$ 器件, 基于 PBZ-Cl/IT-4F $(w / w, 1 ： 1$, $100 \mathrm{~nm}, 1 \mathrm{wt} \% \mathrm{PN})$ 器件的整体性能均有所提升, PCE 由 $6.40 \%$ 提升至 $9.70 \%$; 而基于 PBZ-CISi/IT-4F( $w / w, 1 ： 1$, $100 \mathrm{~nm}, 1 \mathrm{wt} \% \mathrm{PN})$ 器件的 PCE 进一步提升至 $12.80 \%$, 且 $E_{\text {loss }}$ 由 $0.9 \mathrm{eV}(\mathrm{PBZ} / \mathrm{IT}-4 \mathrm{~F})$ 分别降低至 0.7 eV(PBZ-Cl/IT-4F)和 0.57 eV(PBZ-ClSi/IT-4F). 该研究表 明, 在给体分子设计中, 氯化策略也可以有效地提高材
料的光伏性能.

在 J52 和 $\mathrm{J} 71$ 的基础上, 2018 年, 李永舫等 ${ }^{[57]}$ 将 BDT 单元的噻吩共轭侧链替换为并噻吩共轭侧链, 设 计合成了 $\mathrm{J} 46$ 和 $\mathrm{J} 47$ (图 7k). 相比于 $\mathrm{J} 52$ 和 J71, J46 和 J47 的分子链间 $\pi-\pi$ 相互作用有所减弱, $E_{\mathrm{HOMO}}$ 略微降低, 且 吸收边界红移约 $10 \mathrm{~nm}$. 另外, 相比于 J52/ITIC 器件 [46] 和 J71/ITIC 器件 ${ }^{[48]}$, 基于 J46/ITIC 和 J47/ITIC $(w / w, 1$ : $1,95 \mathrm{~nm}, 0.5 \mathrm{vol} \% \mathrm{DIO})$ 器件的整体性能均有所降低, PCE 分别由 $5.51 \%$ 和 $11.41 \%$ 分别降低至 $2.34 \%$ 和 $9.01 \%$.

在 J52、J60 和 J71 的基础上, 2019 年，李永舫等 ${ }^{[58]}$ 将 BTA 单元的侧链替换为以七甲基三硅氧烷 $(1,1,1,3,5,5,5$-heptamethyltrisiloxane, HMTS)为末端的己 基，设计合成了 J55、J65 和 J75(图 71), 探讨了侧链对光 伏性能的影响. 以硅氧烷为末端的侧链可以有效地改善 分子堆叠以及活性层形貌 ${ }^{[59]}$. 从 $\mathrm{J} 55$ 到 $\mathrm{J} 75$, 其 $E_{\mathrm{HOMO} O}$ 逐 渐降低 $(-5.26 、-5.38 、-5.43 \mathrm{eV})$, 带隙也逐渐增大 $(1.68 、 1.78 、 1.85 \mathrm{eV})$, 其中 $\mathrm{J} 75$ 的光伏性能最为优异. 基 于 $\mathrm{J} 75 / \mathrm{ITIC}(w / w, 1.3: 1)$ 器件的 PCE 为 $11.07 \%$.

在 J71 的基础上, 2019 年李永舫、张占军等 ${ }^{[60]}$ 将噻 吩共轭侧链或噻吩共轭 $\pi$ 桥替换为硒吩单元，设计合成 了 $\mathrm{J} 75$ 和 $\mathrm{J} 76$ (图 7m), 探讨了硒吩单元对光伏性能的影 响. 相比于 $\mathrm{J} 71$, 具有硒吩共轭 $\pi$ 桥的 $\mathrm{J} 76$ 表现出更窄的 带隙, 吸收边界红移约 $25 \mathrm{~nm}$, 且 $E_{\mathrm{HOMO}}$ 略微提高 $(0.04$ $\mathrm{eV})$. 从 $\mathrm{J} 71$ 到 $\mathrm{J} 76$, 与 $\mathrm{PC}_{71} \mathrm{BM}$ 匹配 $(w / w, 1: 1,0.5 \mathrm{vol} \%$ $\mathrm{CN})$ 的器件，其 $\mathrm{PCE}$ 呈明显上升趋势 $(6.79 \% 、 7.71 \%$ 、 $8.37 \%)$; 与 $m$-ITIC 匹配 $(w / w, 1: 1.2,0.5 \mathrm{vol} \% \mathrm{CN})$ 器件 的 PCE 呈微弱的下降趋势 $(11.73 \% 、 11.41 \% 、 11.04 \%)$. 该 研究表明, 引入硒吩单元在某些条件下(例如富勒烯受 体体系中作为共轭 $\pi$ 桥) 可以一定程度上提高材料的光 伏性能.

在 J71 的基础上, 2019 年闵杰等 ${ }^{61]}$ 将 BTA 单元进行 双氯取代, 设计合成了 $\mathrm{J} 101$ (图 7n). 基于 $\mathrm{J} 101 / \mathrm{ZITI}(w / w$, $1: 1, \approx 110 \mathrm{~nm})$ 器件获得了较高的 $J_{\mathrm{sc}}\left(21.3 \mathrm{~mA} / \mathrm{cm}^{2}\right)$ 和 $\mathrm{FF}(72.5 \%$ ), PCE 提升至 14.43\%. 基于 J101/ZITI(AVT (average transmittance) $=21.69 \%$ )半透明器件, 其 PCE 仍 可达到 $11.04 \%$. 该研究表明在 BTA 单元上进行双氯化 也是一种有效提高材料的光伏性能的方法.

2019 年, 李永舫等 ${ }^{[62]}$ 通过改变 BDT 单元的噻吩共 轭侧链上的卤素取代和烷基侧链取代位点, 即在 $\alpha$ 位进 行氯取代, $\beta$ 位通过辛基、辛氧基修饰，设计合成了 $\mathrm{J} 11$ 和 $\mathrm{J} 12$ (图 7o), 二者均表现出相似的吸收谱带以及降低 的 $E_{\text {HOMO. }}$. 基于 $\mathrm{J} 11 / m-\mathrm{ITTC}(w / w, 1: 1, \approx 110 \mathrm{~nm})$ 器件 的 $V_{\mathrm{oc}}$ 为 $0.94 \mathrm{~V}, J_{\mathrm{sc}}$ 为 $18.1 \mathrm{~mA} / \mathrm{cm}^{2}, \mathrm{FF}$ 为 $73.0 \%, \mathrm{PCE}$ 为 $12.32 \%$; 基于 $\mathrm{J} 12 / m-\mathrm{ITTC}(w / w, 1: 1, \approx 110 \mathrm{~nm})$ 器件的 $V_{\mathrm{oc}}$ 为 $0.94 \mathrm{~V}, J_{\mathrm{sc}}$ 为 $16.6 \mathrm{~mA} / \mathrm{cm}^{2}, \mathrm{FF}$ 为 $55.7 \%, \mathrm{PCE}$ 为 $8.74 \%$. 基于 $\mathrm{J} 12 / m$-ITTC 器件性能较低的原因是, 烷氧 基侧链的引入使得 $\mathrm{J} 12$ 与 $m$-ITTC 的相分离尺寸较小, 更易发生双分子复合. 
李永舫课题组对于 $\mathrm{J}$ 系列聚合物给体材料的系统性 研究中篮选出了性能优异的给体聚合物，如 J61、J71, 这些聚合物给体材料被多个课题组用于优化器件性能, 制备高效光伏器件, 也为给体材料的设计提供了宝贵的 经验借鉴.

为了更直观地表现分子结构的改变对材料的 $E_{\mathrm{LUMO}}$ 和 $E_{\mathrm{HOMO}}$ 的影响, 我们将以上材料的分子能级图进行对 比, 如图 8 所示. 相关给体材料的电化学性质及相应的 有机太阳能电池器件性能指标如表 2 所示.

针对该体系的聚合物给体材料, 其它课题组也进行 了相关的研究.
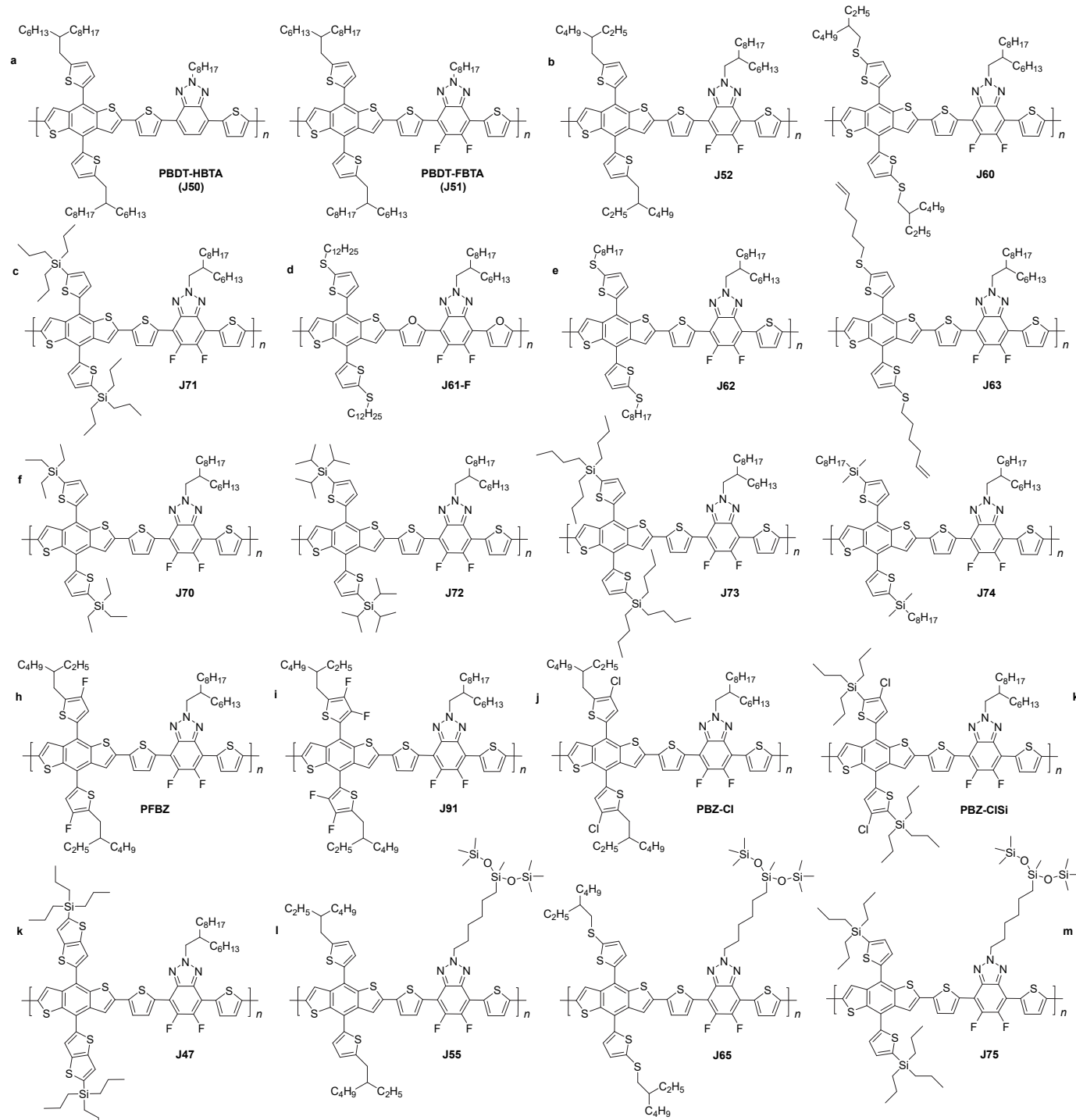

种给体材料的分子结构中均无共轭 $\pi$ 桥，作者探讨 了侧链单元对光伏性能的影响, 其中 PBDTT-YBTz 的 光伏性能最为优异. 基于 $\mathrm{PBDTT}-\mathrm{YBTz} / \mathrm{PC}_{71} \mathrm{BM}(w / w$, $1: 1.5,3.0 \mathrm{vol} \% \mathrm{DIO})$ 器件的 $V_{\mathrm{oc}}$ 为 $0.74 \mathrm{~V}, J_{\mathrm{sc}}$ 为 10.3 $\mathrm{mA} / \mathrm{cm}^{2}, \mathrm{FF}$ 为 $43.0 \%$, PCE 为 $3.20 \%$.
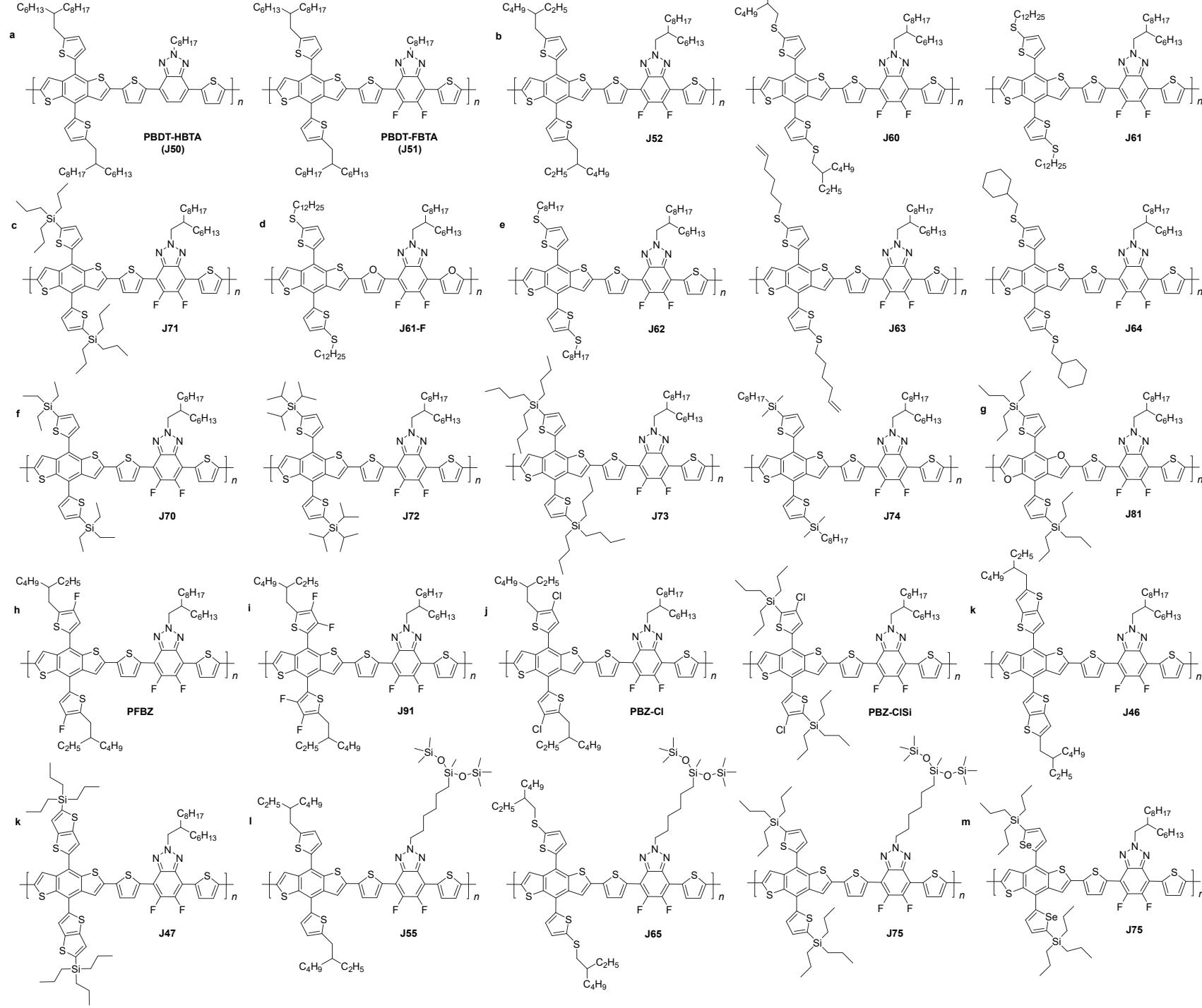
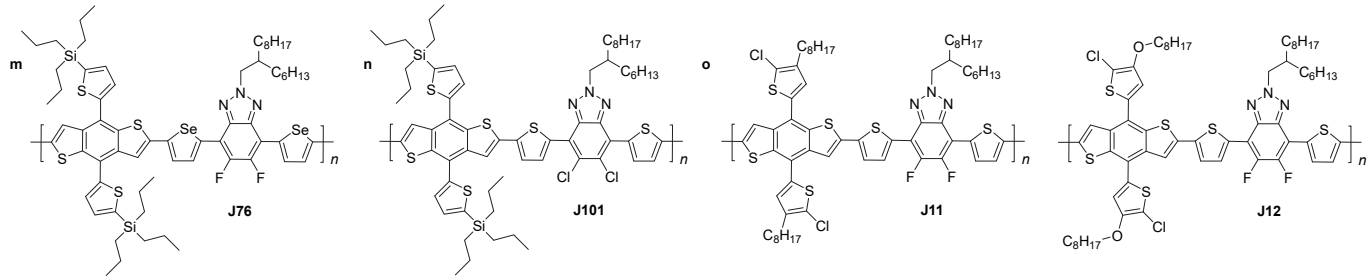

图 7 基于共轭侧链取代的 BDT 单元或其衍生物构筑的 $\mathrm{J}$ 系列给体材料

Figure 7 J-series donor materials based on the BDT or its derivatives with conjugated side-chains 
表 2 基于共轭侧链取代的 BDT 单元或其衍生物构筑的 $\mathrm{J}$ 系列给体材料的电化学性质及相应的有机太阳能电池器件性能指标

Table 2 The electrochemical properties of J-series donor materials based on the BDT or its derivatives with conjugated side-chains and the photovoltaic characteristics of the corresponding solar cells

\begin{tabular}{|c|c|c|c|c|c|c|c|c|c|c|}
\hline \multirow[b]{2}{*}{ Donor } & \multicolumn{4}{|c|}{ Optical and electrochemical property } & \multicolumn{5}{|c|}{ Photovoltaic characteristics of corresponding OSCs device } & \multirow[b]{2}{*}{ Ref. } \\
\hline & $E_{\mathrm{g}}$ opt $a / \mathrm{eV}$ & $\mathrm{HOMO} / \mathrm{eV}$ & $\mathrm{LUMO} / \mathrm{eV}$ & $\begin{array}{c}E_{\mathrm{g}}{ }^{\mathrm{ec} b} / \\
\mathrm{eV}\end{array}$ & Acceptor & $V_{\text {oc }} / \mathrm{V}$ & $\begin{array}{c}J_{\mathrm{sc}} / \\
\left(\mathrm{mA} \cdot \mathrm{cm}^{-2}\right)\end{array}$ & $\mathrm{FF} / \%$ & $\mathrm{PCE} / \%$ & \\
\hline \multirow{3}{*}{$\begin{array}{l}\text { PBDT-HBTA } \\
\quad(\mathrm{J} 50)\end{array}$} & \multirow{3}{*}{1.88} & \multirow{3}{*}{-5.13} & \multirow{3}{*}{-3.16} & \multirow{3}{*}{1.97} & $\mathrm{PC}_{71} \mathrm{BM}$ & 0.58 & 7.4 & 56.5 & 2.43 & {$[10 \mathrm{~b}]$} \\
\hline & & & & & N2200 & 0.60 & 13.9 & 58.7 & 4.90 & [44] \\
\hline & & & & & ITIC & 0.71 & 12.9 & 53.0 & 4.80 & [45] \\
\hline \multirow{3}{*}{$\begin{array}{l}\text { PBDT-FBTA } \\
(\mathrm{J} 51)\end{array}$} & \multirow{3}{*}{1.91} & \multirow{3}{*}{-5.26} & \multirow{3}{*}{-3.08} & \multirow{3}{*}{2.18} & $\mathrm{PC}_{71} \mathrm{BM}$ & 0.75 & 11.9 & 67.2 & 6.00 & [10b] \\
\hline & & & & & N2200 & 0.83 & 14.2 & 70.2 & 8.27 & [44] \\
\hline & & & & & ITIC & 0.82 & 16.5 & 69.0 & 9.26 & [45] \\
\hline \multirow{3}{*}{$\begin{array}{c}\mathrm{J} 52 \\
\text { (PBZ) }\end{array}$} & \multirow{3}{*}{1.96} & \multirow{3}{*}{-5.21} & \multirow{3}{*}{-2.99} & \multirow{3}{*}{2.22} & ITIC & 0.73 & 13.1 & 57.8 & 5.51 & [46] \\
\hline & & & & & IT-4F & 0.60 & 17.0 & 63.2 & 6.40 & [55] \\
\hline & & & & & BTA3 & 1.07 & 14.6 & 60.3 & 9.41 & [63] \\
\hline \multirow[t]{2}{*}{$\mathrm{J} 60$} & 1.93 & -5.32 & -3.08 & 2.24 & ITIC & 0.91 & 16.3 & 60.4 & 8.97 & [46] \\
\hline & & & & & ITIC & 0.89 & 17.4 & 61.5 & 9.53 & [46] \\
\hline J61 & 1.93 & -5.32 & -3.08 & 2.24 & N2200 & 0.90 & 12.1 & 60.2 & 6.58 & [64] \\
\hline & & & & & $m$-ITIC & 0.91 & 18.3 & 70.6 & 11.77 & [47] \\
\hline J61-F & 2.03 & -5.45 & -2.91 & 2.54 & ITIC & 0.95 & 13.1 & 66.1 & 8.24 & [49] \\
\hline $\mathrm{J} 62$ & 1.92 & -5.31 & -3.08 & 2.23 & ITIC & 0.92 & 16.9 & 70.1 & 10.81 & [50] \\
\hline $\mathrm{J} 63$ & 1.92 & -5.28 & -3.04 & 2.24 & ITIC & 0.87 & 15.7 & 59.6 & 8.13 & [50] \\
\hline $\mathrm{J} 64$ & 1.92 & -5.33 & -3.09 & 2.24 & ITIC & 0.89 & 15.4 & 62.7 & 8.59 & [50] \\
\hline $\mathrm{J} 70$ & 1.99 & -5.37 & -2.91 & 2.46 & $m$-ITIC & 0.92 & 18.1 & 69.8 & 11.62 & [51] \\
\hline & & & & & $\mathrm{PC}_{71} \mathrm{BM}$ & 0.92 & 11.0 & 67.0 & 6.79 & [60] \\
\hline J71 & 196 & -540 & -324 & 216 & ITIC & 0.94 & 17.3 & 69.8 & 11.41 & [48] \\
\hline$J / 1$ & 1.90 & -5.40 & 3.24 & 2.16 & N2200 & 0.91 & 13.1 & 78.0 & 9.31 & [64] \\
\hline & & & & & $m$-ITIC & 0.94 & 18.1 & 70.6 & 12.05 & [51] \\
\hline J72 & 1.98 & -5.42 & -3.29 & 2.13 & $m$-ITIC & 0.96 & 16.4 & 65.0 & 10.23 & [51] \\
\hline $\mathrm{J} 73$ & 1.98 & -5.46 & -2.92 & 2.54 & $m$-ITIC & 0.97 & 16.5 & 66.9 & 10.71 & [51] \\
\hline J74 & 1.99 & -5.56 & -3.06 & 2.50 & $m$-ITIC & 0.99 & 15.9 & 61.2 & 9.63 & [51] \\
\hline & & & & & ITIC & 0.95 & 15.3 & 73.1 & 10.60 & [29b] \\
\hline 381 & 1.93 & -5.43 & -2.98 & 2.45 & $m$-ITIC & 0.96 & 16.5 & 69.8 & 11.05 & [29b] \\
\hline J91 & 2.00 & -5.50 & -3.02 & 2.48 & $m$-ITIC & 0.98 & 18.0 & 65.5 & 11.63 & [54] \\
\hline PFBZ & 194 & -5.36 & -342 & 194 & ITIC & 0.89 & 18.8 & 62.0 & 10.40 & [52] \\
\hline & 1.94 & -5.56 & -3.42 & 1.94 & N2200 & 0.90 & 13.5 & 67.0 & 8.10 & [53] \\
\hline & & & & & IT-4F & 0.80 & 17.7 & 68.3 & 9.70 & [55] \\
\hline $\begin{array}{l}\text { PBZ-C1 } \\
\text { (I52-Cl) }\end{array}$ & 1.94 & -5.39 & -3.41 & 1.98 & BTA3 & 1.24 & 13.2 & 66.6 & 10.50 & [63] \\
\hline & & & & & Y6 & 0.84 & 23.8 & 61.4 & 12.31 & [65] \\
\hline PBZ-ClSi & 1.94 & -5.66 & -3.50 & 2.16 & IT-4F & 0.93 & 19.2 & 71.5 & 12.80 & [55] \\
\hline $\mathrm{J} 46$ & 2.00 & -5.27 & -3.27 & 2.00 & ITIC & 0.74 & 7.4 & 42.7 & 2.34 & [57] \\
\hline $\mathrm{J} 47$ & 2.00 & -5.43 & -3.30 & 2.13 & ITIC & 0.96 & 15.6 & 60.0 & 9.01 & [57] \\
\hline J55 & 1.94 & -5.26 & -3.58 & 1.68 & ITIC & 0.81 & 12.8 & 58.0 & 6.03 & [58] \\
\hline $\mathrm{J} 65$ & 1.94 & -5.38 & -3.60 & 1.78 & ITIC & 0.93 & 13.3 & 56.0 & 6.91 & [58] \\
\hline $\mathrm{J} 75$ & 1.96 & -5.43 & -3.58 & 1.85 & ITIC & 0.94 & 17.0 & 69.3 & 11.07 & [58] \\
\hline $\mathrm{J} 75$ & 1.93 & -5.49 & -3.66 & 1.83 & $\mathrm{PC}_{71} \mathrm{BM}$ & 0.94 & 11.6 & 70.8 & 7.71 & [60] \\
\hline (1) & 1.93 & 5.49 & 3.00 & 1.83 & $m$-ITIC & 0.96 & 17.1 & 69.5 & 11.41 & [60] \\
\hline $\mathrm{J} 76$ & 1.86 & -5.41 & -3.66 & 1.75 & $\mathrm{PC}_{71} \mathrm{BM}$ & 0.90 & 12.7 & 73.0 & 8.37 & [60] \\
\hline 年 & & 5.71 & 3.00 & & $m$-ITIC & 0.91 & 17.0 & 71.2 & 11.04 & [60] \\
\hline $\mathrm{J} 101$ & 1.97 & -5.30 & -3.50 & 1.80 & ZITI & 0.94 & 21.3 & 72.5 & 14.43 & [61] \\
\hline $\mathrm{J} 11$ & 1.96 & -5.48 & -3.23 & 2.25 & $m$-ITTC & 0.94 & 18.1 & 73.0 & 12.32 & [62] \\
\hline $\mathrm{J} 12$ & 1.94 & -5.51 & -3.26 & 2.25 & $m$-ITTC & 0.94 & 16.6 & 55.7 & 8.74 & [62] \\
\hline
\end{tabular}

${ }^{a}$ Optical bandgap calculated from the absorption edge (onset) of the polymer films: $E_{\mathrm{g}}{ }^{\text {opt }}=1240 / \lambda_{\text {edge. }}{ }^{b}$ Electrochemical bandgap obtained from: $E_{\mathrm{g}}{ }^{\text {cc }}=E_{\mathrm{LUMO}}-$ E

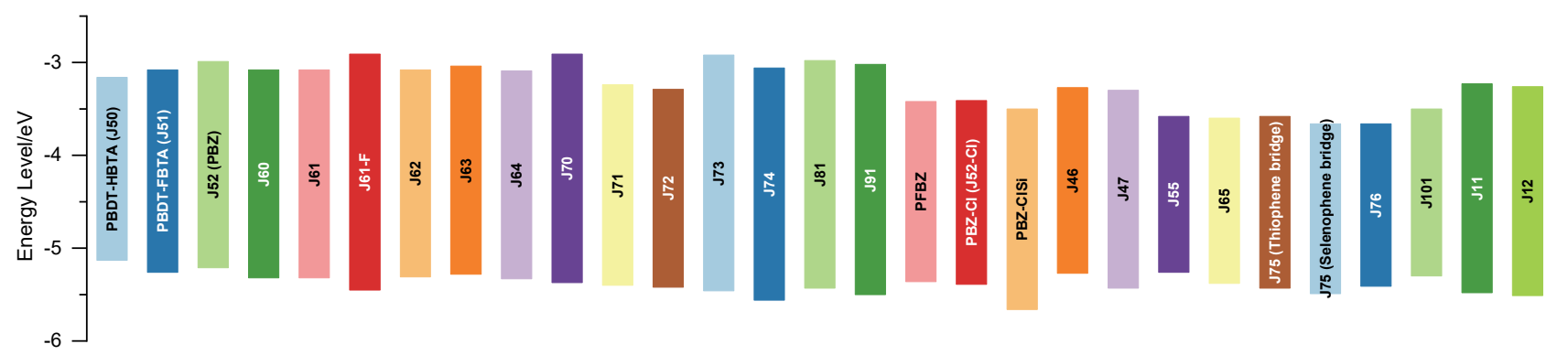

图 8 基于共轭侧链取代的 BDT 单元或其衍生物构筑的 $\mathrm{J}$ 系列给体材料的能级示意图

Figure 8 Energy level diagram of J-series donor materials based on the BDT or its derivatives with conjugated side-chains 
2012 年, 邹应萍等[66]设计合成了 PBDTTDTBTz(图 $9 b$ ), 其 BDT 单元上侧链噻吩单元的烷基链为较短的 2乙基己基. 相比于 $\mathrm{J} 50$, 其 $E_{\mathrm{LUMO}}$ 和 $E_{\mathrm{HOMO}}$ 均有所提高. 基于 PBDTTDTBTz/PC $\mathrm{PC}_{71} \mathrm{BM}(w / w, 1: 1,120 \mathrm{~nm})$ 器件的 $V_{\mathrm{oc}}$ 为 $0.54 \mathrm{~V}, J_{\mathrm{sc}}$ 为 $9.5 \mathrm{~mA} / \mathrm{cm}^{2}, \mathrm{FF}$ 为 $60.6 \%$, PCE 达到 $3.10 \%$.

2016 年, 黄飞、应磊、叶轩立等[67]以具有更长共轭 结构的二噻吩苯并二噻吩 (dithieno[2,3- $\left.d: 2^{\prime}, 3^{\prime}-d^{\prime}\right]-$ benzo[1,2-b:4,5- $b$ ] dithiophene, DTBDT)作为给体单元, 设计合成了 PDTBDT-FBTz(图 9c). 基于 PDTBDT$\mathrm{FBTz} / \mathrm{PC}_{71} \mathrm{BM}(w / w, 1: 1.5, \approx 110 \mathrm{~nm})$ 器件的 $V_{\mathrm{oc}}$ 为 0.95 $\mathrm{V}, J_{\mathrm{sc}}$ 为 $9.3 \mathrm{~mA} / \mathrm{cm}^{2}, \mathrm{FF}$ 为 $62.7 \%, \mathrm{PCE}$ 达到 $5.55 \%$, 高于 基于 PBDTTDTBTz/PC ${ }_{71} \mathrm{BM}$ 器件 ${ }^{[66]}$ 的 $\mathrm{PCE}(3.10 \%)$. 这 表明在该体系中引入 $\mathrm{DTBDT}$ 单元来延长共轭主链长度 有利于提高器件的光伏性能.

2018 年, 黄飞、应磊等[68]设计合成了 PBTA-BO(图 $9 \mathrm{~d}$ ), 其 $\mathrm{BDT}$ 单元上侧链噻吩单元的 $\alpha$ 和 $\beta$ 位上均为己 基. 基于 PBTA-BO/N2200( $w / w, 2 ： 1,100 \mathrm{~nm}, 0.5 \mathrm{wt} \%$ $\mathrm{DBE}$ )器件的 $V_{\mathrm{oc}}$ 为 $0.87 \mathrm{~V}, J_{\mathrm{sc}}$ 为 $11.0 \mathrm{~mA} / \mathrm{cm}^{2}, \mathrm{FF}$ 为 $75.8 \%, \mathrm{PCE}$ 为 $7.05 \%$; 添加 $30 \mathrm{wt} \%$ 的窄带隙聚合物 PNTB 作为第三组分后, 可以形成良好互补的吸收谱带, 有效地提高载流子迁移率和能量转换效率, 基于 PBTA-BO/PNTB/N2200( $w / w, 1.4: 0.6: 1,130 \mathrm{~nm}, 0.5$ $\mathrm{wt} \% \mathrm{DBE}$ ) 的三元器件的 $V_{\mathrm{oc}}$ 为 $0.84 \mathrm{~V}, J_{\mathrm{sc}}$ 为 15.4 $\mathrm{mA} / \mathrm{cm}^{2}, \mathrm{FF}$ 为 $76.7 \%$, $\mathrm{PCE}$ 为 $9.93 \%$; 基于 $\mathrm{PBTA}-\mathrm{BO} /$ PTzBI/N2200( $w / w, 0.6: 1.4: 1,120 \mathrm{~nm}, 0.3$ vol\% DIO) 三元器件 ${ }^{[69]}$ 的 $V_{\mathrm{oc}}$ 为 $0.84 \mathrm{~V}, J_{\mathrm{sc}}$ 为 $15.6 \mathrm{~mA} / \mathrm{cm}^{2}, \mathrm{FF}$ 为 $78.3 \%$, PCE 为 $10.12 \%$.

在 PBTA-BO 的基础上, 黄飞、应否等 ${ }^{[70]}$ 以甲基 三硅氧烷(HMTS)封端的己基作为 BTA 单元上的烷基侧 链, 设计合成了 PBTA-Si(图 9e). 基于 PBTA-Si/N2200 $(w / w, 2: 1,165 \mathrm{~nm})$ 器件的 $V_{\mathrm{oc}}$ 为 $0.92 \mathrm{~V}, J_{\mathrm{sc}}$ 为 13.8 $\mathrm{mA} / \mathrm{cm}^{2}, \mathrm{FF}$ 为 $73.1 \%, \mathrm{PCE}$ 为 $8.31 \%$, 相比于基于 PBTA-BO/N2200 器件 ${ }^{66]}$ 的 $\operatorname{PCE}(7.05 \%)$ 略有提高, 表明 在该体系中, 在 BTA 单元上引入 HMTS 侧链有利于提 高材料的光伏性能. 该研究也引领了另一个体系即 PTzBI-Si 的设计合成 ${ }^{[59]}$, 且添加 PTzBI-Si 作为第三组 分后, 基于 PBTA-Si/PTzBI-Si/N2200( $w / w, 1: 1: 1,150$ $\mathrm{nm})$ 小面积 $\left(0.04 \mathrm{~cm}^{2}\right)$ 三元器件的 PCE 进一步提升至 $9.56 \%$, 并表现出较低的膜厚依赖性. 基于 PBTA-Si/PTzBI-Si/N2200(w/w, $1.3: 0.7: 1,350 \mathrm{~nm}, 0.1$ $\mathrm{vol} \% \mathrm{DBE})$ 大面积 $\left(0.91 \mathrm{~cm}^{2}\right)$ 三元器件 ${ }^{[71]}$ 的 PCE 可达到 $10.00 \%$.

2018 年, 段春晖等 ${ }^{[72]}$ 引 $\operatorname{TPD}$ (噻吩并吡咯二酮, thieno[3,4-c]pyrrole-4,6-(5H)-dione) 受体单元，以 BDTT-BTA 与 BDTT-TPD 作为主链, 得到无规共聚物 PTAZ-TPDx(图 9f), 并将其与基于同样思路在 N2200 的 基础上得到的无规共聚物受体材料 PNDI-Tx 匹配, 探讨 了分子堆叠及结晶性、活性层形貌对光伏性能的影响.
研究结果表明, 聚合物分子主链规整性会显著影响其分 子的结晶性、分子堆叠以及相应的活性层形貌. 基于 PTAZ-TPD00/PNDI-T00(w/w, $1.5: 1,100 \mathrm{~nm}, 2.0 \mathrm{wt} \%$ ODT) 器件的 $V_{\mathrm{oc}}$ 为 $0.87 \mathrm{~V}, J_{\mathrm{sc}}$ 为 $11.3 \mathrm{~mA} / \mathrm{cm}^{2}, \mathrm{FF}$ 为 $68.0 \%$, PCE 为 $6.60 \%$.

2018 年，陈义旺等 ${ }^{[73]}$ 探讨了 BTA 单元上的不同烷 基对光伏性能的影响，设计合成了 L24、L68(即 $\mathrm{PBZ}-\mathrm{Cl}$ )、 L810(图 9g), 其中 BTA 单元上的烷基侧链逐 渐增长, 分别为 2-乙基己基、2-己基壬基、2-辛基十二 烷基. 从 $\mathrm{L} 24$ 到 L68, 再到 L810, $E_{\mathrm{LUMO}}$ 和 $E_{\mathrm{HOMO}}$ 逐渐降 低, 且与 IT-4F 的共混薄膜表现出更规整的形貌、更好 的共混均匀性(表现为纤维状的纳米级相分离). 基于与 IT-4F( $w / w, 1: 1,100 \mathrm{~nm}, 0.25 \mathrm{wt} \%$ DIO)器件的主要性 能指标均逐渐提升, $V_{\mathrm{oc}}$ 从 $0.50 \mathrm{~V}(\mathrm{~L} 24)$ 提升至 0.79 $\mathrm{V}(\mathrm{L} 810), J_{\mathrm{sc}}$ 从 $7.4 \mathrm{~mA} / \mathrm{cm}^{2}(\mathrm{~L} 24)$ 提 升至 20.8 $\mathrm{mA} / \mathrm{cm}^{2}(\mathrm{~L} 810), \mathrm{FF}$ 从 36.3\%(L24)提升至 73.5\%(L810), PCE 从 $1.33 \%(\mathrm{~L} 24)$ 提升至 $12.10 \%(\mathrm{~L} 810)$.

2019年，孙艳明等 ${ }^{[74]}$ 设计合成了 L2(图 9h). L2 可以 看成是把 L68 结构中的 BDT 单元替换为 BDF 单元得到. 相比之下, 其 $E_{\mathrm{LUMO}}$ 和 $E_{\mathrm{HOMO}}$ 降低约 $0.02 \mathrm{eV}$, 且 $\mathrm{L} 2$ 分子 更趋于平面化. 基于 L2/TTPT-T- $4 \mathrm{~F}(w / w, 1 ： 1.5,0.5$ $\mathrm{wt} \% \mathrm{DIO}$ )器件的 $V_{\mathrm{oc}}$ 为 $0.86 \mathrm{~V}, J_{\mathrm{sc}}$ 为 $22.2 \mathrm{~mA} / \mathrm{cm}^{2}, \mathrm{FF}$ 为 $73.6 \%, \mathrm{PCE}$ 为 $14.00 \%$, 高于基于 L68/IT-4F 器件的 $\operatorname{PCE}(9.30 \%)$, 表明该体系中引入 $\mathrm{BDF}$ 单元有利于提高 材料的光伏性能. 另外, 值得注意的是, 该体系表现出 良好的稳定性，在空气中放置 $1800 \mathrm{~h}$ 后, PCE 仍可达到 原来的 $92 \%$.

2019 年, 周二军等 ${ }^{[63]}$ 基于 “给受体相同吸电子单元 的策略” (same-acceptor-strategy, SAS)策略, 将 J52-Cl(即 $\mathrm{PBZ}-\mathrm{Cl}$, 图 9g) 与同样具有 BTA 受体单元的受体材料 BTA3 匹配. 二者的 $\Delta E_{\mathrm{HOMO}}$ 为 $0.10 \mathrm{eV}, \Delta E_{\mathrm{LUMO}}$ 为 0.28 $\mathrm{eV}$, 基于 $\mathrm{J} 52-\mathrm{Cl} / \mathrm{BTA} 3(w / w, 1: 1, \approx 100 \mathrm{~nm})$ 器件表现 出具有良好的载流子迁移率、平衡的电荷传输, 并能有 效地降低了双分子复合损失，使得 $E_{\mathrm{loss}}$ 仅为 $0.52 \mathrm{eV}, V_{\mathrm{oc}}$ 为 $1.24 \mathrm{~V}, J_{\mathrm{sc}}$ 为 $13.2 \mathrm{~mA} / \mathrm{cm}^{2}, \mathrm{FF}$ 为 $66.6 \%, \mathrm{PCE}$ 为 $10.5 \%$, 高 $V_{\mathrm{oc}}$ 为其在串联 OSCs 上的应用提供了潜力. 在此基础 上, 采用氟化的策略, 设计合成了 J52-F(即 PFBZ) 和 $\mathrm{J} 52-\mathrm{FS}$ (即 J60-F) ${ }^{[75]}$ (图 9i), 基于 J52-F/BTA13(w/w, $1: 1$, $\approx 100 \mathrm{~nm}$ )器件表现出更为优异的光伏性能, $V_{\mathrm{oc}}$ 为 1.18 $\mathrm{V}, J_{\mathrm{sc}}$ 为 $11.6 \mathrm{~mA} / \mathrm{cm}^{2}, \mathrm{FF}$ 为 $61.3 \%$, PCE 达到 $8.36 \%$. 进 一步地, 他们设计合成了 PE31、PE32 和 PE4(图 9j) ${ }^{[65]}$, 并与 J52- $\mathrm{Cl}$ 对比, 研究了分子的结构和构象与器件性能 的关系. 与 PE31 相比, PE32 分子中 BTA 单元上甲氧基 的引入，使其分子骨架扭曲，不利于载流子的传输; $\mathrm{J} 52-\mathrm{Cl}$ 分子中 BTA 单元上的氟取代增强了其分子链内 及分子链间的相互作用力, 优化了分子堆叠, 该效果与 以往的氟化效应的经验一致. 而相比于其它三种分子的 “之” 字形分子构象, PE4 分子中以并噻吩单元作为共轭 $\pi$ 桥, 使其分子骨架呈现为直线型，与 Y6 的共混薄膜表 
现出缩短的 $\pi-\pi$ 堆积面间距以及较好的结晶性. 基于 $\mathrm{PE} 4 / \mathrm{Y} 6\left(w / w, 1: 1.2, \approx 100 \mathrm{~nm}, 0.5 \mathrm{wt} \% \mathrm{CN}\right.$ )器件的 $V_{\mathrm{oc}}$ 为 $0.84 \mathrm{~V}, J_{\mathrm{sc}}$ 为 $22.2 \mathrm{~mA} / \mathrm{cm}^{2}, \mathrm{FF}$ 为 $75.4 \%, \mathrm{PCE}$ 为 $14.02 \%$. 该研究表明, 合理地调整分子构象也是一种有 效优化光伏性能的策略.

2018 年, 彭强等 ${ }^{[76]}$ 探讨了硒吩共轭侧链对光伏性 能的影响, 将 J51 上的噻吩共轭侧链替换为硒吩单元, 以及将硒吩单元上的烷基链替换为烷硫链, 设计合成了 PBDT-Se-TAZ 和 PBDTS-Se-TAZ(图 9k). 硫原子和硒原 子的协同作用, 赋予了 PBDTS-Se-TAZ 更好的结晶性. 基于 PBDTS-Se-TAZ/ITIC $(w / w, 1: 1,110 \mathrm{~nm}, 0.3 \mathrm{wt} \%$ $\mathrm{DIO}$ )器件的 $V_{\mathrm{oc}}$ 为 $0.84 \mathrm{~V}, J_{\mathrm{sc}}$ 为 $19.5 \mathrm{~mA} / \mathrm{cm}^{2}, \mathrm{FF}$ 为 $75.1 \%$, PCE 为 $12.31 \%$. J51 和 PBDT-Se-TAZ 的差别在于 将 $\mathrm{BDT}$ 单元的噻吩共轭侧链替换为硒吩, 基于 PBDT-Se-TAZ/ITIC 器件的 PCE(10.07\%)略高于基于 J51/ITIC 器件的 PCE $(9.26 \%)$. 表明在该体系中引入硒吩 共轭侧链有利于提高材料的光伏性能, 验证了前述的引 入硒吩单元在 $\mathrm{J} 75$ 和 $\mathrm{J} 76^{[60]}$ 上的正面效果.

2018 年, 阳仁强等 ${ }^{[77]}$ 探讨了烷硫基在苯基侧链上 的取代位置对光伏性能的影响, 他们将 BDT 单元上的 侧链噻吩单元替换为苯环单元, 通过在苯环对位或间位 连接 2-乙基己硫基, 设计合成了 $m$-PBDTPS-FTAZ 和 $p$-PBDTPS-FTAZ(图 91). 烷硫基间位取代的 $m$-PBDTPS-FTAZ 表现出更低的分子能级、蓝移的吸收 谱带, 但取代位点的不同对分子的结晶性未表现出明显 影响. 基于 $m$-PBDTPS-FTAZ/ITIC $(w / w, 1: 1, \approx 110$ $\mathrm{nm}$ ) 器件的 $V_{\mathrm{oc}}$ 为 $0.95 \mathrm{~V}, J_{\mathrm{sc}}$ 为 $18.8 \mathrm{~mA} / \mathrm{cm}^{2}, \mathrm{FF}$ 为 $73.9 \%$, PCE 为 $13.16 \%$. 随后, 阳仁强、包西昌等 ${ }^{[78]}$ 又通过在 BDT 单元两侧增加稠合噻吩环, 构成结构不对称的噻 吩并苯并二噻吩(thienobenzodithiophene, TBDT)单元和 结构对称的二噻吩苯并二噻吩 (dithieno[2,3- $\left.d: 2^{\prime}, 3^{\prime}-d^{\prime}\right]-$ benzo[1,2- $b: 4,5-b]$ dithiophene, DTBDT)单元, 设计合成 了 PBDT-BZ、PTBD-BZ 和 PDTBDT-BZ(图 9m), 研究 了分子构象对光伏性能的影响. 相比于 PBDT-BZ 和 PDTBDT-BZ 的 “之” 字形分子构象, PTBD-BZ 的分子 构象更趋于直线形. 因此, 其与四种不同的非富勒烯受 体材料(BDTB-Ph、BDTB-Na、TBDB-Ph、TBDB-Na) 的共混薄膜表现出更好的结晶性、更规整的 $\pi-\pi$ 堆积, 以及更好的受体材料兼容性, PCE 普遍在 $9.2 \% \sim 12.5 \%$. 基于 PTBD-BZ/TBDB-Na $(w / w, 1: 1)$ 器件的 $V_{\mathrm{oc}}$ 为 0.91 $\mathrm{V}, J_{\mathrm{sc}}$ 为 $19.6 \mathrm{~mA} / \mathrm{cm}^{2}, \mathrm{FF}$ 为 $70.2 \%$, $\mathrm{PCE}$ 为 $12.47 \%$.

2018 年, 何凤等 [79] 设计合成了 PBT1Cl-Bz, PBT2Cl ${ }^{\mathrm{as}}-\mathrm{Bz} 、 \mathrm{PBT} 2 \mathrm{Cl}^{\mathrm{s}}-\mathrm{Bz}$ 和 PBT4Cl-Bz(图 9n), 探讨了 噻吩共轭侧链上氯取代的位点及个数对 $E_{\text {loss }}$ 的影响. 得 益于 $\mathrm{C}-\mathrm{Cl}$ 之间较大的偶极矩, $\mathrm{Cl} \cdots \mathrm{S} 、 \mathrm{Cl} \cdots \pi$ 等强非共 价键相互作用以及更强的 $\pi-\pi$ 堆积相互作用, 氯取代有 利于改善分子堆积、共混层形貌. 因此, 所合成的四种
材料中, 噻吩共轭链上全氯(即四氯)取代的 PBT4Cl-Bz 表现出最低的 $E_{\mathrm{HOMO}}$ ，基于 PBT4Cl-Bz/IT-4F $(w / w, 1: 1$, $100 \mathrm{~nm}$ ) 器件的 $V_{\mathrm{oc}}$ 为 $0.96 \mathrm{~V}, J_{\mathrm{sc}}$ 为 $16.4 \mathrm{~mA} / \mathrm{cm}^{2}, \mathrm{FF}$ 为 $58.7 \%$, PCE 为 $9.25 \%, E_{\text {loss }}$ 仅为 $0.54 \mathrm{eV}$.

2020 年, 王智杰、谭付瑞等 ${ }^{[80]}$ 以氟化苯环侧链取代 的 $\mathrm{BDF}$ 单元作为给体单元, 设计合成了 PBDFP-Bz(图 9o). PBDFP-Bz 与 ITIC、IT-M 均表现出良好互补的吸收 谱带、匹配的能级. 基于 PBDFP-Bz/IT-M $(w / w, 1 ： 1)$ 器 件的 $V_{\mathrm{oc}}$ 为 $1.02 \mathrm{~V}, J_{\mathrm{sc}}$ 为 $18.3 \mathrm{~mA} / \mathrm{cm}^{2}, \mathrm{FF}$ 为 $69.4 \%, \mathrm{PCE}$ 为 $12.93 \%$, 且 $E_{\text {loss }}$ 仅为 $0.57 \mathrm{eV}$. 将 $p$-PBDTPS-FTAZ与 PBDFP-Bz 对比发现, 引入 $B D F$ 单元和侧链苯环单元的 单氟取代使得基于 PBDFP-Bz/ITIC 器件的 PCE(11.10\%) 略高于基于 $p$-PBDTPS-FTAZ/ITIC 器件的 PCE(10.86\%), 这也一定程度上表明该体系中引入 $\mathrm{BDF}$ 单元有利于提 高材料的光伏性能, 与前述的 L2 ${ }^{[74]}$ 类似.

2020 年, 霍利军等 ${ }^{81]}$ 在兼顾材料的低合成成本和 高能量转化效率的基础上, 利用 “位阻诱导相容性” (steric effect-induced miscibility, SEIM) 分子设计策略, 通过空间位阻效应来调节烷基侧链的朝向，平衡了聚合 物的结晶性与受体的相容性, 设计合成了 PBTZa 和 $P B T Z b$ (图 9p). 具有邻位烷基侧链的 PBTZb 比具有对位 烷基侧链的 PBTZa 表现出更平衡的电荷传输能力和光 伏性能. 基于 $\mathrm{PBTZb} / \mathrm{ITIC}-4 \mathrm{Cl}(w / w, 1: 1.3)$ 器件的 $V_{\mathrm{oc}}$ 为 $0.87 \mathrm{~V}, J_{\mathrm{sc}}$ 为 $21.8 \mathrm{~mA} / \mathrm{cm}^{2}, \mathrm{FF}$ 为 $76.8 \%, \mathrm{PCE}$ 为 $14.53 \%$.

2020 年，陈义旺等 ${ }^{[82]}$ 设计合成了 DZ1、DZ2 和 DZ3(图 9q), 探讨了烷氧基苯共轭侧链上氯取代的个数 对光伏性能的影响. 双氯原子取代的 DZ2 表现出最优 良的光伏性能, 基于 $\mathrm{DZ} 2 / \mathrm{MeIC}(w / w, 1: 1)$ 器件的 $V_{\mathrm{oc}}$ 为 $0.88 \mathrm{~V}, J_{\mathrm{sc}}$ 为 $17.1 \mathrm{~mA} / \mathrm{cm}^{2}, \mathrm{FF}$ 为 $68.4 \%$, PCE 为 $10.22 \%$, 高于无氯取代的 DZ1(PCE 为 $8.26 \%$ ) 和四氯取代的 $\mathrm{DZ3}$ (PCE 为 $5.97 \%$ ).

为了更直观地表现分子结构的改变对材料的 $E_{\mathrm{LUMO}}$ 和 $E_{\mathrm{HOMO}}$ 的影响, 我们将以上材料的分子能级图进行对 比，如图 10 所示. 相关给体材料的电化学性质及相应的 有机太阳能电池器件性能指标如表 3 所示.

\subsection{3 基于噻吩给体单元构筑的给体材料}

2014 年，陈军武等 ${ }^{[17]}$ 以双氟化的苯并三氮唑单元 和噻吩为主链单元, 设计合成了 PFBTA-3T 和 PFBTA-4T(图 11a). 为了提高溶解性, 其三氮唑环上的 烷基链为 1-(2'-乙基己基)-3-乙基庚基, 而与 BTA 单元相 邻的两个噻吩单元外侧 $\beta$ 位上的烷基为 2-乙基已基. 基 于 PFBTA-3T/PC ${ }_{61} \mathrm{BM}(w / w, 1: 1.5,100 \mathrm{~nm}, 1.2 \mathrm{vol} \%$ $\mathrm{DBE}$ ) 器件的 $V_{\mathrm{oc}}$ 为 $0.81 \mathrm{~V}, J_{\mathrm{sc}}$ 为 $6.73 \mathrm{~mA} / \mathrm{cm}^{2}, \mathrm{FF}$ 为 $55.0 \%, \mathrm{PCE}$ 为 $3.00 \%$; 基于 $\mathrm{PFBTA}-4 \mathrm{~T} / \mathrm{PC}_{61} \mathrm{BM}(w / w, 1$ : $1.5,100 \mathrm{~nm}, 1.2 \mathrm{vol} \% \mathrm{DBE}$ )器件的 $V_{\mathrm{oc}}$ 为 $0.74 \mathrm{~V}, J_{\mathrm{sc}}$ 为 $5.46 \mathrm{~mA} / \mathrm{cm}^{2}, \mathrm{FF}$ 为 $62.1 \%$, PCE 为 $2.51 \%$. 

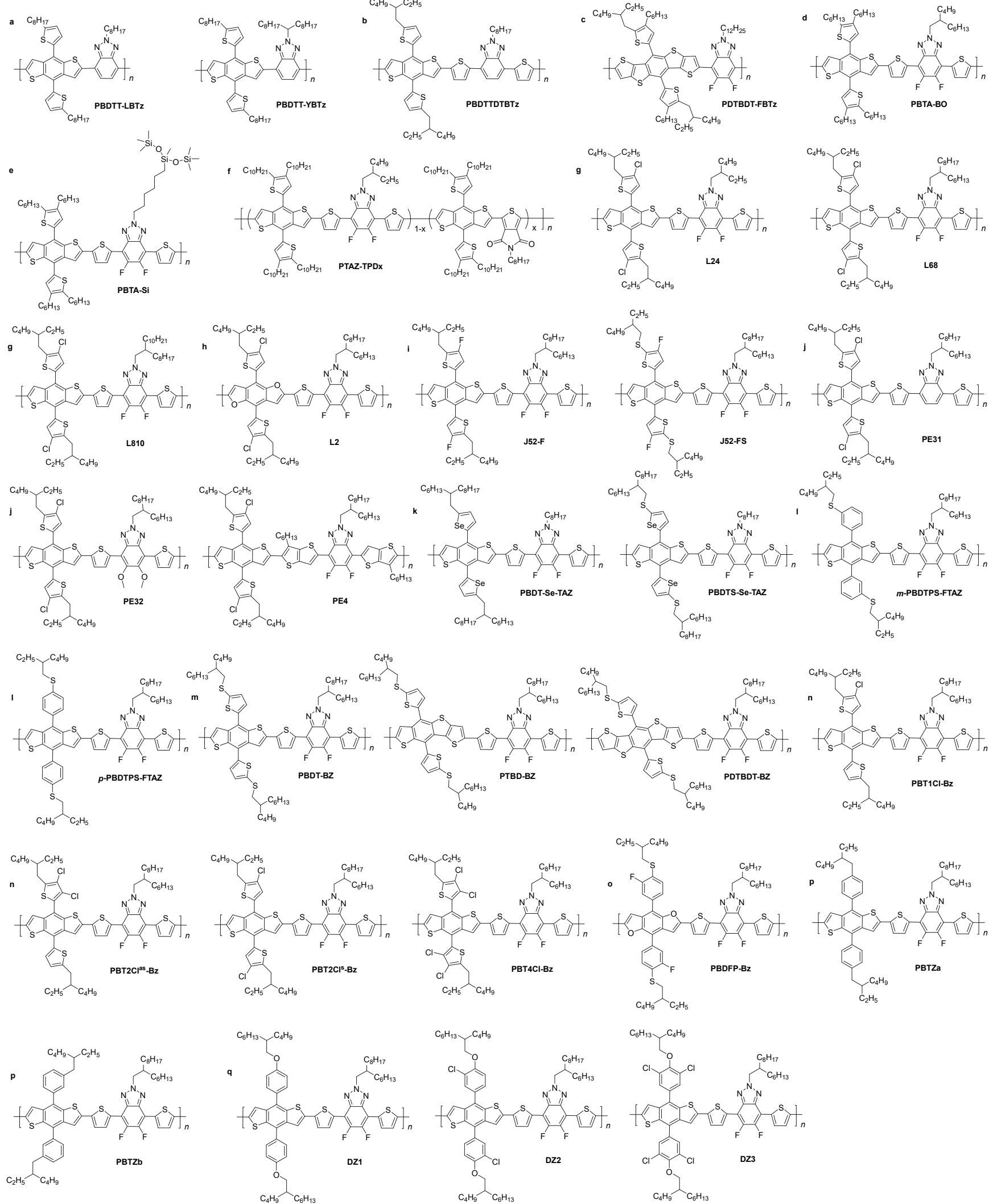

图 9 基于共轭侧链取代的 BDT 单元或其衍生物构筑的给体材料

Figure 9 Donor materials based on the BDT or its derivatives with conjugated side-chains 
表 3 基于共轭侧链取代的 BDT 单元或其衍生物构筑的给体材料的电化学性质及相应的有机太阳能电池器件性能指标

Table 3 The electrochemical properties of donor materials based on the BDT or its derivatives with conjugated side-chains and the photovoltaic characteristics of the corresponding solar cells

\begin{tabular}{|c|c|c|c|c|c|c|c|c|c|c|}
\hline \multirow[b]{2}{*}{ Donor } & \multicolumn{4}{|c|}{ Optical and electrochemical property } & \multicolumn{5}{|c|}{ Photovoltaic characteristics of corresponding OSCs device } & \multirow[b]{2}{*}{ Ref. } \\
\hline & $E_{\mathrm{g}}{ }^{\text {opt } a} / \mathrm{eV}$ & $\mathrm{HOMO} / \mathrm{eV}$ & $\mathrm{LUMO} / \mathrm{eV}$ & $\begin{array}{c}E_{\mathrm{g}}^{\mathrm{gec} b} / \\
\mathrm{eV}\end{array}$ & Acceptor & $V_{\mathrm{oc}} / \mathrm{V}$ & $\begin{array}{c}J_{\mathrm{sc}} / \\
\left(\mathrm{mA} \cdot \mathrm{cm}^{-2}\right)\end{array}$ & $\mathrm{FF} / \%$ & $\mathrm{PCE} / \%$ & \\
\hline PBDTT-LBTz & 1.94 & -5.41 & -3.47 & 1.94 & $\mathrm{PC}_{71} \mathrm{BM}$ & 0.67 & 4.5 & 42.0 & 1.25 & [43] \\
\hline PBDTT-YBTz & 1.90 & -5.48 & -3.58 & 1.90 & $\mathrm{PC}_{71} \mathrm{BM}$ & 0.74 & 10.3 & 43.0 & 3.20 & [43] \\
\hline PBDTTDTBTz & 1.82 & -4.92 & -3.01 & 1.91 & $\mathrm{PC}_{71} \mathrm{BM}$ & 0.54 & 9.5 & 60.6 & 3.10 & [66] \\
\hline PDTBDT-FBTz & 2.02 & -5.47 & -3.25 & 2.22 & $\mathrm{PC}_{71} \mathrm{BM}$ & 0.95 & 9.3 & 62.7 & 5.55 & [67] \\
\hline PBTA-BO & $\approx 1.92$ & -5.39 & -2.80 & 2.59 & N2200 & 0.87 & 11.0 & 75.8 & 7.05 & [68] \\
\hline PBTA-Si & 1.93 & -5.32 & -2.93 & 2.39 & N2200 & 0.92 & 13.8 & 73.1 & 8.31 & [70] \\
\hline PTAZ-TPD00 & 1.94 & -5.23 & -3.24 & 1.99 & PNDI-T00 & 0.87 & 11.3 & 68.0 & 6.60 & [72] \\
\hline L24 & 1.95 & -5.42 & -3.47 & 1.95 & IT-4F & 0.50 & 7.4 & 36.3 & 1.33 & [73] \\
\hline L68 & 1.95 & -5.51 & -3.56 & 1.95 & IT-4F & 0.76 & 19.5 & 63.2 & 9.30 & [73] \\
\hline L810 & 1.99 & -5.56 & -3.57 & 1.99 & IT-4F & 0.79 & 20.8 & 73.5 & 12.10 & [73] \\
\hline L2 & 1.86 & -5.50 & -3.39 & 2.11 & TTPT-T-4F & 0.86 & 22.2 & 73.6 & 14.00 & [74] \\
\hline J52-F & 1.94 & -5.36 & -3.42 & 1.94 & BTA13 & 1.18 & 11.6 & 61.3 & 8.36 & [75] \\
\hline J52-FS & 1.93 & -5.32 & -3.39 & 1.93 & BTA13 & 1.24 & 6.74 & 46.0 & 3.84 & [75] \\
\hline PE31 & 1.89 & -5.24 & -3.35 & 1.89 & Y6 & 0.80 & 20.5 & 46.9 & 7.62 & [65] \\
\hline PE32 & 1.92 & -5.20 & -3.28 & 1.92 & Y6 & 0.75 & 18.4 & 53.0 & 7.31 & [65] \\
\hline PE4 & 1.93 & -5.42 & -3.49 & 1.93 & Y6 & 0.84 & 22.2 & 75.4 & 14.02 & [65] \\
\hline PBDT-Se-TAZ & 1.92 & -5.23 & -3.43 & 1.80 & ITIC & 0.81 & 18.6 & 66.7 & 10.07 & [76] \\
\hline PBDTS-Se-TAZ & 1.90 & -5.29 & -3.52 & 1.77 & ITIC & 0.84 & 19.5 & 75.1 & 12.31 & [76] \\
\hline$m$-PBDTPS-FTAZ & 2.00 & -5.40 & -3.40 & 2.00 & ITIC & 0.95 & 18.8 & 73.9 & 13.16 & [77] \\
\hline$p$-PBDTPS-FTAZ & 1.96 & -5.32 & -3.36 & 1.96 & ITIC & 0.89 & 18.1 & 67.4 & 10.86 & [77] \\
\hline PBDT-BZ & 1.92 & -5.38 & -3.56 & 1.82 & BDTB-Ph & 0.92 & 17.6 & 65.2 & 10.59 & [78] \\
\hline PTBD-BZ & 1.90 & -5.40 & -3.59 & 1.81 & TBDB-Na & 0.91 & 19.6 & 70.2 & 12.47 & [78] \\
\hline PDTBDT-BZ & 1.91 & -5.32 & -3.51 & 1.81 & BDTB-Ph & 0.88 & 13.3 & 55.3 & 6.50 & [78] \\
\hline PBT1Cl-Bz & 1.93 & -5.39 & -3.57 & 1.82 & IT-4F & 0.71 & 16.9 & 63.5 & 7.60 & [79] \\
\hline $\mathrm{PBT} 2 \mathrm{Cl}^{\text {as }}-\mathrm{Bz}$ & 1.97 & -5.48 & -3.56 & 1.92 & IT-4F & 0.79 & 13.4 & 41.8 & 4.43 & [79] \\
\hline $\mathrm{PBT} 2 \mathrm{Cl}^{\mathrm{s}}-\mathrm{Bz}$ & 1.96 & -5.47 & -3.58 & 1.89 & IT-4F & 0.77 & 15.6 & 65.2 & 7.80 & [79] \\
\hline PBT4Cl-Bz & 2.01 & -5.64 & -3.57 & 2.07 & IT-4F & 0.96 & 16.4 & 58.7 & 9.25 & [79] \\
\hline PBDFP-Bz & 1.91 & -5.46 & -3.41 & 2.04 & ITIC & 0.97 & 17.8 & 64.2 & 11.10 & [80] \\
\hline PDDTY-DZ & 1.91 & & 5.41 & & IT-M & 1.02 & 18.3 & 69.4 & 12.93 & [80] \\
\hline PBTZa & 1.93 & -5.12 & -3.14 & 1.98 & ITIC-4Cl & 0.84 & 13.7 & 73.6 & 8.50 & [81] \\
\hline PBTZb & 1.93 & -5.20 & -3.23 & 1.97 & ITIC-4Cl & 0.87 & 21.8 & 76.8 & 14.53 & [81] \\
\hline DZ1 & 1.84 & -5.26 & -3.05 & 2.21 & MeIC & 0.81 & 15.2 & 66.7 & 8.26 & [82] \\
\hline DZ2 & 1.92 & -5.32 & -3.13 & 2.19 & MeIC & 0.88 & 17.1 & 68.4 & 10.22 & [82] \\
\hline DZ3 & 1.97 & -5.40 & -3.17 & 2.23 & MeIC & 1.00 & 10.3 & 60.9 & 5.97 & [82] \\
\hline
\end{tabular}

${ }^{a}$ Optical bandgap calculated from the absorption edge (onset) of the polymer films: $E_{\mathrm{g}}{ }^{\text {pt }}=1240 / \lambda_{\text {edge }}{ }^{b}$ Electrochemical bandgap obtained from: $E_{\mathrm{g}}{ }^{\text {ec }}=E_{\mathrm{LumO}}-$ $E_{\mathrm{HOMO}}$

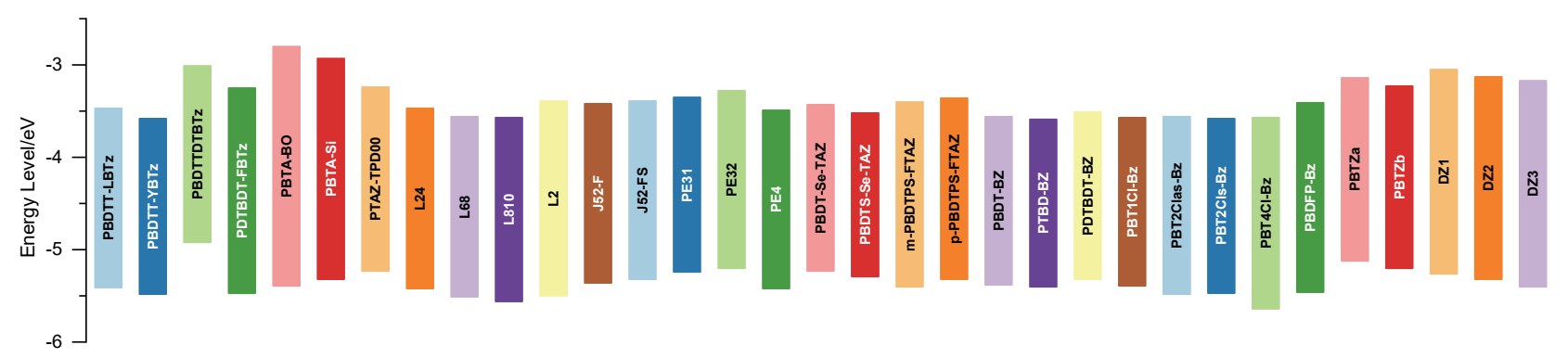

图 10 基于共轭侧链取代的 BDT 单元或其衍生物构筑的给体材料能级示意图

Figure 10 Energy level diagram of donor materials based on the BDT or its derivatives with conjugated side-chains

2014 年, 颜河等 ${ }^{[83]}$ 设计合成了含有四个噻吩单元 的 PffT2-FTAZ(图 11b). 在该聚合物中, 与 BTA 单元相 邻的两个噻吩单元外侧 $\beta$ 位的取代基为 2-辛基十二烷 基, 另两个噻吩单元则单氟化. 相比于未氟化的 PT2-FTAZ, 氟化效应使 PffT2-FTAZ 的吸收谱带红移, 分子能级降低. 基于 $\operatorname{PffT} 2-\mathrm{FTAZ} / \mathrm{PC}_{71} \mathrm{BM}(w / w, 1: 1.2$,
$250 \mathrm{~nm}, 2.5 \mathrm{wt} \% \mathrm{DIO}$ )器件的 $V_{\mathrm{oc}}$ 为 $0.82 \mathrm{~V}, J_{\mathrm{sc}}$ 为 13.6 $\mathrm{mA} / \mathrm{cm}^{2}, \mathrm{FF}$ 为 $71.0 \%$, PCE 为 $7.80 \%$. 在 PffT2-FTAZ 的 基础上, 他们将 $\mathrm{BTA}$ 单元两侧噻吩上的烷基链替换为 更长的 2-癸基十四烷基，设计合成了 PffT2-FTAZ2DT(图 11c) $)^{[84]}$. 基于 PffT2-FTAZ-2DT/IEIC( $w / w, 1$ : $1.5,80 \mathrm{~nm}$ ) 器件的 $V_{\mathrm{oc}}$ 明显提升至 $1.00 \mathrm{~V}$, 但器件性能有 
所降低, PCE 降低至 $7.20 \%$.

进一步地，颜河等 ${ }^{[85}$ 将苯环引入分子主链，探讨苯 环上的双氟取代位点对光伏性能的影响, 设计合成了 PTFB-P(对位双氟取代)和 PTFB-O(邻位双氟取代)(图 $11 \mathrm{~d})$. 从分子构象上看, 由于 $\mathrm{F} \cdots \mathrm{S}$ 键的作用, PTFB-O 上 的两个噻吩环取向同侧, 而 PTFB-P 上的两个噻吩环取 向异侧, 进而影响了相邻噻吩单元上烷基链的取向, 即 PTFB-O 上的烷基链呈 “八” 字型排列, 而 PTFB-P 上的 烷基链呈平行排列. 这种排列使得 PTFB-P 的分子呈现 出高度有序的层状堆叠, 即具有更好的结晶性. 另外, 取代基的位置的不同，也影响了给体与受体的兼容性， 由于 PTFB-P 与 ITIC 共混时不能保持其高结晶性, 形成 良好的形貌, 器件性能要低于基于 $\mathrm{PTFB}-\mathrm{P} / \mathrm{PC}_{71} \mathrm{BM}$ 器 件性能器件; 与之相反, 基于 PTFB-O/ITIC 器件的 $\mathrm{PCE}(10.13 \%)$ 高于基于 $\mathrm{PTFB}-\mathrm{O} / \mathrm{PC}_{71} \mathrm{BM}$ 器件(6.53\%). 进一步地, 基于 PTFB-O/ITIC-Th $(w / w, 1 ： 1.5,100 \mathrm{~nm})$ 器件的 $V_{\mathrm{oc}}$ 为 $0.92 \mathrm{~V}, J_{\mathrm{sc}}$ 为 $17.1 \mathrm{~mA} / \mathrm{cm}^{2}, \mathrm{FF}$ 为 $67.0 \%$, PCE 达到 $10.88 \%$.

在 PTFB-P 的基础上, 颜河等 ${ }^{[86]}$ 将双氟取代的苯环 替换为 5-氟-苯并噻二唑受体单元, 设计合成了 PfBTAZ, 又将 BTA 单元两侧噻吩上的烷基链调整至 5氟-苯并噻二唑两侧的噻吩上, 合成了 PfBTAZS(图 11e), 并研究了该体系中烷基链取代位点对光伏性能的影响.
二者的分子结构、分子量、光学性质、溶解性、结晶性、 空穴传输率等极为相近. 相比之下, PfBTAZ 具有更趋于 平面化的分子骨架，更易发生聚集，其薄膜倾向于形成 尺寸更大的纤维状形貌，因此其与非富勒烯受体材料 O-IDTBR 的共混薄膜表现出更大的相分离, 导致器件 性能下降，PCE 为 $7.70 \%$, 而基于 PfBTAZS/O-IDTBR $(w / w, 1: 1.5)$ 器件的 $V_{\mathrm{oc}}$ 为 $0.98 \mathrm{~V}, J_{\mathrm{sc}}$ 为 $16.4 \mathrm{~mA} / \mathrm{cm}^{2}, \mathrm{FF}$ 为 $62.0 \%, \mathrm{PCE}$ 为 $10.40 \%$. 基于同样的设计思路, 在 PTFB-P 的分子结构的基础上，颜河等又将 BTA 单元两 侧噻吩上的烷基链移动到了双氟取代苯环的两侧的噻 吩上，设计合成了 PTFB-PS(图 11f), 将其与 PTFB-P 对 比分析得到了与前述体系(PfBTAZ/PfBTAZS)相似的结 果. 也就是对于该体系的聚合物给体材料，当烷基链位 于 BTA 单元两侧噻吩上时, 所得聚合物更容易发生聚 集，表明烷基链的空间选择性对于聚合物分子的聚集行 为有着显著的影响, 进而影响了其器件的光伏性能.

在 PfBTAZS 的基础上, 将 5-氟-苯并噻二唑单元用 纵向共轭的 BDT 单元取代，颜河等 ${ }^{[87]}$ 设计合成了 PvBDTTAZ(图 11g). 基于 PvBDTTAZ/O-IDTBR(w/w, $1: 1.5)$ 器件的 $V_{\mathrm{oc}}$ 为 $1.08 \mathrm{~V}, J_{\mathrm{sc}}$ 为 $16.3 \mathrm{~mA} / \mathrm{cm}^{2}, \mathrm{FF}$ 为 $63.6 \%, \mathrm{PCE}$ 为 $11.60 \%$, 且 $E_{\mathrm{loss}}$ 仅为 $0.55 \mathrm{~V}$, 内量子效率 可达到 $90 \%$.
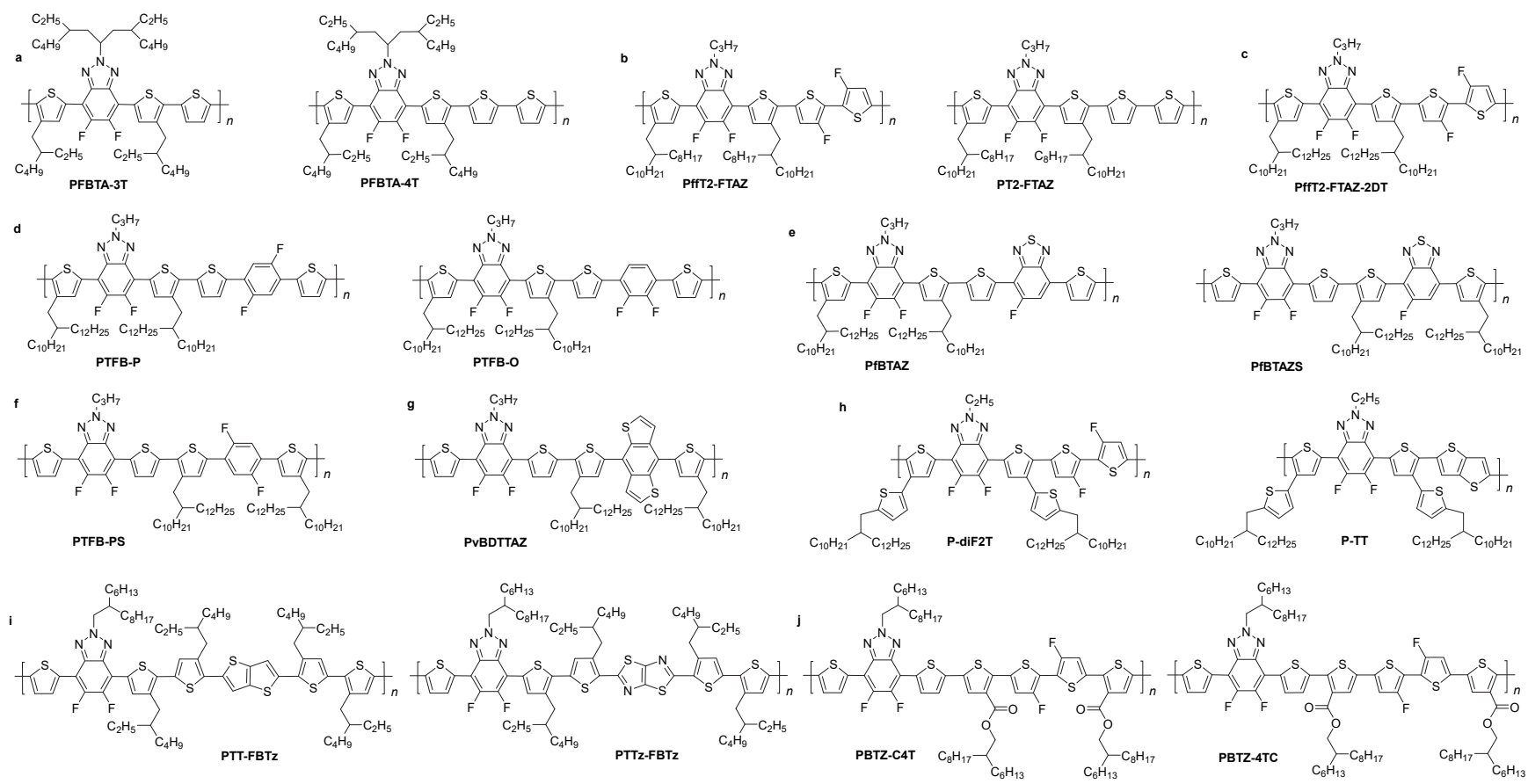

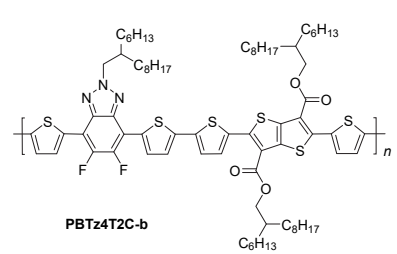

图 11 基于噻吩给体单元构筑的给体材料

Figure 11 Donor materials based on the thiophene units 
2018 年, 耿延侯等 ${ }^{[88}$ 在 BTA 单元两侧的噻吩单元 上引入共轭侧链, 设计合成了具有四个噻吩单元的 P-diF2T, 并进一步将远离 BTA 单元的两个噻吩单元替 换为并噻吩单元, 合成了 P-TT(图 11h). P-diF2T 与 ITIC-Th 的共混薄膜表现出更好的形貌, 较高且平衡 $\left(\mu_{\mathrm{e}} / \mu_{\mathrm{h}}=1.2\right)$ 的空穴迁移率 $\left(\mu_{\mathrm{h}}=7.2 \times 10^{-4} \mathrm{~cm}^{2} \cdot \mathrm{V}^{-1} \cdot \mathrm{s}^{-1}\right)$ 和 电子迁移率 $\left(\mu_{\mathrm{e}}=6.0 \times 10^{-4} \mathrm{~cm}^{2} \cdot \mathrm{V}^{-1} \cdot \mathrm{s}^{-1}\right)$. 基于 $\mathrm{P}-\mathrm{diF} 2 \mathrm{~T} /$ ITIC-Th( $w / w, 1: 1.2,105 \mathrm{~nm}, 0.3 \mathrm{vol} \%$ DIO)器件的 $V_{\mathrm{oc}}$ 为 $0.91 \mathrm{~V}, J_{\mathrm{sc}}$ 为 $15.0 \mathrm{~mA} / \mathrm{cm}^{2}, \mathrm{FF}$ 为 $74.1 \%, \mathrm{PCE}$ 为 $10.08 \%$.

2018 年, 孙艳明等 ${ }^{[89}$ 将并噻吩、并噻唑单元分别引 入分子主链, 设计合成了具有四个噻吩单元的 PTT-FBTz 和 PTTz-FBTz(图 11i). 与 PTT-FBTz 相比, PTTz-FBTz 表现出较低的 $E_{\mathrm{LUMO}}$ 和 $E_{\mathrm{HOMO}}$, 以及更有序 的分子堆叠. 基于 $\mathrm{PTTz}-\mathrm{FBTz} / \mathrm{PC}_{71} \mathrm{BM}(w / w, 1: 1.5,100$ $\mathrm{nm}, 3.0 \mathrm{wt} \% \mathrm{DIO}$ )器件的 $V_{\mathrm{oc}}$ 为 $0.88 \mathrm{~V}, J_{\mathrm{sc}}$ 为 11.3 $\mathrm{mA} / \mathrm{cm}^{2}, \mathrm{FF}$ 为 $69.9 \%$, PCE 为 $7.03 \%$.

2019 年, 陈义旺、谌烈等 ${ }^{[90]}$ 设计合成了具有六个噻 吩单元的 PBTZ-C4T 和 PBTZ-4TC(图 11j), 探讨了酯基 的区域规整性对光伏性能的影响. PBTZ-C4T 表现出更 趋于平面的分子构象, 因此具有更好的吸收系数、更高 的结晶度以及更好的活性层形貌. 基于 PBTZ-C4T/ $\mathrm{O}-\operatorname{IDTBR}(w / w, 1: 1,0.75 \mathrm{wt} \% \mathrm{DIO})$ 器件的 $V_{\mathrm{oc}}$ 为 $0.84 \mathrm{~V}$, $J_{\mathrm{sc}}$ 为 $16.6 \mathrm{~mA} / \mathrm{cm}^{2}, \mathrm{FF}$ 为 $66.7 \%$, $\mathrm{PCE}$ 为 $9.34 \%$.

2020 年，陈义旺、廖勋凡等 ${ }^{[91]}$ 设计合成了 PBTz4T2C-a 和 PBTz4T2C-b(图 11k), 探讨异构效应对 材料光伏性能的影响. 通过调控酯基官能团的位置, 两
种材料表现出不同的分子构象，并导致了其结晶性的差 异, PBTz4T2C-b 的结晶性过强，相分离过大，反而导致 其光伏性能的下降. 基于 $\mathrm{PBTz} 4 \mathrm{~T} 2 \mathrm{C}-\mathrm{a} / \mathrm{IT} 2 \mathrm{~F}(w / w, 1$ : 1.5 )器件的 $V_{\mathrm{oc}}$ 为 $0.87 \mathrm{~V}, J_{\mathrm{sc}}$ 为 $17.8 \mathrm{~mA} / \mathrm{cm}^{2}, \mathrm{FF}$ 为 $71.5 \%$, $\mathrm{PCE}$ 为 $11.02 \%$.

为了更直观地表现分子结构的改变对材料的 $E_{\mathrm{LUMO}}$ 和 $E_{\mathrm{HOMO}}$ 的影响, 我们将以上材料的分子能级图进行对 比，如图 12 所示. 相关给体材料的电化学性质及相应的 有机太阳能电池器件性能指标如表 4 所示.

\section{1 .4 基于其它类型给体单元构筑的给体材料}

2010 年，陈军武等 ${ }^{[92]}$ 以芴 (fluorene) 、咔唑 (carbazole)、苯环为给体单元, 设计合成了 PF-DTBTA、 PCz-DTBTA 和 PPh-DTBTA(图 13a). 从 PF-DTBTA、 PCz-DTBTA 到 PPh-DTBTA, 其 $E_{\mathrm{LUMO}}$ 和 $E_{\mathrm{HOMO}}$ 逐渐提 高, 带隙也相应变窄, 其中 PCz-DTBTA 的光伏性能最 为优异. 基于 PCz-DTBTA $/ \mathrm{PC}_{61} \mathrm{BM}(w / w, 1: 2,80 \mathrm{~nm})$ 器 件的 $V_{\mathrm{oc}}$ 为 $0.90 \mathrm{~V}, J_{\mathrm{sc}}$ 为 $4.7 \mathrm{~mA} / \mathrm{cm}^{2}, \mathrm{FF}$ 为 $65.3 \%, \mathrm{PCE}$ 为 $2.75 \%$.

2011 年, 李永舫等 ${ }^{[93]}$ 以具有强给电子性的噻咯并 二噻吩(dithienosilole, DTS)为给体单元 ${ }^{[94]}$, 设计合成了 PDTS-BTA 和 PDTS-DTBTA( 图 13b). 相比于 PDTS-BTA, 具有噻吩共轭 $\pi$ 桥的 PDTS-DTBTA 分子更 趋于平面化, 且分子主链的共轭性增强, 赋予其强的吸 收谱带、较窄的带隙、更高的空穴迁移率。基于 PDTS-DTBTA/PC ${ }_{71} \mathrm{BM}(w / w, 1: 1,80 \mathrm{~nm})$ 器件的 $V_{\mathrm{oc}}$ 为 $0.63 \mathrm{~V}, J_{\mathrm{sc}}$ 为 $9.5 \mathrm{~mA} / \mathrm{cm}^{2}, \mathrm{FF}$ 为 $63.3 \%$, $\mathrm{PCE}$ 为 $3.80 \%$.

表 4 基于噻吩给体单元构筑的给体材料的电化学性质及相应的有机太阳能电池器件性能指标

Table 4 The electrochemical properties of donor materials based on the thiophene units and the photovoltaic characteristics of the corresponding solar cells

\begin{tabular}{|c|c|c|c|c|c|c|c|c|c|c|}
\hline \multirow[b]{2}{*}{ Donor } & \multicolumn{4}{|c|}{ Optical and electrochemical property } & \multicolumn{5}{|c|}{ Photovoltaic characteristics of corresponding OSCs device } & \multirow[b]{2}{*}{ Ref. } \\
\hline & $E_{\mathrm{g}}{ }^{\mathrm{opt} a} / \mathrm{eV}$ & $\mathrm{HOMO} / \mathrm{eV}$ & $\mathrm{LUMO} / \mathrm{eV}$ & $\begin{array}{c}E_{\mathrm{g}}{ }^{\mathrm{ec} b} b / \\
\mathrm{eV}\end{array}$ & Acceptor & $V_{\mathrm{oc}} / \mathrm{V}$ & $\begin{array}{c}J_{\mathrm{sc}} / \\
\left(\mathrm{mA} \cdot \mathrm{cm}^{-2}\right)\end{array}$ & $\mathrm{FF} / \%$ & $\mathrm{PCE} / \%$ & \\
\hline PFBTA-3T & 1.85 & -5.48 & -3.65 & 1.83 & $\mathrm{PC}_{61} \mathrm{BM}$ & 0.81 & 6.73 & 55.0 & 3.00 & [17] \\
\hline PFBTA-4T & 1.82 & -5.30 & -3.90 & 1.40 & $\mathrm{PC}_{61} \mathrm{BM}$ & 0.74 & 5.46 & 62.1 & 2.51 & [17] \\
\hline PT2-FTAZ & 1.94 & -5.30 & -3.36 & 1.94 & $\mathrm{PC}_{71} \mathrm{BM}$ & 0.73 & 5.3 & 55.0 & 2.10 & [83] \\
\hline PffT2-FTAZ & 1.88 & -5.43 & -3.55 & 1.88 & $\mathrm{PC}_{71} \mathrm{BM}$ & 0.82 & 13.6 & 71.0 & 7.80 & [83] \\
\hline \multirow[t]{2}{*}{ PffT2-FTAZ-2DT } & 1.91 & -5.28 & -3.37 & 1.91 & IEIC & 1.00 & 12.2 & 59.0 & 7.20 & [84] \\
\hline & & & & & $\mathrm{PC}_{71} \mathrm{BM}$ & 0.83 & 13.1 & 59.0 & 6.53 & [85] \\
\hline \multirow[t]{2}{*}{ PTFB-O } & 2.00 & -5.36 & -3.36 & 2.00 & ITIC & 0.92 & 15.5 & 70.0 & 10.13 & [85] \\
\hline & & & & & ITIC-Th & 0.92 & 17.1 & 67.0 & 10.88 & [85] \\
\hline \multirow{2}{*}{ PTFB-P } & \multirow{2}{*}{1.97} & \multirow{2}{*}{-5.30} & \multirow{2}{*}{-3.33} & \multirow{2}{*}{1.97} & $\mathrm{PC}_{71} \mathrm{BM}$ & 0.81 & 12.9 & 72.0 & 7.59 & [85] \\
\hline & & & & & ITIC & 0.92 & 12.8 & 65.0 & 7.85 & [85] \\
\hline PfBTAZ & 1.65 & N/A & N/A & N/A & O-IDTBR & 1.00 & 11.7 & 64.0 & 7.70 & [86] \\
\hline PfBTAZS & 1.65 & N/A & N/A & N/A & O-IDTBR & 0.98 & 16.4 & 62.0 & 10.40 & [86] \\
\hline PvBDTTAZ & 2.05 & -5.47 & -3.42 & 2.05 & O-IDTBR & 1.08 & 16.3 & 63.6 & 11.60 & [87] \\
\hline P-diF2T & 1.83 & -5.41 & -3.00 & 2.41 & ITIC-Th & 0.91 & 15.0 & 74.1 & 10.08 & [88] \\
\hline P-TT & 1.85 & -5.35 & -2.93 & 2.42 & ITIC-Th & 0.83 & 13.0 & 67.3 & 7.23 & [88] \\
\hline PTT-FBTz & 1.91 & -5.29 & -3.38 & 1.91 & $\mathrm{PC}_{71} \mathrm{BM}$ & 0.85 & 7.4 & 41.9 & 2.63 & [89] \\
\hline PTTz-FBTz & 1.84 & -5.38 & -3.55 & 1.83 & $\mathrm{PC}_{71} \mathrm{BM}$ & 0.88 & 11.3 & 69.9 & 7.03 & [89] \\
\hline PBTZ-C4T & 1.90 & -5.52 & -3.65 & 1.87 & ITIC-Th1 & 0.84 & 16.6 & 66.7 & 9.34 & [90] \\
\hline PBTZ-4TC & 1.91 & -5.56 & -3.68 & 1.88 & ITIC-Th1 & 0.88 & 15.7 & 62.6 & 8.72 & [90] \\
\hline PBTz4T2C-a & 1.89 & -5.49 & -3.60 & 1.89 & IT2F & 0.87 & 17.8 & 71.5 & 11.02 & [91] \\
\hline PBTz4T2C-b & 1.83 & -5.40 & -3.57 & 1.83 & IT2F & 0.77 & 12.9 & 64.4 & 6.41 & [91] \\
\hline
\end{tabular}

${ }^{a}$ Optical bandgap calculated from the absorption edge (onset) of the polymer films: $E_{\mathrm{g}}{ }^{\text {opt }}=1240 / \lambda_{\text {edge }}{ }^{b}$ Electrochemical bandgap obtained from: $E_{\mathrm{g}}{ }^{\text {ec }}=E_{\mathrm{LUMO}}-$ $E_{\text {номо. }}$ 


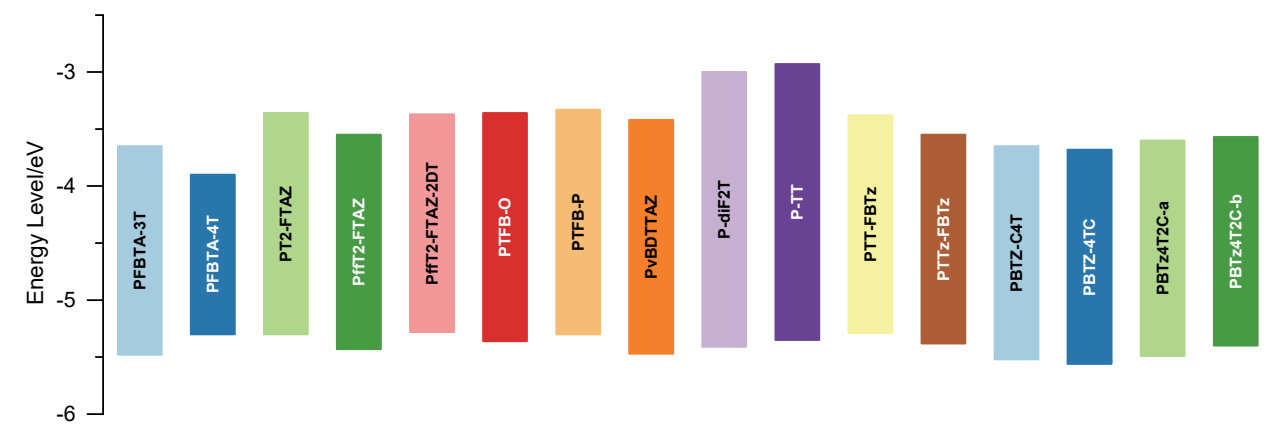

图 12 基于噻吩给体单元构筑的给体材料的能级示意图

Figure 12 Energy level diagram of donor materials based on the thiophene units

2013 年, 李 永 舫 等 ${ }^{[95]}$ 以引达省并二噻吩 (indacenodithiophene, IDT) 为给体单元, 设计合成了 PIDT-FBTA(图 13c). 基于 PIDT-FBTA/PC ${ }_{71} \mathrm{BM}(w / w, 1$ : $3,5 \mathrm{wt} \% \mathrm{CN}$ )器件的 $V_{\mathrm{oc}}$ 为 $0.92 \mathrm{~V}, J_{\mathrm{sc}}$ 为 $9.6 \mathrm{~mA} / \mathrm{cm}^{2}, \mathrm{FF}$ 为 $55.0 \%$, PCE 为 $4.90 \%$.

2018 年, 彭强等 ${ }^{[96]}$ 分别以吡喃并二噻吩 (5H-Dithieno[3,2-b:2', $\left.3^{\prime}-d\right]$ pyran, DTP)、噻喃并二噻吩 (5H-dithieno[3,2-b:2', $\left.3^{\prime}-d\right]$ thiopyran, DTTP) 为给体单元, 设计合成了 PDTP-FBTA 和 PDTTP-FBTA(图 13d). 而相 比于 DTP 单元, DTTP 单元的供电子能力较弱, 但分子 骨架的平面共轭性更强, 因此 PDTTP-FBTA 具有较低 的 $E_{\mathrm{HOMO}}$ 、更高的摩尔吸收系数以及更好的结晶性. 基 于 PDTTP-FBTA/IT-M $(w / w, 1: 1,0.5 \mathrm{vol} \%$ DIO, $100 \mathrm{~nm})$ 反向器件的 $V_{\mathrm{oc}}$ 为 $0.81 \mathrm{~V}, J_{\mathrm{sc}}$ 为 $17.2 \mathrm{~mA} / \mathrm{cm}^{2}, \mathrm{FF}$ 为 $75.3 \%$, PCE 为 $10.51 \%$; 添加小分子受体 meta-TrBRCN ${ }_{x}$ 作为第三组分形成互补性更好的吸收谱带后, 基于 PBTA-Si/PTzBI-Si/N2200( $w / w, 1: 0.2: 1,0.5$ vol\% DIO, $150 \mathrm{~nm}$ ) 的三元器件的 $V_{\mathrm{oc}}$ 为 $0.83 \mathrm{~V}, J_{\mathrm{sc}}$ 为 $18.2 \mathrm{~mA} / \mathrm{cm}^{2}$, $\mathrm{FF}$ 为 $76.5 \%$, $\mathrm{PCE}$ 提升至 $11.57 \%$.

2018 年, 沈平、谭松庭等 ${ }^{[97]}$ 分别以环戊联噻吩芴螺 (spiro[cyclopenta[1,2-b:5,4-b' ]dithiophene-4,9'-fluorene],

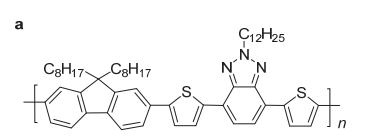

PF-DTBTA
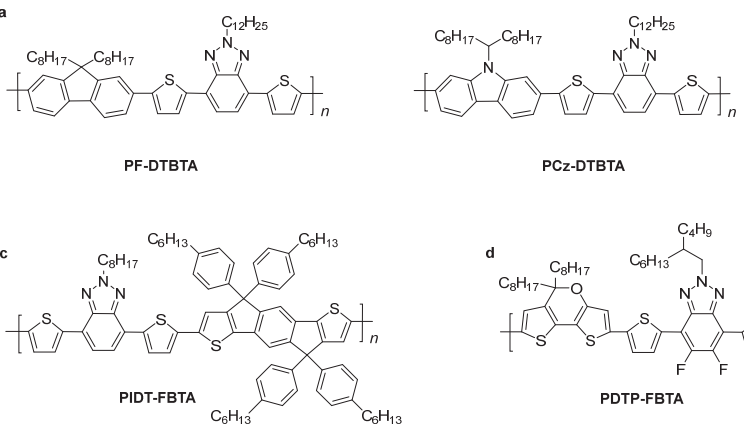

PCZ-DTBTA
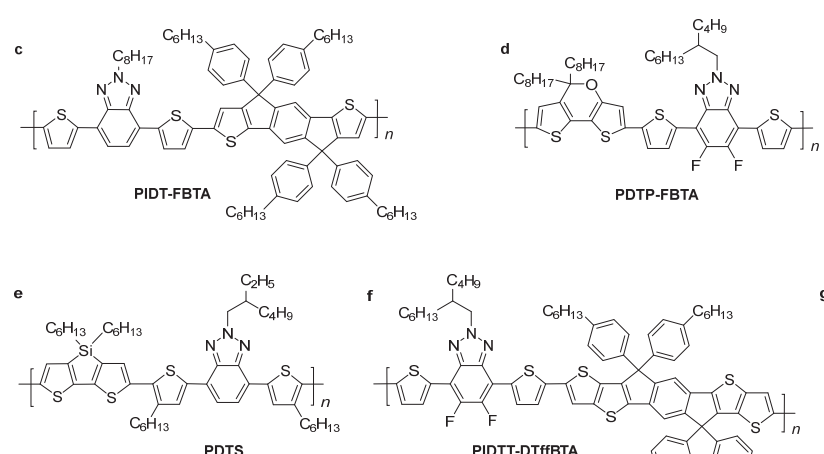

PDTS

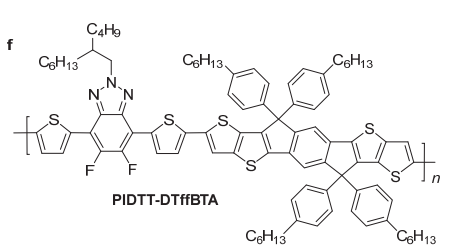

STF)、DTS 为给体单元, 设计合成了 PSTF 和 PDTS(图 13e). 相比于 PDTS, PSTF 表现出较弱的 $\pi-\pi$ 堆积相互作 用, $E_{\text {Hомо }}$ 明显降低. PSTF、PDTS 与 $\mathrm{PC}_{61} \mathrm{BM}$ 匹配器件 的 $\operatorname{PCE}(3.66 \% 、 2.18 \%)$ 明显高于与 ITIC 匹配器件的 $\mathrm{PCE}(2.42 \% 、 0.99 \%)$. 基于 $\mathrm{PSTF} / \mathrm{PC}_{61} \mathrm{BM}(w / w, 1: 1,70$ $\mathrm{nm}$ ) 器件的 $V_{\mathrm{oc}}$ 为 $0.77 \mathrm{~V}, J_{\mathrm{sc}}$ 为 $8.9 \mathrm{~mA} / \mathrm{cm}^{2}, \mathrm{FF}$ 为 $54.0 \%$, $\mathrm{PCE}$ 为 $3.66 \%$.

2019 年, 周二军等 ${ }^{[98]}$ 以引达省并二并噻吩 (indacenodithieno[3,2-b]thiophene, IDTT)为给体单元, 设 计合成了 PIDTT-DTffBTA(图 13f). 基于 PIDTTDTffBTA/Y $6(w / w, 1.5: 1,120 \mathrm{~nm})$ 器件的 $V_{\mathrm{oc}}$ 为 $0.74 \mathrm{~V}$, $J_{\mathrm{sc}}$ 为 $22.7 \mathrm{~mA} / \mathrm{cm}^{2}, \mathrm{FF}$ 为 $65.7 \%$, PCE 为 $11.05 \%$.

2019 年, 黄飞、张杰等 ${ }^{[99]}$ 以二氰基苯乙烯基 (dicyanodistyrylbenzene, DCN) 为给体单元, 改变 DCN 单元上烷氧基侧链以及聚合分子量, 设计合成了 PT-68 和 PT-810(图 13g). 引入 DCN 单元使三种分子均具有刚 性的共轭分子骨架, 且薄膜具有良好的空穴迁移率, 而 分子量较高的 PT-810-H 与 ITIC 的共混薄膜的形貌和相 分离状态更好. 基于 PT-810-H/ITIC $(w / w, 2 ： 1,100 \mathrm{~nm})$ 器件的 $V_{\mathrm{oc}}$ 为 $1.04 \mathrm{~V}, J_{\mathrm{sc}}$ 为 $12.3 \mathrm{~mA} / \mathrm{cm}^{2}, \mathrm{FF}$ 为 $55.0 \%$, PCE 为 $7.03 \%$.
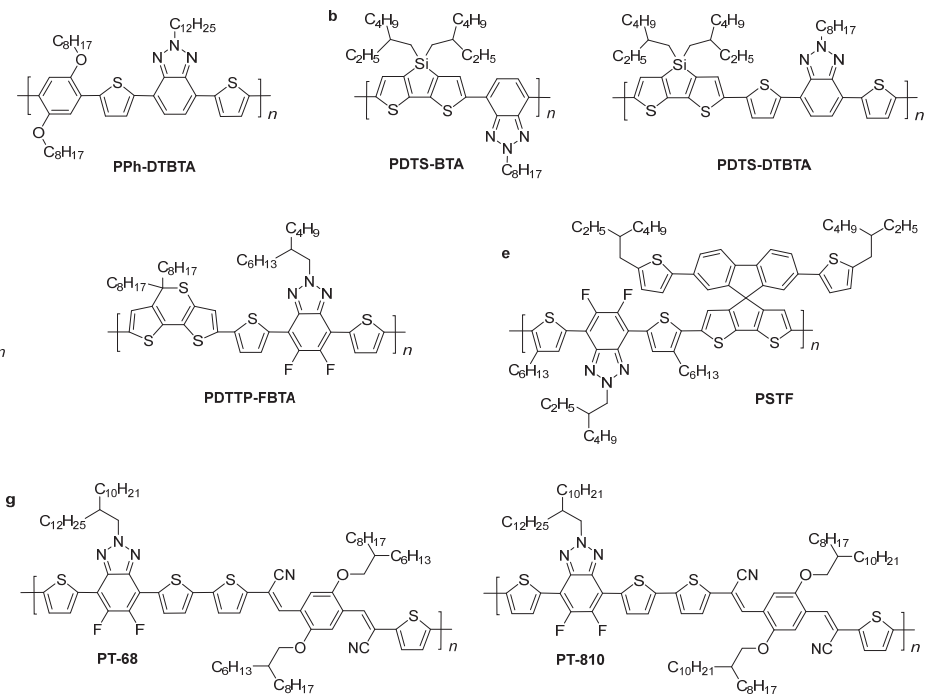

图 13 基于其它类型给体单元构筑的给体材料

Figure 13 Donor materials based on other types of donor units 
为了更直观地表现分子结构的改变对材料的 $E_{\mathrm{LUMO}}$ 和 $E_{\mathrm{HOMO}}$ 的影响, 我们将以上材料的分子能级图进行对 比, 如图 14 所示. 相关给体材料的电化学性质及相应的 有机太阳能电池器件性能指标如表 5 所示.

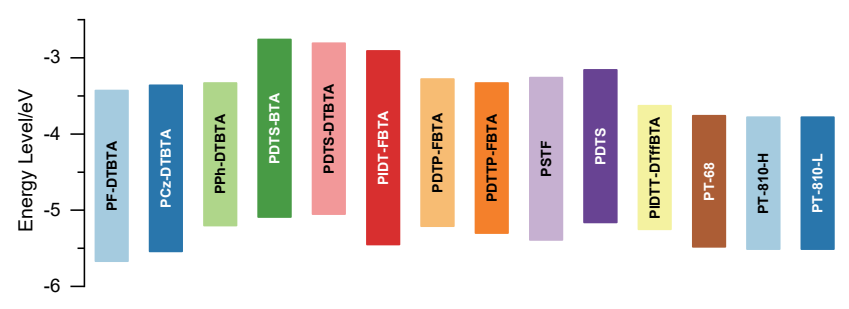

图 14 基于其它类型给体单元构筑的给体材料的能级示意图

Figure 14 Energy level diagram of donor materials based on other types of donor units

\section{1 .5 基于苯并三氮唑衍生物构筑的给体材料}

基于苯并三氮唑衍生物构筑的给体材料主要为黄 飞课题组研发的以噻二唑并苯并三氮唑 $([1,2,5]$ thiadiazolo[3,4-f]benzotriazole, TZBTTT)、䓺二并 三氮唑(naphtho[1,2-c:5,6-c]bis-[1,2,3]triazole, TZNT)、酰 亚胺 (imide) 稠 合 的苯并三氮 唑 (pyrrolo[3,4-f]benzotriazole-5,7-dione, TzBI) 为受体单元的相关聚合物.

2012 年, 黄飞等 ${ }^{[100]}$ 以噻二唑并苯并三氮唑 $([1,2,5]$ thiadiazolo[3,4-f]benzotriazole, TZBTTT) 为受体 单元, 以芴(fluorene)、咔唑(carbazole)为给体单元, 设计 合成了 PF-TZBTTT、PCZ-TZBTTT(图 15a), 两种材料 均表现出较窄的带隙 $(\approx 1.30 \mathrm{eV})$. 基于 PCZ-TZBTTT/ $\mathrm{PC}_{71} \mathrm{BM}(w / w, 1: 4, \approx 75 \mathrm{~nm})$ 器件的 $V_{\mathrm{oc}}$ 为 $0.70 \mathrm{~V}, J_{\mathrm{sc}}$ 为 $8.5 \mathrm{~mA} / \mathrm{cm}^{2}, \mathrm{FF}$ 为 $41.0 \%$, PCE 为 $3.17 \%$.

2013 年, 黄飞、应䂞等 ${ }^{[101]}$ 以 TZBTTT 为受体单元, 以共轭侧链取代的 BDT 为给体单元, 设计合成了 $\mathrm{P} 1$ 、
$\mathrm{P} 2$ 和 P3(图 15b), 考察了有无噻吩 $\pi$ 桥以及烷基取代的 噻吩 $\pi$ 桥对光伏性能的影响. 三种材料均表现出极窄的 带隙(分别为 $0.96 、 1.00 、 1.10 \mathrm{eV}$ ), 且吸收边界大幅度 红移，其中 P1 的吸收边界达到 $1065 \mathrm{~nm}$. 而其极低的 $E_{\mathrm{LUMO}}$ (分别为 $-4.16 、-4.04 、-4.03 \mathrm{eV}$ ) 以及与 $\mathrm{PC}_{61} \mathrm{BM}$ 的共混薄膜较差的相分离状态，则使得基于三种材料的 器件性能极低( PCE 分别为 $0.10 \% 、 0.40 \% 、 0.25 \%$ ).

2013 年, 黄飞等 ${ }^{[102]}$ 以芸二并三氮唑 (Naphtho$[1,2-c: 5,6-c]$ bis- $[1,2,3]$ triazole, TZNT)为受体单元，通过 调控侧链上的烷基，设计合成了 P1、P2 和 P3(图 15c). TZNT 单元可以视为稠合的双 BTA 单元, 相比于 BTA 单元，提高了分子的平面共轭性，并增加了一个可连接 烷基侧链的位点. 因此, P1 与具有单 BTA 单元的 J50(图 $7 \mathrm{a})$ 相比, 其 $E_{\mathrm{LUMO}}$ 和 $E_{\mathrm{HOMO}}$ 有所下降, 且带隙变窄. 这 三种给体材料中, $\mathrm{P} 2$ 与 $\mathrm{PC}_{71} \mathrm{BM}$ 的共混薄膜具有更好的 形貌，且空穴迁移率 $\left(1 \times 10^{-4} \mathrm{~cm}^{2} \cdot \mathrm{V}^{-1} \cdot \mathrm{s}^{-1}\right)$ 比 $\mathrm{P} 1\left(3 \times 10^{-5}\right.$ $\left.\mathrm{cm}^{2} \cdot \mathrm{V}^{-1} \cdot \mathrm{s}^{-1}\right)$ 和 $\mathrm{P} 3\left(5 \times 10^{-6} \mathrm{~cm}^{2} \cdot \mathrm{V}^{-1} \cdot \mathrm{s}^{-1}\right)$ 高出一个数量级. 基于 $\mathrm{P} 2 / \mathrm{PC}_{71} \mathrm{BM}(w / w, 1: 2,80 \sim 90 \mathrm{~nm})$ 反向器件的 $V_{\mathrm{oc}}$ 为 $0.92 \mathrm{~V}, J_{\mathrm{sc}}$ 为 $11.7 \mathrm{~mA} / \mathrm{cm}^{2}, \mathrm{FF}$ 为 $65.0 \%$, $\mathrm{PCE}$ 为 $7.11 \%$.

2015 年，黄飞、应䂞等[103]以噻咯并二噻吩(DTS)为 给体单元, 以 $\mathrm{TZNT}$ 为受体单元, 设计合成了 $\mathrm{P} 1 、 \mathrm{P} 2$ (图 $15 \mathrm{~d})$, 其 $E_{\mathrm{g}}{ }^{\mathrm{opt}}(\approx 1.80 \mathrm{eV})$ 相比于前述的三种基于 $\mathrm{TZNT}$ 和 BDT 单元的给体材料 $(\approx 1.90 \mathrm{eV}$, 图 $8 \mathrm{a})$ 明显下降, 这 得益于 DTS 给体单元和 TZNT 受体单元之间更强的分 子内电荷传输( $\mathrm{ICT})$ 效应. 基于 $\mathrm{P} 1 / \mathrm{PC}_{61} \mathrm{BM}(w / w, 1: 2$, $90 \mathrm{~nm}, 2.0 \mathrm{vol} \% \mathrm{DIO}$ )器件的 $V_{\mathrm{oc}}$ 为 $0.83 \mathrm{~V}, J_{\mathrm{sc}}$ 为 5.5 $\mathrm{mA} / \mathrm{cm}^{2}, \mathrm{FF}$ 为 $56.1 \%$, PCE 为 $2.58 \%$.

2019 年，彭强等 ${ }^{[104]}$ 以 TZNT 为受体单元，设计合 成了 PBDTS-TZNT 和 PBDTSF-TZNT(图 15e), 后者的 $\mathrm{BDT}$ 给体单元的噻吩共轭侧链上单氟取代. 基于

表 5 基于其它类型给体单元构筑的给体材料的电化学性质及相应的有机太阳能电池器件性能指标

Table 5 The electrochemical properties of donor materials based on other types of donor units and the photovoltaic characteristics of the corresponding solar cells

\begin{tabular}{|c|c|c|c|c|c|c|c|c|c|c|}
\hline \multirow[b]{2}{*}{ Donor } & \multicolumn{4}{|c|}{ Optical and electrochemical property } & \multicolumn{5}{|c|}{ Photovoltaic characteristics of corresponding OSCs device } & \multirow[b]{2}{*}{ Ref. } \\
\hline & $E_{\mathrm{g}}{ }^{\text {opt } a} / \mathrm{eV}$ & $\mathrm{HOMO} / \mathrm{eV}$ & $\mathrm{LUMO} / \mathrm{eV}$ & $\begin{array}{c}E_{\mathrm{g}}{ }^{\mathrm{cc} b} b \\
\mathrm{eV}\end{array}$ & Acceptor & $V_{\mathrm{oc}} / \mathrm{V}$ & $\begin{array}{c}J_{\mathrm{sc}} / \\
\left(\mathrm{mA} \cdot \mathrm{cm}^{-2}\right)\end{array}$ & $\mathrm{FF} / \%$ & $\mathrm{PCE} / \%$ & \\
\hline PF-DTBTA & 2.24 & -5.67 & -3.43 & 2.24 & $\mathrm{PC}_{61} \mathrm{BM}$ & 1.00 & 2.6 & 51.5 & 1.30 & [92] \\
\hline PCz-DTBTA & 2.18 & -5.54 & -3.36 & 2.18 & $\mathrm{PC}_{61} \mathrm{BM}$ & 0.90 & 4.7 & 65.3 & 2.75 & [92] \\
\hline PPh-DTBTA & 1.87 & -5.20 & -3.33 & 1.87 & $\mathrm{PC}_{61} \mathrm{BM}$ & 0.55 & 4.5 & 56.1 & 1.39 & [92] \\
\hline PDTS-BTA & 1.81 & -5.09 & -2.76 & 2.33 & $\mathrm{PC}_{71} \mathrm{BM}$ & 0.71 & 5.7 & 40.8 & 1.64 & [93] \\
\hline PDTS-DTBTA & 1.78 & -5.05 & -2.81 & 2.24 & $\mathrm{PC}_{71} \mathrm{BM}$ & 0.63 & 9.5 & 63.3 & 3.80 & [93] \\
\hline PIDT-FBTA & 2.02 & -5.45 & -2.91 & 2.54 & $\mathrm{PC}_{71} \mathrm{BM}$ & 0.92 & 9.6 & 55.0 & 4.90 & [95] \\
\hline PDTP-FBTA & 1.78 & -5.21 & -3.28 & 1.93 & IT-M & 0.76 & 16.2 & 68.1 & 8.38 & [96] \\
\hline PDTTP-FBTA & 1.85 & -5.30 & -3.33 & 1.97 & IT-M & 0.81 & 17.2 & 75.3 & 10.51 & [96] \\
\hline PSTF & 183 & -5.39 & -326 & 213 & $\mathrm{PC}_{61} \mathrm{BM}$ & 0.77 & 8.9 & 54.0 & 3.66 & [97] \\
\hline & & & & & ITIC & 0.81 & 8.8 & 34.0 & 2.42 & [97] \\
\hline PDTS & 184 & -516 & -3.16 & 200 & $\mathrm{PC}_{61} \mathrm{BM}$ & 0.56 & 9.1 & 43.0 & 2.18 & [97] \\
\hline & & & & & ITIC & 0.69 & 5.3 & 27.0 & 0.99 & [97] \\
\hline PIDTT-DTffBTA & 2.02 & -5.25 & -3.63 & 1.62 & Y6 & 0.74 & 22.7 & 65.7 & 11.05 & [98] \\
\hline PT-68 & 1.76 & -5.48 & -3.76 & 1.72 & ITIC & 1.02 & 11.5 & 46.1 & 5.39 & [99] \\
\hline PT-810-H & 1.76 & -5.51 & -3.78 & 1.73 & ITIC & 1.04 & 12.3 & 55.0 & 7.03 & [99] \\
\hline PT-810-L & 1.76 & -5.51 & -3.78 & 1.73 & ITIC & 1.04 & 10.3 & 55.9 & 5.99 & [99] \\
\hline
\end{tabular}

${ }^{a}$ Optical bandgap calculated from the absorption edge (onset) of the polymer films: $E_{\mathrm{g}}{ }^{\text {opt }}=1240 / \lambda_{\text {edge }}{ }^{b}$ Electrochemical bandgap obtained from: $E_{\mathrm{g}}{ }^{\text {ec }}=E_{\mathrm{LUMO}}-$ Eнмо. 
PBDTSF-TZNT/ITIC( $w / w, 1: 1,100 \mathrm{~nm}, 0.2$ vol\% DIO) 器件的 $V_{\mathrm{oc}}$ 为 $0.98 \mathrm{~V}, J_{\mathrm{sc}}$ 为 $17.6 \mathrm{~mA} / \mathrm{cm}^{2}, \mathrm{FF}$ 为 $70.6 \%$, $\mathrm{PCE}$ 为 $12.16 \%$. 以 IT-4F 为受体, PCE 可进一步提高至 $13.25 \%$, 且基于 PBDTSF-TZNT/IT-4F 体系的叠层器件 的 PCE 可达到 $14.52 \%$.

2016 年, 黄飞、应否等 ${ }^{[105]}$ 设计合成了酰亚胺(imide) 稠合的苯并三氮唑(pyrrolo[3,4-f]benzotriazole-5,7-dione, $T z B I$ ), 以 $T z B I$ 为受体单元, 设计合成了 PTZBIBDT(即 PTzBI, 图 15f). 引入酰亚胺结构可以同时降低共轭分 子的 $E_{\mathrm{LUMO}}$ 和 $E_{\mathrm{HOMO}}{ }^{[106]}$, 且可在氮原子上引入烷基链进 一步调节材料的溶解性. 基于 PTZBIBDT/PC $\mathrm{PC}_{71} \mathrm{BM}(w / w$, $1: 1,80 \mathrm{~nm}$ ) 器件的 $V_{\mathrm{oc}}$ 为 $0.87 \mathrm{~V}, J_{\mathrm{sc}}$ 为 $13.5 \mathrm{~mA} / \mathrm{cm}^{2}, \mathrm{FF}$ 为 $74.0 \%, \mathrm{PCE}$ 为 $8.63 \%$.

在 PTzBI 的基础上, 他们 ${ }^{[107]}$ 以 DTBDT 为给体单 元, 并在噻吩共轭侧链 $\beta$ 位引入烷基, 设计合成了 PTzBI-DT(图 15g). 相比于 PTzBI, PTzBI-DT 的分子主 链中离域 $\pi$ 电子增多, $E_{\mathrm{LUMO}}$ 和 $E_{\mathrm{HOMO}}$ 均下降 $0.05 \mathrm{eV}$, 提 高了基于 PTzBI-DT/ITIC $(w / w, 1 ： 1,95 \mathrm{~nm})$ 器件的 $V_{\mathrm{oc}}(0.87 \mathrm{~V}$ 至 $0.91 \mathrm{~V})$, 然而其在 $420 \sim 660 \mathrm{~nm}$ 范围内的 吸收强度明显下降, 导致其外量子效率明显下降, 另外, FF 有所降低(64.3\%至 61.5\%), 进而综合表现为器件的 PCE 由 10.24\%降低至 $9.43 \%$. 值得注意的是, 基于 PTzBI/ITIC 器件, 在活性层膜厚为 $300 \mathrm{~nm}$ 时, PCE 仍可 达到 7.09\%, 而使用非卤溶剂 2-甲基四氢呋喃 (2-methyl-tetrahydrofuran, MeTHF) 制 备的基于 $\mathrm{PTzBI} / \mathrm{N} 2200(w / w, 1: 0.5,103 \mathrm{~nm})$ 器件 ${ }^{[108]}$ 的 $V_{\mathrm{oc}}$ 为 0.86 $\mathrm{V}, J_{\mathrm{sc}}$ 为 $14.8 \mathrm{~mA} / \mathrm{cm}^{2}, \mathrm{FF}$ 为 $62.2 \%, \mathrm{PCE}$ 为 $8.06 \%$, 这些 结果表明基于 PTzBI 的给体材料具有良好的潜力.

对于基于 PTzBI 的聚合物给体材料, 黄飞等通过优 化侧链, 探索了他们在全聚合物太阳能电池中的应用. 他们将酰亚胺环上的烷基侧链替换为烷氧基侧链, 合成 了 PTzBI-O(图 15h ${ }^{[109]}$. 使用甲苯制备的基于 $\mathrm{PTzBI}-\mathrm{O} / \mathrm{N} 2200(w / w, 1: 0.5,110 \mathrm{~nm})$ 器件的 $V_{\mathrm{oc}}$ 为 0.86 $\mathrm{V}, J_{\mathrm{sc}}$ 为 $14.4 \mathrm{~mA} / \mathrm{cm}^{2}, \mathrm{FF}$ 为 $63.0 \%, \mathrm{PCE}$ 为 $7.91 \%$. 将 BTA 的辛基侧链替换为以七甲基三硅氧烷(HMTS)为末 端的己基, 设计合成了 PTzBI-Si(图 15i) ${ }^{[59]}$, 硅氧基功能 化侧链提高了其在 MeTHF 中的溶解性, 改善了与 $\mathrm{N} 2200$ 的共混薄膜的形貌. 基于 PTzBI-Si/N2200( $w / w$, $1: 0.5,140 \mathrm{~nm}$ )器件的 $V_{\mathrm{oc}}$ 为 $0.87 \mathrm{~V}, J_{\mathrm{sc}}$ 为 $15.8 \mathrm{~mA} / \mathrm{cm}^{2}$, $\mathrm{FF}$ 为 $73.8 \%$, PCE 为 $10.05 \%$, 且表现出良好的热退火耐 候性. 进一步地, 他们 ${ }^{[110]}$ 通过优化 PTzBI-Si 分子量来 优化活性层形貌，基于高分子量的 PTzBI-Si 给体与 N2200 受体的 All-PSCs 的 PCE 提升至 11.5\%. 这些研究 也表明 PTzBI-Si 是一类性能优异的聚合物给体材料, 在 全聚合物太阳能电池中有广阔的应用前景.

在 PTzBI 的基础上, 黄飞、应否等 ${ }^{[111]}$ 将 BDT 单元 的噻吩共轭侧链替换为双氟取代的苯环共轭侧链, 设计 合成了 PTzBI-2FT(图 15j). 相比于 PTzBI, 其 $E_{\mathrm{LUMO}}$ 明
显提高约 $0.40 \mathrm{eV}$, 带隙则相应变宽. 基于 PTzBI-2FT/ ITIC- $4 \mathrm{~F}(w / w, 1: 1,100 \mathrm{~nm})$ 器件的 $V_{\mathrm{oc}}$ 为 $0.88 \mathrm{~V}, J_{\mathrm{sc}}$ 为 $18.2 \mathrm{~mA} / \mathrm{cm}^{2}, \mathrm{FF}$ 为 $72.6 \%, \mathrm{PCE}$ 为 $11.80 \%$; 基于 PTzBI-2FT/ITIC-4F/N2200(w/w, 20:20:1, $100 \mathrm{~nm})$ 三 元器件的 $V_{\mathrm{oc}}$ 为 $0.88 \mathrm{~V}, J_{\mathrm{sc}}$ 为 $19.8 \mathrm{~mA} / \mathrm{cm}^{2}, \mathrm{FF}$ 为 $74.5 \%$, $\mathrm{PCE}$ 为 $13.00 \%$. 进一步地, 黄飞、应䂞、李宁等 ${ }^{[112]}$ 通过 微调 TzBI 单元上与支化烷基连接的碳原子的个数, 设 计合成了 $\mathrm{P} 2 \mathrm{~F}-\mathrm{EH}$ (一个碳原子，2-乙基已基), P2F-EHp(两个碳原子, 3-乙基庚基)和 P2F-EO(三个碳原 子, 4-乙基辛基)(图 15k), 研究了烷基链对该材料体系光 学、电学以及聚集特性的差异与规律, 调控了聚合物与 受体共混膜的形貌, 其中 P $2 \mathrm{~F}-\mathrm{EHp}$ 的光伏性能最为优 异, 基于 $\mathrm{P} 2 \mathrm{~F}-\mathrm{EHp} / \mathrm{IT}-2 \mathrm{~F}(w / w, 1: 1, \approx 100 \mathrm{~nm})$ 器件的 $V_{\mathrm{oc}}$ 为 $0.89 \mathrm{~V}, J_{\mathrm{sc}}$ 为 $19.8 \mathrm{~mA} / \mathrm{cm}^{2}, \mathrm{FF}$ 为 $68.5 \%, \mathrm{PCE}$ 为 $12.11 \%$. 大面积 $\left(1.00 \mathrm{~cm}^{2}\right)$ 器件也获得了 $12.25 \%$ 的认证 效率，且稳定性良好. 基于 $\mathrm{P} 2 \mathrm{~F}-\mathrm{EHp} / \mathrm{Y} 6(w / w, 1: 1.2$, $120 \mathrm{~nm}, 1.0 \mathrm{vol} \% \mathrm{DBE}$ ) 器件 ${ }^{[113]}$ 的 $V_{\mathrm{oc}}$ 为 $0.81 \mathrm{~V}, J_{\mathrm{sc}}$ 为 26.7 $\mathrm{mA} / \mathrm{cm}^{2}, \mathrm{FF}$ 为 $74.1 \%$, PCE 为 $16.02 \%$.

基于该体系, 他们又探讨了侧链噻吩 $\beta$ 位上卤素取 代基对光伏性能的影响，设计合成了 PFT-EHp、 PCT-EHp (图 151) ${ }^{[114]}$. PFT-EHp、PCT-EHp、P2F-EHp 的 $E_{\mathrm{LUMO}}$ 相近, 约为 $-3.20 \mathrm{eV}, E_{\mathrm{HOMO}}$ 也相近, 约为 -5.40 $\mathrm{eV}$. 表明在该体系中 BDT 单元上共轭侧链对于分子能 级的影响甚微. 三种给体材料与非富勒烯受体材料 Y6 匹配, 小面积 $\left(0.04 \mathrm{~cm}^{2}\right)$ 器件的 PCE 分别为 $14.16 \%$ 、 $15.06 \%$ 、 $15.65 \%$, 而后两者的大面积 $\left(1.0 \mathrm{~cm}^{2}\right)$ 器件的 PCE 仍可达到 $13.42 \%$ 和 $14.39 \%$. 通过添加 $\mathrm{PC}_{61} \mathrm{BM}$ 作 为第三组分调整活性层形貌后, 所制备的面积为 1.116 $\mathrm{cm}^{2}$ 的基于 $\mathrm{P} 2 \mathrm{~F}-\mathrm{EHp} / \mathrm{PC}_{61} \mathrm{BM} / \mathrm{Y} 6(w / w, 1: 0.3: 1,100$ $\mathrm{nm}$ )三元器件的 $V_{\mathrm{oc}}$ 为 $0.83 \mathrm{~V}, J_{\mathrm{sc}}$ 为 $26.9 \mathrm{~mA} / \mathrm{cm}^{2}, \mathrm{FF}$ 为 $67.7 \%$, PCE 为 $15.13 \%$.

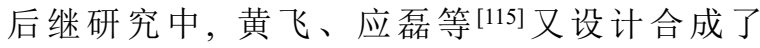
PTzBI- $p$ F 和 PTzBI- $d \mathrm{~F}$ (图 $15 \mathrm{~m}$ ), 探讨了通过微调噻吩 $\pi$ 桥上的氟取代位点对光伏性能的影响. 该体系中, 氟取 代位点对分子构象、吸收谱带、空穴迁移率等均有显著 的影响, 其中氟取代位点远离 PTzBI 单元的 PTzBI- $d \mathrm{~F}$ 具有更为平面化的分子构象, 较窄的带隙, 且空穴迁移 率 $\left(1.06 \times 10^{-2} \mathrm{~cm}^{2} \cdot \mathrm{V}^{-1} \cdot \mathrm{s}^{-1}\right)$ 比 PTzBI- $p \mathrm{~F}\left(2.14 \times 10^{-7}\right.$ $\left.\mathrm{cm}^{2} \cdot \mathrm{V}^{-1} \cdot \mathrm{s}^{-1}\right)$ 高出五个数量级, 这些因素综合影响了其 器件的整体性能. 基于 PTzBI- $d \mathrm{~F} / \mathrm{Y} 6(w / w, 1 ： 1,0.3$ $\mathrm{vol} \% \mathrm{CN}$ )器件的 $V_{\mathrm{oc}}$ 为 $0.85 \mathrm{~V}, J_{\mathrm{sc}}$ 为 $26.3 \mathrm{~mA} / \mathrm{cm}^{2}, \mathrm{FF}$ 为 $75.5 \%$, PCE 为 $16.8 \%$.

其它课题组也合成了新型的苯并三氮唑衍生物，构 筑了新型聚合物给体. 2015 年, 尤为等 ${ }^{[116]}$ 以哒嗪并三氮 唑([1,2,3]triazolo[4,5- $d]$ pyridazine)、2-氰基-吡啶并三氮 唑(2-cyano-[1,2,3]triazolo[3,4-c]pyridine)、二氰基-苯并三 氮唑(dicyano-benzotriazole)分别作为受体单元, 合成了 PrzTAZ、PyCNTAZ 和 CNTAZ(图 15n), 并与 PBnDT- 
FTAZ 对比, 其 $E_{\mathrm{LUMO}} 、 E_{\mathrm{HOMO}}$ 和 $E_{\mathrm{g}}$ opt 均呈下降趋势. 基 于 $\operatorname{PyCNTAZ} / \mathrm{PC}_{61} \mathrm{BM}(w / w, 1: 2)$ 器件表现出较高的性 能, 当活性层为 $300 \mathrm{~nm}$ 时, 其 $V_{\mathrm{oc}}$ 为 $0.96 \mathrm{~V}, J_{\mathrm{sc}}$ 为 14.1
$\mathrm{mA} / \mathrm{cm}^{2}, \mathrm{FF}$ 为 $62.0 \%$, PCE 为 $8.37 \%$, 且 $104 \sim 527 \mathrm{~nm}$ 的 活性层膜厚范围内, PCE 表现出较低的膜厚依赖性, 均 可保持 $6.00 \%$ 以上.

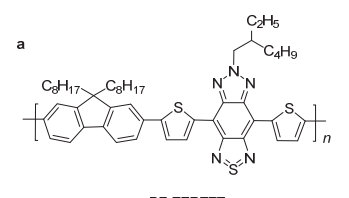

PF-TZBTTT
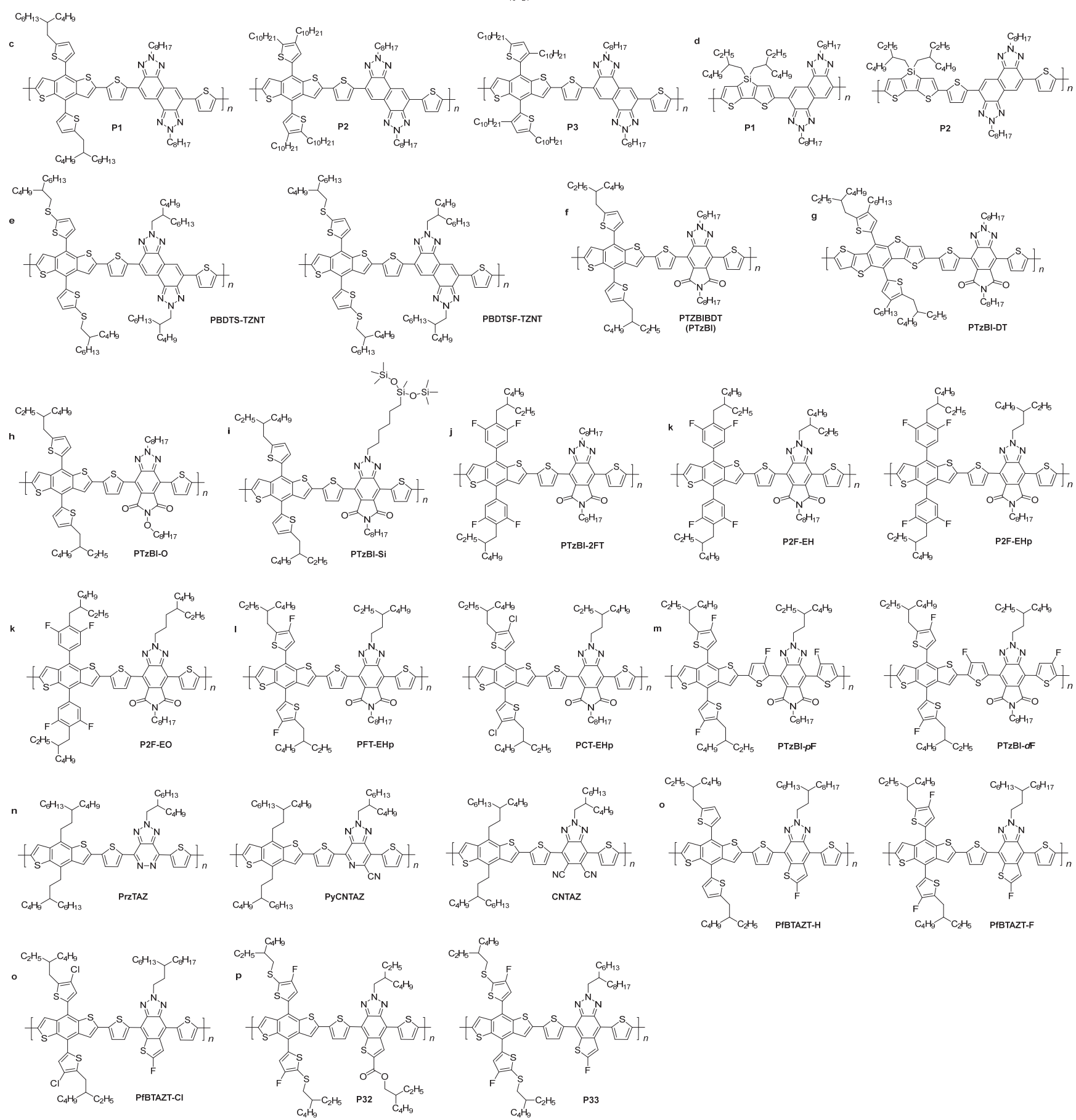

图 15 基于苯并三氮唑衍生物构筑的给体材料

Figure 15 Donor materials based on the BTA derivatives 
2019 年, 陈兴国、周二军等[117]以噻吩稠合苯并三 氮唑为受体单元, 通过对 $\mathrm{BDT}$ 单元上侧链噻吩单元的 $\beta$ 位进行氟取代和氯取代, 设计合成了 PfBTAZT-H、 PfBTAZT-F 和 PfBTAZT-Cl(图 15o). 基于 “SAS” 策略 匹配的 PfBTAZT-Cl/BTA3(w/w, $1: 1,108 \mathrm{~nm}$ )器件的 $V_{\mathrm{oc}}$ 为 $1.20 \mathrm{~V}, J_{\mathrm{sc}}$ 为 $11.1 \mathrm{~mA} / \mathrm{cm}^{2}, \mathrm{FF}$ 为 $60.0 \%$, PCE 为 $8.00 \%$.

2019 年, 陈兴国、占肖卫等 $[118]$ 以噻吩稠合苯并三 氮唑为受体单元, 通过调控噻吩和三氮唑环上的侧链, 设计合成了 P32 和 P33(图 15p), 探讨吸电子基团(酯基、 氟原子)对光伏性能的影响. P32 与 IHIC 的共混薄膜表 现出更为互补的强吸收谱带, 更好的形貌, 较高且平衡 $\left(\mu_{\mathrm{e}} / \mu_{\mathrm{h}}=1.5\right)$ 的空穴迁移率 $\left(\mu_{\mathrm{h}}=1.05 \times 10^{-3} \mathrm{~cm}^{2} \cdot \mathrm{V}^{-1} \cdot \mathrm{s}^{-1}\right)$ 和 电子迁移率 $\left(\mu_{\mathrm{e}}=9.12 \times 10^{-4} \mathrm{~cm}^{2} \cdot \mathrm{V}^{-1} \bullet \mathrm{s}^{-1}\right)$. 基于 $\mathrm{P} 32 / \mathrm{IHIC}(w / w, 1: 1,0.75 \mathrm{vol} \% \mathrm{DIO})$ 器件的 $V_{\mathrm{oc}}$ 为 $0.77 \mathrm{~V}$,
$J_{\mathrm{sc}}$ 为 $17.4 \mathrm{~mA} / \mathrm{cm}^{2}, \mathrm{FF}$ 为 $64.4 \%$, PCE 为 $8.59 \%$.

为了更直观地表现分子结构的改变对材料的 $E_{\mathrm{LUMO}}$ 和 $E_{\mathrm{HOMO}}$ 的影响, 我们将以上材料的分子能级图进行对 比，如图 16 所示. 相关给体材料的电化学性质及相应的 有机太阳能电池器件性能指标如表 6 所示.

\subsection{6 小分子类给体材料}

基于 BTA 单元的小分子类给体材料的相关研究相 对较少. 2012 年, 李永舫等 ${ }^{[119]}$ 以三苯胺(triphenylamine, TPA) 为给体单元, 以 BTA 为受体单元, 设计合成了 TPA-DTBTz-TPA(图 17a). 具有三维结构的 TPA 单元可 以赋予分子良好的溶液加工性、较高的空穴迁移率 ${ }^{[120]}$. 基于 TPA-DTBTz-TPA/PC ${ }_{60} \mathrm{BM}(w / w, 1: 2,69 \mathrm{~nm})$ 器件 的 $V_{\mathrm{oc}}$ 为 $0.74 \mathrm{~V}, J_{\mathrm{sc}}$ 为 $4.3 \mathrm{~mA} / \mathrm{cm}^{2}, \mathrm{FF}$ 为 $29.0 \%, \mathrm{PCE}$ 为 $0.93 \%$.

表 6 基于苯并三氮唑衍生物构筑的给体材料的电化学性质及相应的有机太阳能电池器件性能指标

Table 6 The electrochemical properties of donor materials based on the BTA derivatives and the photovoltaic characteristics of the corresponding solar cells

\begin{tabular}{|c|c|c|c|c|c|c|c|c|c|c|}
\hline \multirow[b]{2}{*}{ Donor } & \multicolumn{4}{|c|}{ Optical and electrochemical property } & \multicolumn{5}{|c|}{ Photovoltaic characteristics of corresponding OSCs device } & \multirow[b]{2}{*}{ Ref. } \\
\hline & $E_{\mathrm{g}}{ }^{\mathrm{opt} a} / \mathrm{eV}$ & $\mathrm{HOMO} / \mathrm{eV}$ & $\mathrm{LUMO} / \mathrm{eV}$ & $\begin{array}{c}E_{\mathrm{g}} \mathrm{gc} b / \\
\mathrm{eV}\end{array}$ & Acceptor & $V_{\mathrm{oc}} / \mathrm{V}$ & $\begin{array}{c}J_{\mathrm{sc}} / \\
\left(\mathrm{mA} \cdot \mathrm{cm}^{-2}\right)\end{array}$ & $\mathrm{FF} / \%$ & $\mathrm{PCE} / \%$ & \\
\hline PF-TZBTTT & 1.33 & -5.16 & -3.83 & 1.33 & $\mathrm{PC}_{71} \mathrm{BM}$ & 0.65 & 6.9 & 44.0 & 2.56 & [100] \\
\hline PCZ-TZBTTT & 1.35 & -5.18 & -3.83 & 1.35 & $\mathrm{PC}_{71} \mathrm{BM}$ & 0.70 & 8.5 & 41.0 & 3.17 & {$[100]$} \\
\hline P1 & 0.96 & -5.12 & -4.16 & 0.96 & $\mathrm{PC}_{61} \mathrm{BM}$ & 0.51 & 0.5 & 32.0 & 0.10 & [101] \\
\hline P2 & 1.00 & -5.04 & -4.04 & 1.00 & $\mathrm{PC}_{61} \mathrm{BM}$ & 0.38 & 1.7 & 43.0 & 0.40 & [101] \\
\hline P3 & 1.10 & -5.13 & -4.03 & 1.10 & $\mathrm{PC}_{61} \mathrm{BM}$ & 0.62 & 0.9 & 32.0 & 0.25 & [101] \\
\hline P1 & 1.90 & -5.21 & -3.31 & 1.90 & $\mathrm{PC}_{71} \mathrm{BM}$ & 0.88 & 7.4 & 51.0 & 3.35 & [102] \\
\hline P2 & 1.93 & -5.23 & -3.30 & 1.93 & $\mathrm{PC}_{71} \mathrm{BM}$ & 0.92 & 11.7 & 65.0 & 7.11 & [102] \\
\hline P3 & 1.90 & -5.21 & -3.31 & 1.90 & $\mathrm{PC}_{71} \mathrm{BM}$ & 0.84 & 3.6 & 49.0 & 1.50 & [102] \\
\hline P1 & 1.80 & -5.15 & -3.35 & 1.80 & $\mathrm{PC}_{61} \mathrm{BM}$ & 0.83 & 5.5 & 56.1 & 2.58 & [103] \\
\hline P2 & 1.81 & -4.95 & -3.14 & 1.81 & $\mathrm{PC}_{61} \mathrm{BM}$ & 0.52 & 6.7 & 53.2 & 1.84 & [103] \\
\hline \multirow[t]{2}{*}{ PBDTS-TZNT } & \multirow{2}{*}{1.99} & \multirow{2}{*}{-5.39} & \multirow{2}{*}{-3.30} & \multirow{2}{*}{2.09} & ITIC & 0.94 & 16.9 & 65.7 & 10.45 & [104] \\
\hline & & & & & $11-4 \mathrm{~F}$ & 0.88 & 18.7 & 68.9 & 11.31 & [104] \\
\hline PBDTSF-TZNT & \multirow{2}{*}{1.97} & \multirow{2}{*}{-5.45} & \multirow{2}{*}{-3.41} & \multirow{2}{*}{2.04} & ITIC & 0.98 & 17.6 & 70.6 & 12.16 & [104] \\
\hline \multirow{3}{*}{$\begin{array}{l}\text { PTZBIBDT } \\
\text { (PTzBI) }\end{array}$} & & & & & IT-4F & 0.93 & 19.2 & 74.1 & 13.25 & [104] \\
\hline & \multirow{2}{*}{1.81} & \multirow{2}{*}{-5.34} & \multirow{2}{*}{-3.46} & \multirow{2}{*}{1.88} & $\begin{array}{l}\mathrm{PC}_{71} \mathrm{BM} \\
\text { ITIC }\end{array}$ & $\begin{array}{l}0.87 \\
0.87\end{array}$ & $\begin{array}{l}13.5 \\
183\end{array}$ & $\begin{array}{l}74.0 \\
64.3\end{array}$ & $\begin{array}{r}8.63 \\
1024\end{array}$ & $\begin{array}{l}{[105]} \\
{[107]}\end{array}$ \\
\hline & & & & & $\mathrm{N} 2200_{\mathrm{HM}}{ }^{c}$ & 0.86 & 14.8 & 62.2 & 8.06 & [108] \\
\hline PTzBI-DT & 1.81 & -5.39 & -3.51 & 1.88 & ITIC & 0.91 & 16.8 & 61.5 & 9.43 & [107] \\
\hline PTzBI-O & 1.75 & -5.44 & -3.44 & 2.00 & $\mathrm{~N} 2200$ & 0.86 & 14.4 & 63.0 & 7.91 & [109] \\
\hline PTzBI-Si & 1.78 & -5.31 & -3.10 & 2.21 & $\mathrm{~N} 2200$ & 0.87 & 15.8 & 73.8 & 10.05 & [59] \\
\hline PTzBI-2FT & 2.30 & -5.38 & -3.08 & 2.30 & ITIC-4F & 0.88 & 18.2 & 72.6 & 11.80 & [111] \\
\hline \multirow[t]{2}{*}{ P2F-EH } & \multirow[t]{2}{*}{1.85} & \multirow[t]{2}{*}{-5.36} & \multirow[t]{2}{*}{-3.04} & \multirow[t]{2}{*}{2.32} & ITIC & 0.98 & 12.4 & 50.5 & 6.13 & [112] \\
\hline & & & & & ITIC & 1.02 & 13.0 & 54.8 & 7.28 & [112] \\
\hline P2F-EHp & 1.85 & -5.38 & -3.06 & 2.32 & IT-2F & 0.89 & 19.8 & 68.5 & 12.11 & [112] \\
\hline & & & & & Y6 & 0.81 & 26.7 & 74.1 & 16.02 & [113] \\
\hline P2F-EO & 1.85 & -5.41 & -3.08 & 2.33 & ITIC & 1.01 & 12.7 & 52.5 & 6.73 & [112] \\
\hline PFT-EHp & 1.80 & -5.38 & -3.24 & 2.14 & Y6 & 0.78 & 25.3 & 71.1 & 14.16 & [114] \\
\hline РCT-EHp & 1.83 & -5.46 & -3.13 & 2.33 & Y6 & 0.79 & 26.1 & 72.2 & 15.06 & [114] \\
\hline PTzBI- $p$ F & 2.09 & -5.67 & -3.58 & 2.09 & Y6 & 0.80 & 4.9 & 36.5 & 1.4 & [115] \\
\hline PTzBI- $d$ F & 1.72 & -5.55 & -3.83 & 1.72 & Y6 & 0.85 & 26.3 & 75.5 & 16.8 & [115] \\
\hline PrzTAZ & 1.93 & -5.66 & -3.73 & 1.93 & $\mathrm{PC}_{61} \mathrm{BM}$ & 0.96 & 8.3 & 59.7 & 4.75 & [116] \\
\hline PyCNTAZ & 1.84 & -5.67 & -3.83 & 1.84 & $\mathrm{PC}_{61} \mathrm{BM}$ & 0.96 & 14.1 & 62.0 & 8.37 & [116] \\
\hline CNTAZ & 1.77 & -5.73 & -3.96 & 1.77 & $\mathrm{PC}_{61} \mathrm{BM}$ & 1.03 & 9.0 & 59.9 & 5.53 & [116] \\
\hline PfBTAZT-H & 1.82 & -5.27 & -3.45 & 1.82 & BTA3 & 0.99 & 11.6 & 58.0 & 6.65 & [117] \\
\hline PfBTAZT-F & 1.79 & -5.37 & -3.58 & 1.79 & BTA3 & 1.05 & 11.8 & 62.0 & 7.69 & [117] \\
\hline PfBTAZT-Cl & 1.85 & -5.44 & -3.59 & 1.85 & BTA3 & 1.20 & 11.1 & 60.0 & 8.00 & [117] \\
\hline P32 & 1.68 & -5.32 & -3.64 & 1.68 & IHIC & 0.77 & 17.4 & 64.4 & 8.59 & [118] \\
\hline P33 & 1.79 & -5.24 & -3.46 & 1.78 & IHIC & 0.77 & 15.2 & 56.6 & 6.63 & [118] \\
\hline
\end{tabular}

${ }^{a}$ Optical bandgap calculated from the absorption edge (onset) of the polymer films: $E_{\mathrm{g}}{ }^{\text {opt }}=1240 / \lambda_{\text {edge. }}{ }^{b}$ Electrochemical bandgap obtained from: $E_{\mathrm{g}}{ }^{\text {ec }}=E_{\mathrm{LUMO}}-$ $E_{\text {HOMO }}{ }^{c} \mathrm{HM}$ means N2200 used was with high molecular weights of $75.1 \mathrm{~kg} / \mathrm{mol}$. 


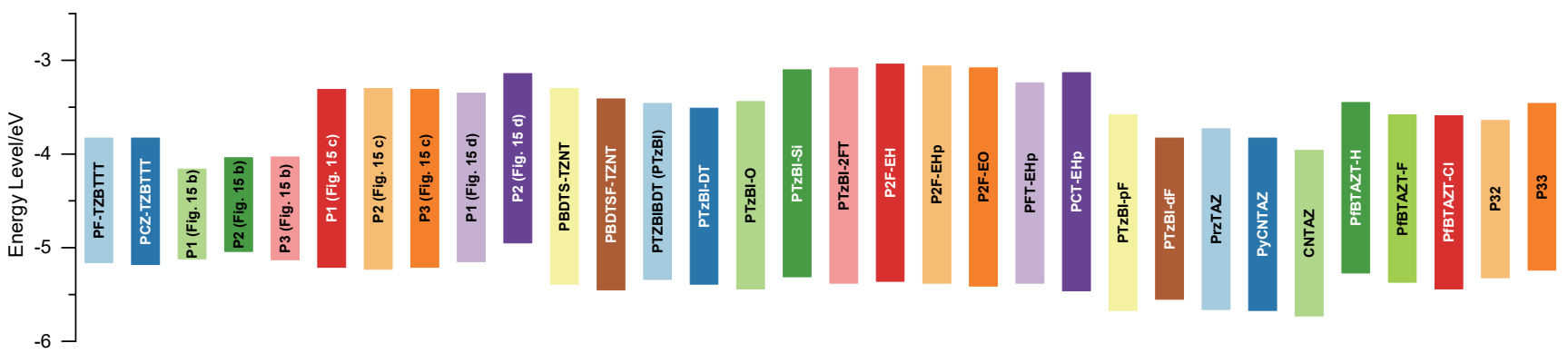

图 16 基于苯并三氮唑衍生物构筑的给体材料的能级示意图

Figure 16 Energy level diagram of donor materials based on the BTA derivatives

2014 年, 阳仁强等 ${ }^{[121]}$ 以噻吩共轭侧链取代的 BDT 单元为中心给体单元, 以 FBTA 为共轭 $\pi$ 桥, 设计合成 了 $\mathrm{D}$ (CATBTzT)BDT(图 17b). 基于 $\mathrm{D}$ (CATBTzT)BDT/ $\mathrm{PC}_{61} \mathrm{BM}(w / w, 1: 1,100 \mathrm{~nm})$ 器件的 $V_{\mathrm{oc}}$ 为 $0.93 \mathrm{~V}, J_{\mathrm{sc}}$ 为 6.0 $\mathrm{mA} / \mathrm{cm}^{2}, \mathrm{FF}$ 为 $64.0 \%, \mathrm{PCE}$ 为 $3.61 \%$.

2016 年, 在 $\mathrm{J}$ 系列聚合物给体材料的基础上，李永 舫等 ${ }^{[122]}$ 设计合成了 $\mathrm{H} 11$ 和 H12(图 17c), 其 BDT 单元上 分别为噻吩共轭烷基链和烷氧基. 相比于 $\mathrm{H} 12$, 具有 $2 \mathrm{D}$ 共轭结构的 $\mathrm{H} 11$ 表现出较强的吸收系数、降低的 $E_{\mathrm{HOMO}}$ 以及更有序的分子堆叠. 基于 $\operatorname{H} 11 / \operatorname{IDIC}(w / w, 2 ： 1)$ 器件 的 $V_{\mathrm{oc}}$ 为 $0.98 \mathrm{~V}, J_{\mathrm{sc}}$ 为 $15.2 \mathrm{~mA} / \mathrm{cm}^{2}, \mathrm{FF}$ 为 $65.5 \%, \mathrm{PCE}$ 为 $9.73 \%$, 且所制备的面积为 $1.00 \mathrm{~cm}^{2}$ 器件的 PCE 仍可达

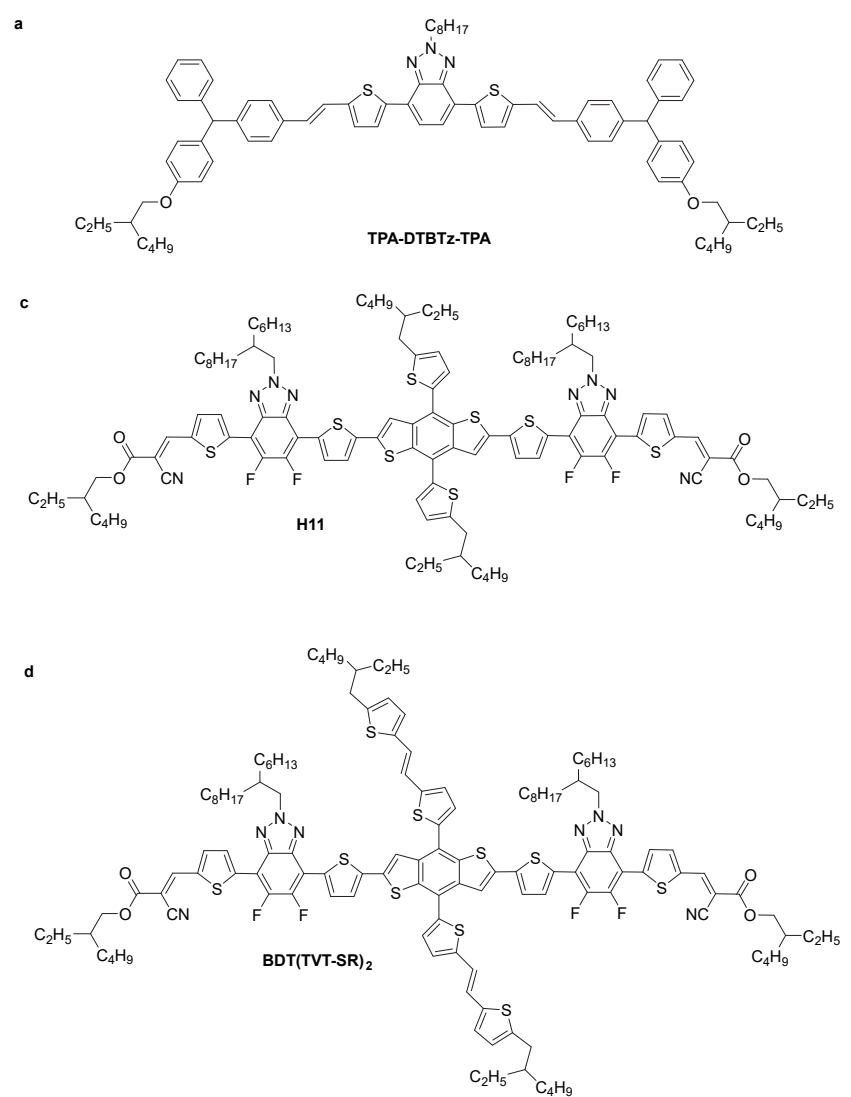

到 $8.52 \%$.

在 $\mathrm{H} 11$ 的基础上, 2018 年, 闵杰、李永舫等 ${ }^{[123]}$ 以烷 硫基侧链取代的噻吩乙烯基噻吩作为 BDT 单元的共轭 侧链，设计合成了 BDT(TVT-SR) 2 (图 17d), 相比于 H11, 其吸收边界明显红移约 $74 \mathrm{~nm}, E_{\mathrm{HOMO}}$ 略微降低 $(0.02$ $\mathrm{eV})$, 空穴迁移率有所提高 $\left(3.07 \times 10^{-5} \mathrm{~cm}^{2} \cdot \mathrm{V}^{-1} \cdot \mathrm{s}^{-1}\right.$ 至 $\left.6.21 \times 10^{-5} \mathrm{~cm}^{2} \cdot \mathrm{V}^{-1} \cdot \mathrm{s}^{-1}\right)$. 基于 BDT(TVT-SR $)_{2} / \mathrm{IDIC}(w / w$, $2: 1$ )器件的 $V_{\mathrm{oc}}$ 为 $0.98 \mathrm{~V}, J_{\mathrm{sc}}$ 为 $15.9 \mathrm{~mA} / \mathrm{cm}^{2}, \mathrm{FF}$ 为 $71.2 \%$, PCE 为 $11.10 \%$.

2019 年, 秦元成等 ${ }^{[124]}$ 设计合成了 SM-OF、SM-2F 和 SM-4F(图 17e), 研究氟取代数量对光伏性能的影响. 引入氟原子使得 $\mathrm{SM}-2 \mathrm{~F}$ 和 $\mathrm{SM}-4 \mathrm{~F}$ 的 $E_{\mathrm{HOMO}}$ 明显下降,
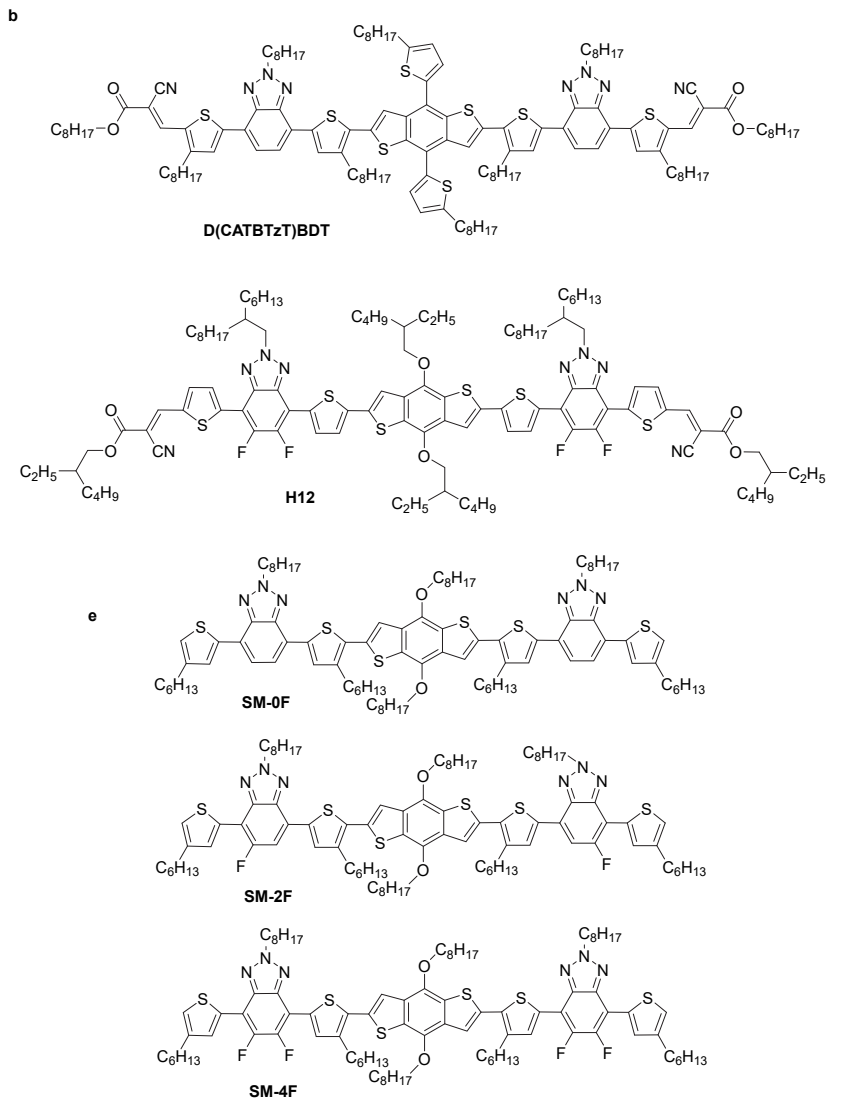

图 17 小分子类给体材料

Figure 17 Small molecule donor materials 
其中 $\mathrm{SM}-2 \mathrm{~F}$ 的空穴迁移率 $\left(3.52 \times 10^{-4} \mathrm{~cm}^{2} \cdot \mathrm{V}^{-1} \cdot \mathrm{s}^{-1}\right)$ 略高 于 $\mathrm{SM}-4 \mathrm{~F}\left(2.35 \times 10^{-4} \mathrm{~cm}^{2} \cdot \mathrm{V}^{-1} \bullet \mathrm{s}^{-1}\right), \mathrm{EQE}$ 也略高于 $\mathrm{SM}-4 \mathrm{~F}$, 因此其器件表现出更高的 $J_{\mathrm{sc}}$. 基于 $\mathrm{SM}-2 \mathrm{~F} / \mathrm{PC}_{71} \mathrm{BM}(w / w$, $1: 1.5$ ) 器件的 $V_{\mathrm{oc}}$ 为 $0.75 \mathrm{~V}, J_{\mathrm{sc}}$ 为 $11.0 \mathrm{~mA} / \mathrm{cm}^{2}, \mathrm{FF}$ 为 $44.9 \%$, PCE 为 $3.94 \%$.

为了更直观地表现分子结构的改变对材料的 $E_{\mathrm{LUMO}}$ 和 $E_{\mathrm{HOMO}}$ 的影响, 我们将以上材料的分子能级图进行对 比, 如图 18 所示. 相关给体材料的电化学性质及相应的 有机太阳能电池器件性能指标如表 7 所示.

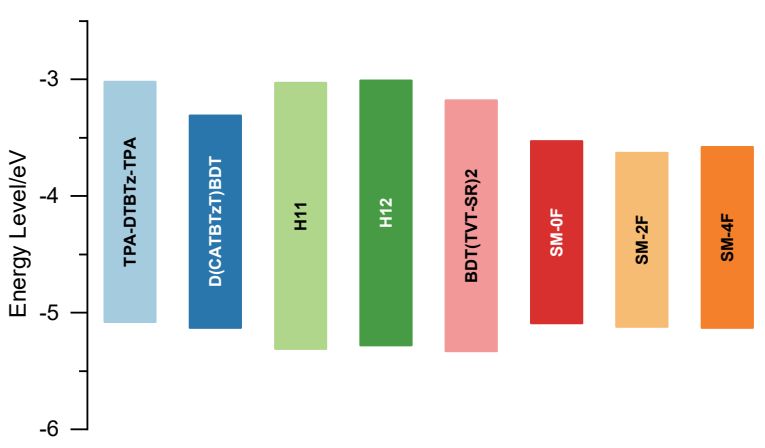

图 18 小分子类给体材料的能级示意图

Figure 18 Energy level diagram of small molecule donor materials

\section{2 基于苯并三氮唑单元的受体材料}

得益于强电子亲和性、各向同性的零维的分子结 构、较高的电子传输性能等优点, 富勒烯及其衍生物受 体材料(例如 $\mathrm{PC}_{60} \mathrm{BM} 、 \mathrm{PC}_{71} \mathrm{BM}$ ), 在早期研究中推动了 OSCs 发展. 然而其诸多缺点也限制了器件性能的提高 和实际应用: (1)合成难度及成本较高; (2)分子能级很难 调节; (3)只能吸收并利用紫外可见光区(UV-visible)的光 子; (4)至少需要 $0.3 \mathrm{eV}$ 的能极差作为激子有效分离的驱 动力; (5)分子聚集和光化学反应导致共混薄膜形貌不稳 定等.

近几年, 为了进一步推进 OSCs 的发展, 非富勒烯 型受体材料(non-fullerene acceptors, NFAs)得到了广泛 的关注, 基于非富勒烯受体的器件在 PCE 上更是接连 取得突破性的进展. NFAs 具有以下的优点: (1)合成过程
相对简单; (2)光学带隙可调, 可吸收并利用可见红外光 区(visible-NIR)的光子，提高了太阳光的利用率；(3)分 子能级易调, 且激子分离的驱动力需求极低, 降低了器 件能量损失，从而可以同时得到高 $V_{\mathrm{oc}}$ 和 $J_{\mathrm{sc}}$; (4)分子间 较强的 $\pi-\pi$ 堆积相互作用以及较高的电子迁移率 等[18b,125].

基于三氮唑单元的受体材料，在早期的研究中，采 用了 A-A 型设计策略, 例如 Gwinner 等 ${ }^{[126]}$ 以苯并三氮 唑(BTA)和苯并噻二唑(benzothiadiazole, BT)单元为主 链, 设计合成了聚合物受体材料 P1 和 P2(图 19a), 与给 体材料 P3HT 匹配器件的 PCE 为 $0.31 \%$. 而随着相关研 究的深入, D-A 共轭策略仍然是目前性能优化最有效策 略，例如 A-D-A、A- $\pi-D-\pi-A 、 A-D A D-A$ 等. 这些丰富 的化学策略赋予了其更大的调控空间，来优化分子的光 电性质、共混薄膜形貌以及器件性能. 例如, 有效延伸 的分子共轭长度, 可以将吸收谱带向长波长方向拓宽, 改善分子内电荷传输效应. 基于 BTA 单元的受体材料 根据其分子主链结构的不同, 主要分为由周二军课题组 研发的 BTA 为 $\pi$ 桥的系列, 以及由邹应萍课题组研发的 BTA 为稠环核的 $\mathrm{Y}$ 系列. 前者作为受体，显示出了高 $E_{\mathrm{LUMO}}$ 和高 $V_{\mathrm{oc}}$ 的特点, 有望应用于叠层电池的前电池或 者室内光伏器件; 而后者作为受体则显示出窄带隙和高 PCE, 作为一种性能最为优异的受体材料而备受关注.

\subsubsection{BTA 系列受体材料}

BTA 系列是一类基于 $A-\pi-D-\pi-A\left(A-A^{\prime}-D-A^{\prime}-A\right)$ 型设 计策略的受体分子. 2016 年, 周二军等 ${ }^{[127]}$ 以 BTA 单元 为 $\pi$ 桥, 以 IDT 为中心给体 $\mathrm{D}$ 单元, 以绕丹宁 (2,4-thiazolidinedione, Rhodanine, $R)$ 为末端“ $A$ ”单元，设 计合成了含有 BTA 单元的非富勒烯型受体分子 BTA1(图 19b). BTA1 具有平面型的分子骨架、分子间良 好的 $\pi-\pi$ 堆叠和较高的载流子迁移率, 在 $450 \sim 670 \mathrm{~nm}$ 范围内具有较高的吸收系数; 且其 $E_{\mathrm{LUMO}}$ 和 $E_{\mathrm{HOMO}}$ 相比 于 $\mathrm{PC}_{61} \mathrm{BM}$ 明显提升, 有利于提升器件的 $V_{\mathrm{oc}}$. 基于 P3HT/BTA1( $w / w, 1: 0.6,0.8 \mathrm{wt}^{2} \% \mathrm{CN}, 120 \mathrm{~nm}$ )器件的 $V_{\mathrm{oc}}$ 为 $1.02 \mathrm{~V}, J_{\mathrm{sc}}$ 为 $7.3 \mathrm{~mA} / \mathrm{cm}^{2}, \mathrm{FF}$ 为 $70.0 \%, \mathrm{PCE}$ 为 $5.24 \%$.

表 7 小分子类给体材料的电化学性质及相应的有机太阳能电池器件性能指标

Table 7 The electrochemical properties of small molecule donor materials and the photovoltaic characteristics of the corresponding solar cells

\begin{tabular}{|c|c|c|c|c|c|c|c|c|c|c|}
\hline \multirow[b]{2}{*}{ Donor } & \multicolumn{4}{|c|}{ Optical and electrochemical property } & \multicolumn{5}{|c|}{ Photovoltaic characteristics of corresponding OSCs device } & \multirow[b]{2}{*}{ Ref. } \\
\hline & $E_{\mathrm{g}}{ }^{\text {opt } a} / \mathrm{eV}$ & $\mathrm{HOMO} / \mathrm{eV}$ & $\mathrm{LUMO} / \mathrm{eV}$ & $\begin{array}{c}E_{\mathrm{g}}^{\mathrm{ec} b /} \\
\mathrm{eV}\end{array}$ & Acceptor & $V_{\mathrm{oc}} / \mathrm{V}$ & $\begin{array}{c}J_{\mathrm{sc}} / \\
\left(\mathrm{mA} \cdot \mathrm{cm}^{-2}\right)\end{array}$ & $\mathrm{FF} / \%$ & $\mathrm{PCE} / \%$ & \\
\hline TPA-DTBTz-TPA & 2.00 & -5.08 & -3.02 & 2.06 & $\mathrm{PC}_{60} \mathrm{BM}$ & 0.74 & 4.3 & 29.0 & 0.93 & [119] \\
\hline $\mathrm{D}$ (CATBTzT)BDT & 1.85 & -5.13 & -3.31 & 1.82 & $\mathrm{PC}_{61} \mathrm{BM}$ & 0.93 & 6.0 & 64.0 & 3.61 & [121] \\
\hline $\mathrm{H} 11$ & 1.87 & -5.31 & -3.03 & 2.28 & IDIC & 0.98 & 15.2 & 65.5 & 9.73 & [122] \\
\hline H12 & 1.87 & -5.28 & -3.01 & 2.27 & IDIC & 0.96 & 10.5 & 54.9 & 5.51 & [122] \\
\hline $\mathrm{BDT}(\mathrm{TVT}-\mathrm{SR})_{2}$ & 1.82 & -5.33 & -3.18 & 2.15 & IDIC & 0.98 & 15.9 & 71.2 & 11.10 & [123] \\
\hline SM-0F & 1.56 & -5.09 & -3.53 & 1.56 & $\mathrm{PC}_{71} \mathrm{BM}$ & 0.73 & 7.3 & 43.4 & 2.56 & [124] \\
\hline SM-2F & 1.49 & -5.12 & -3.63 & 1.49 & $\mathrm{PC}_{71} \mathrm{BM}$ & 0.75 & 11.0 & 44.9 & 3.94 & [124] \\
\hline SM-4F & 1.55 & -5.13 & -3.58 & 1.55 & $\mathrm{PC}_{71} \mathrm{BM}$ & 0.77 & 9.1 & 46.7 & 3.48 & [124] \\
\hline
\end{tabular}

${ }^{a}$ Optical bandgap calculated from the absorption edge (onset) of the polymer films: $E_{\mathrm{g}}{ }^{\text {opt }}=1240 / \lambda_{\text {edge. }}{ }^{b}$ Electrochemical bandgap obtained from: $E_{\mathrm{g}}{ }^{\text {ec }}=E_{\mathrm{LUMO}}-$ $E_{\text {номо. }}$ 
在 BTA1 的基础上, 以噻唑二酮(thiazolidine-2,4dione, $\mathrm{TD})$ 作为末端 $\mathrm{A}$ 单元，周二军等设计合成了 BTA2(图 19c) ${ }^{[128]}$, 相比于 BTA1, 吸收谱带发生明显的 蓝移, $E_{\mathrm{LUMO}}$ 与 $E_{\mathrm{HOMO}}$ 则进一步提升. 基于 $\mathrm{P} 3 \mathrm{HT} / \mathrm{BTA} 2$ $(w / w, 0.6: 1,0.8 \mathrm{wt} \% \mathrm{DIO})$ 器件的 $V_{\mathrm{oc}}$ 为 $1.22 \mathrm{~V}, J_{\mathrm{sc}}$ 为 6.2 $\mathrm{mA} / \mathrm{cm}^{2}, \mathrm{FF}$ 为 $60.0 \%, \mathrm{PCE}$ 为 $4.50 \%$. 进一步地, 将二氧 甲烯基(dicyanomethylene)引入至末端 $\mathrm{A}$ 单元, 得到二氧 基绕丹宁(2-(1,1-dicyanomethylene)rhodanine, $\mathrm{RCN})$, 进 而合成了 BTA3(图 19d) ${ }^{[129]}$. 由于二氰甲烯基为强吸电 子基团，相比于 BTA1 和 BTA2, BTA3 的吸收谱带发生 更为明显的红移, 吸收边界扩展至 $704 \mathrm{~nm}$, 而其 $E_{\mathrm{LUMO}}$ 与 $E_{\mathrm{HOMO}}$ 则明显降低. 基于 “ $\mathrm{SAS}$ ” 策略与 $\mathrm{J} 61$ 匹配器 件的 $V_{\mathrm{oc}}$ 为 $1.15 \mathrm{~V}, J_{\mathrm{sc}}$ 为 $10.8 \mathrm{~mA} / \mathrm{cm}^{2}, \mathrm{FF}$ 为 $66.2 \%, \mathrm{PCE}$ 为 $8.25 \%$.

在 BTA3 的基础上, 周二军等[75]将 IDT 单元两侧的 噻吩单元替换为并噻吩单元, 设计合成了 BTA13(图 $19 \mathrm{e}$ ), 其 $E_{\mathrm{LUMO}}$ 与 $E_{\mathrm{HOMO}}$ 相比于 BTA3 略有提升, 并基于 “SAS” 策略与 J52、J52-F、J52-FS 匹配. 其给受体间 $\Delta E_{\mathrm{LUMO}}(0.40 、 0.25 、 0.23 \mathrm{eV})$ 和 $\Delta E_{\mathrm{HUMO}}(0.21 、 0.05 、 0.02$ $\mathrm{eV}$ )均呈下降趋势, 因此其器件的 $V_{\mathrm{oc}}$ 呈上升趋势 (1.05、 $1.18 、 1.24 \mathrm{~V}), E_{\mathrm{loss}}$ 呈现下降趋势 $(0.67 、 0.54 、 0.48 \mathrm{eV})$, 这 得益于所引入的 $\mathrm{F} \cdots \mathrm{C}$ 和 $\mathrm{S} \cdots \mathrm{C}$ 非共价键. 然而由于 J52-FS/BTA13 体系的 $\Delta E_{\mathrm{HUMO}}$ 过低, 导致其空穴和电子 传输率较低, 影响了其器件性能. 基于 J52-F/BTA13 $(w / w, 1: 1, \approx 100 \mathrm{~nm})$ 器件的 $V_{\mathrm{oc}}$ 为 $1.18 \mathrm{~V}, J_{\mathrm{sc}}$ 为 11.6 $\mathrm{mA} / \mathrm{cm}^{2}, \mathrm{FF}$ 为 $61.3 \%$, PCE 为 $8.36 \%$.

在 BTA1、BTA3 的基础上, 周二军等 ${ }^{[130]}$ 以螺二芴 (spirobifluorene, $\mathrm{SF}$ ) 为中心给体 “ $\mathrm{D}$ ” 单元, 设计合成了
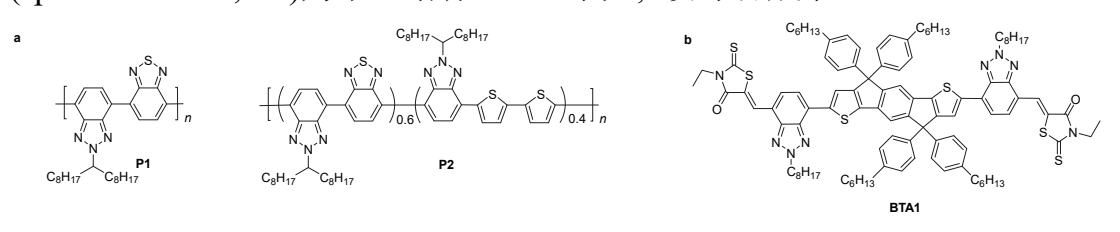

BTA21、BTA23 和 BTA27(图 19f), 探讨不同的末端“A” 单元对光伏性能的影响. 研究结果表明, 末端单元对分 子吸收谱带、能级以及共混薄膜形貌有显著的影响, 其 中 BTA21 的光伏性能最为优异, 基于 P3HT/BTA21 $(w / w, 1: 1,0.8 \mathrm{vol} \% \mathrm{CN})$ 器件的 $V_{\mathrm{oc}}$ 为 $1.02 \mathrm{~V}, J_{\mathrm{sc}}$ 为 5.5 $\mathrm{mA} / \mathrm{cm}^{2}, \mathrm{FF}$ 为 $59.0 \%$, PCE 为 $3.28 \%$.

在 BTA2、BTA1 和 BTA3 的基础上，周二军等 ${ }^{[131]}$ 通过在 BTA 单元上进行双甲氧基取代，设计合成了 BTA100、BTA101 和 BTA103(图 19g), 同样探讨了不同 的末端 “ $\mathrm{A}$ ” 单元对光伏性能的影响. 引入甲氧基降低 了材料的 $E_{\mathrm{LUMO}}$, 且氧原子可以与相邻噻吩单元上的硫 原子形成弱相互作用，从而促进分子内电荷传输. 基于 $\mathrm{P} 3 \mathrm{HT} / \mathrm{BTA} 103(w / w, 1: 2, \approx 85 \mathrm{~nm})$ 器件的 $V_{\mathrm{oc}}$ 为 $0.94 \mathrm{~V}$, $J_{\mathrm{sc}}$ 为 $8.6 \mathrm{~mA} / \mathrm{cm}^{2}, \mathrm{FF}$ 为 $66.0 \%, \mathrm{PCE}$ 为 $5.31 \%$. 值得注意 的是, 基于 $\mathrm{P} 3 \mathrm{HT} / \mathrm{BTA} 100(w / w, 1: 1, \approx 85 \mathrm{~nm})$ 器件获 得了 $1.34 \mathrm{~V}$ 的高 $V_{\mathrm{oc}}$.

进一步地，将氧原子引入至 IDT 单元的不同位置， 设计合成了 BTA43 和 BTA53(图 19h) ${ }^{[132]}$. 相比于 BTA3, BTA43 中烷氧基侧链的引入对分子构型无明显影响, 但 明显提高了其吸收系数, 而 BTA53 的分子主链上 C$\mathrm{O}-\mathrm{C}$ 键的引入所形成的具有强给电子性的吡喃环, 使 其分子发生轻度的扭曲，扩展了其共轭面，且吸收谱带 发生明显的红移，吸收边界扩展至 $737 \mathrm{~nm}$. 基于 P3HT/BTA43 $(w / w, 1: 0.5)$ 器件的 $V_{\mathrm{oc}}$ 为 $0.89 \mathrm{~V}, J_{\mathrm{sc}}$ 为 $10.8 \mathrm{~mA} / \mathrm{cm}^{2}, \mathrm{FF}$ 为 $68.0 \%$, $\mathrm{PCE}$ 为 $6.56 \%$; 基于 $\mathrm{P} 3 \mathrm{HT} / \mathrm{BTA} 53(w / w, 1: 0.8)$ 器件的 $V_{\mathrm{oc}}$ 为 $0.88 \mathrm{~V}, J_{\mathrm{sc}}$ 为 11.6 $\mathrm{mA} / \mathrm{cm}^{2}, \mathrm{FF}$ 为 $62.0 \%$, PCE 为 $6.31 \%$.

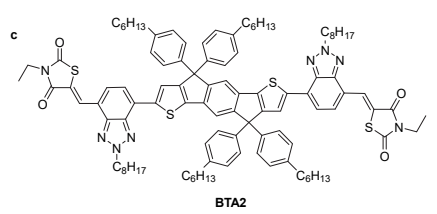

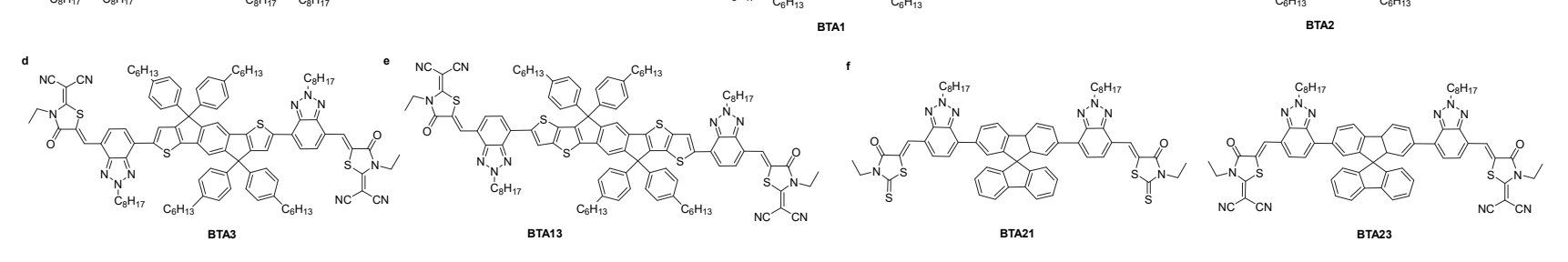
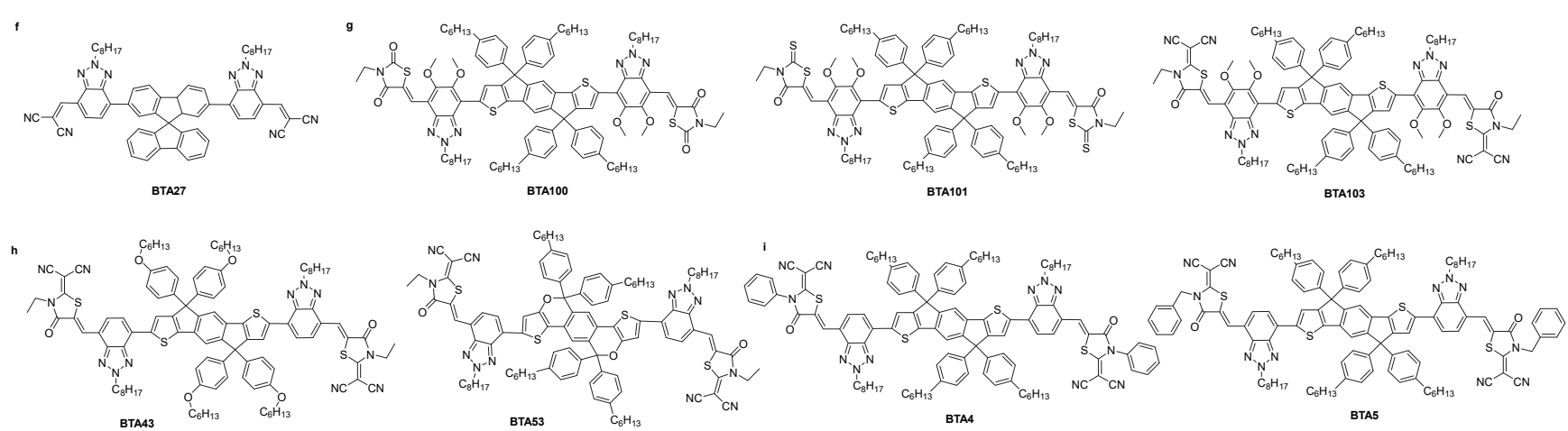

图 19 基于三氮唑单元的 BTA 系列受体材料

Figure 19 BTA series acceptor materials based on BTA units 
为了探讨末端取代基的结构对分子堆叠的影响, 在 BTA3 的基础上, 将苯基和芐基分别引入末端, 设计合 成了 BTA4 和 BTA5(图 19i) ${ }^{[133]}$. 研究表明, BTA3 分子的 堆积方式为异核堆积, 通过引入苄基, BTA5 的堆积方式 变为同核堆积, 堆积方式改变的驱动力主要来自于茮基 的苯环与 BTA 单元上苯环的相互作用. 基于 $\mathrm{J} 52-\mathrm{F} / \mathrm{BTA} 5(w / w, 1: 0.8)$ 器件的 $V_{\mathrm{oc}}$ 为 $1.17 \mathrm{~V}, J_{\mathrm{sc}}$ 为 13.8 $\mathrm{mA} / \mathrm{cm}^{2}, \mathrm{FF}$ 为 $69.8 \%$, PCE 为 $11.27 \%$.

为了更直观地表现分子结构的改变对材料的 $E_{\mathrm{LUMO}}$ 和 $E_{\mathrm{HOMO}}$ 的影响, 我们将以上材料的分子能级图进行对 比, 如图 20 所示. 相关受体材料的电化学性质及相应的 有机太阳能电池器件性能指标如表 8 所示.

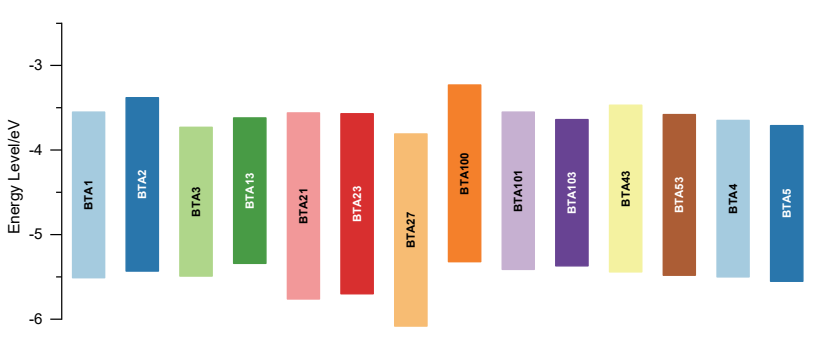

图 20 基于三氮唑单元的 BTA 系列受体材料的能级示意图

Figure 20 Energy level diagram of BTA series acceptor materials based on BTA units

\subsubsection{Y 系列受体材料}

$\mathrm{Y}$ 系列是一类基于 A-DAD-A 结构设计策略的受体 分子, 也就是将吸电子 $\mathrm{A}$ 基团引入到 $\mathrm{A}-\mathrm{D}-\mathrm{A}$ 结构中的芳 香稠环 D 单元中, 设计合成 DAD 型芳香稠环. 2017 年, 邹应萍等 [134] 以二噻吩并吡咯稠合苯并三氮唑 (dithieno[3,2-b]pyrrolobenzotriazole, BZTP) 为 “DAD” 核,
以 1,1-二氭甲烯基 -3- 狮酮 (1,1-dicyanomethylene3-indanone, INCN)为末端 A 单元，首次合成了基于 BTA 单元的梯形五元稠环非富勒烯型受体分子 BZIC(图 21a). 其五元稠环中, 富电子的噻吩单元、吡咯单元和缺 电子的苯并三氮唑单元形成了稠合的 “D-A-D”结构, 增 强了分子内电荷的相互作用, 促进了 $\pi$ 电子的离域化和 电荷的有效传输. 与 “明星分子” ITIC $\left(E_{\mathrm{g}}{ }^{\mathrm{opt}}=1.59 \mathrm{eV}\right)$ 相比, BZIC 的吸收边界红移了 $79 \mathrm{~nm}$, 扩展至 $857 \mathrm{~nm}$, $E_{\mathrm{g}}{ }^{\mathrm{opt}}$ 降低至 $1.45 \mathrm{eV}$, 且吸收系数也明显提高. 基于 HFQx-T/BZIC $(w / w, 1: 1.5,0.25 \mathrm{wt} \% \mathrm{CN}, 100 \mathrm{~nm})$ 器件 的 $V_{\mathrm{oc}}$ 为 $0.84 \mathrm{~V}, J_{\mathrm{sc}}$ 为 $12.7 \mathrm{~mA} / \mathrm{cm}^{2}, \mathrm{FF}$ 为 $59.0 \%$, PCE 为 $6.30 \%$. 该研究为 $\mathrm{Y}$ 系列 “明星分子” 受体材料的开端, BZIC 也被称为 $\mathrm{Y} 0$.

在 BZIC 的基础上, 邹应萍等 [135] 将并噻吩 (thieno[3,2-b]thiophene, TT)引入至 “DAD” 核心单元中 作为“D”单元，合成了具有七元稠环核心结构的 Y1, 和 以 INTC(2-(6-oxo-5,6-dihydro-4H-cyclopenta[c]thiophen4-ylidene)-malononitrile)作为末端“ $A$ ”单元的 $Y 2$ (图 21b). 与 BZIC 相比, Y1 和 Y2 的吸收边界进一步红移至 905 $\mathrm{nm}$ 和 $925 \mathrm{~nm}$, 且由于 INTC 末端的吸电子能力强于 INCN, $\mathrm{Y} 2$ 的 $E_{\mathrm{LUMO}}$ 略低于 $\mathrm{Y} 1$. 基于 $\mathrm{PBDB}-\mathrm{T} / \mathrm{Y} 1(w / w$, $1: 1,0.8 \mathrm{vol} \% \mathrm{CN}, 100 \mathrm{~nm}$ )器件的 $V_{\mathrm{oc}}$ 为 $0.87 \mathrm{~V}, J_{\mathrm{sc}}$ 为 $22.4 \mathrm{~mA} / \mathrm{cm}^{2}$, $\mathrm{FF}$ 为 $69.1 \%, \mathrm{PCE}$ 为 $13.42 \%$; 基于 PBDB-T/Y2 $(w / w, 1: 1,0.8 \mathrm{vol} \% \mathrm{CN}, 100 \mathrm{~nm})$ 器件的 $V_{\mathrm{oc}}$ 为 $0.82 \mathrm{~V}, J_{\mathrm{sc}}$ 为 $23.6 \mathrm{~mA} / \mathrm{cm}^{2}, \mathrm{FF}$ 为 $69.4 \%, \mathrm{PCE}$ 为 $13.40 \%$, 且该两种体系的 $E_{\mathrm{loss}}$ 均较小, 仅为 $0.57 \mathrm{eV}$.

在 Y1 的基础上，通过在 “DAD” 核心单元末端即 $\mathrm{TT}$ 单元的 $\beta$ 位上引入不同的烷基侧链, 邹应萍等合成

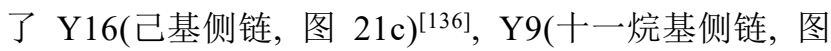

表 8 基于三氮唑单元的 BTA 系列受体材料的电化学性质及相应的有机太阳能电池器件性能指标

Table 8 The electrochemical properties of BTA series acceptor materials based on BTA units and the photovoltaic characteristics of the corresponding solar cells

\begin{tabular}{|c|c|c|c|c|c|c|c|c|c|c|}
\hline \multirow[b]{2}{*}{ Acceptor } & \multicolumn{4}{|c|}{ Optical and electrochemical property } & \multicolumn{5}{|c|}{ Photovoltaic characteristics of corresponding OSCs device } & \multirow[b]{2}{*}{ Ref. } \\
\hline & $E_{\mathrm{g}}{ }^{\text {opt } a} / \mathrm{eV}$ & $\mathrm{HOMO} / \mathrm{eV}$ & $\mathrm{LUMO} / \mathrm{eV}$ & $E_{\mathrm{g}}{ }^{\mathrm{ec} b} / \mathrm{eV}$ & Donor & $V_{\mathrm{oc}} / \mathrm{V}$ & $\begin{array}{c}J_{\mathrm{sc}} / \\
\left(\mathrm{mA} \cdot \mathrm{cm}^{-2}\right)\end{array}$ & $\mathrm{FF} / \%$ & $\mathrm{PCE} / \%$ & \\
\hline \multirow[b]{2}{*}{ BTA1 } & \multirow[b]{2}{*}{1.85} & \multirow[b]{2}{*}{-5.51} & \multirow[b]{2}{*}{-3.55} & \multirow[b]{2}{*}{1.96} & P3HT & 1.02 & 7.3 & 70.0 & 5.24 & [127] \\
\hline & & & & & $\mathrm{J} 61$ & 1.24 & 5.2 & 46.7 & 3.02 & [128] \\
\hline \multirow{2}{*}{ BTA2 } & \multirow{2}{*}{2.00} & \multirow{2}{*}{-5.43} & \multirow{2}{*}{-3.38} & \multirow{2}{*}{1.95} & P3HT & 1.22 & 6.2 & 60.0 & 4.50 & [128] \\
\hline & & & & & $\mathrm{J} 61$ & 1.29 & 0.8 & 23.8 & 0.26 & [128] \\
\hline \multirow[t]{2}{*}{ BTA3 } & \multirow[t]{2}{*}{1.76} & \multirow[t]{2}{*}{-5.49} & \multirow[t]{2}{*}{-3.73} & \multirow[t]{2}{*}{1.76} & J61 & 1.15 & 10.8 & 66.2 & 8.25 & [129] \\
\hline & & & & & $\mathrm{J} 52$ & 1.05 & 12.7 & 58.7 & 7.82 & [75] \\
\hline \multirow[t]{2}{*}{ BTA13 } & \multirow[t]{2}{*}{1.72} & \multirow[t]{2}{*}{-5.34} & \multirow[t]{2}{*}{-3.62} & \multirow[t]{2}{*}{1.72} & J52-F & 1.18 & 11.6 & 61.3 & 8.36 & [75] \\
\hline & & & & & J52-FS & 1.24 & 6.7 & 46.0 & 3.84 & [75] \\
\hline BTA21 & 2.19 & -5.76 & -3.56 & 2.20 & Р3HT & 1.02 & 5.5 & 59.0 & 3.28 & [130] \\
\hline BTA23 & 2.15 & -5.70 & -3.57 & 2.13 & P3HT & 0.90 & 4.0 & 52.0 & 1.86 & [130] \\
\hline BTA27 & 2.21 & -6.08 & -3.81 & 2.27 & P3HT & 0.60 & 2.9 & 36.0 & 0.62 & [130] \\
\hline BTA100 & 2.05 & -5.32 & -3.23 & 2.09 & P3HT & 1.34 & 1.7 & 47.0 & 1.04 & [131] \\
\hline BTA101 & 1.88 & -5.41 & -3.55 & 1.86 & P3HT & 1.19 & 5.3 & 56.0 & 3.55 & [131] \\
\hline BTA103 & 1.76 & -5.37 & -3.64 & 1.73 & P3HT & 0.94 & 8.6 & 66.0 & 5.31 & [131] \\
\hline BTA43 & 1.78 & -5.44 & -3.47 & 1.97 & P3HT & 0.89 & 10.8 & 68.0 & 6.56 & [132] \\
\hline BTA53 & 1.68 & -5.48 & -3.58 & 1.90 & P3HT & 0.88 & 11.6 & 62.0 & 6.31 & [132] \\
\hline BTA4 & 1.79 & -5.50 & -3.65 & 1.85 & J52-F & 1.21 & 8.39 & 55.3 & 5.61 & [133] \\
\hline BTA5 & 1.76 & -5.55 & -3.71 & 1.84 & J52-F & 1.17 & 13.80 & 69.8 & 11.27 & [133] \\
\hline
\end{tabular}

${ }^{a}$ Optical bandgap calculated from the absorption edge (onset) of the polymer films: $E_{\mathrm{g}}{ }^{\text {opt }}=1240 / \lambda_{\text {edge }}{ }^{b}$ Electrochemical bandgap obtained from: $E_{\mathrm{g}}{ }^{\text {ec }}=E_{\mathrm{LUMO}}-$ $E_{\text {HOMO. }}$ 
$21 \mathrm{~d})^{[137]}$, 烷基侧链的引入对其 $E_{\mathrm{g}}{ }^{\text {opt }}$ 无明显影响. 基于 PBDB-T-F/Y $16(w / w, 1: 1,1.0 \mathrm{vol} \% \mathrm{CN})$ 器件的 $V_{\mathrm{oc}}$ 为 $0.91 \mathrm{~V}, J_{\mathrm{sc}}$ 为 $21.3 \mathrm{~mA} / \mathrm{cm}^{2}, \mathrm{FF}$ 为 $66.7 \%$, PCE 为 $13.00 \%$, 添加 $15 \mathrm{wt} \% \mathrm{MeIC} 1$ 作为第三组分制备的三元器件的 $\mathrm{PCE}$ 可达到 14.11\%. 基于 PBDB-T-F/Y9(w/w, 1: 1, 0.5 $\mathrm{vol} \% \mathrm{CN}$ )器件的 $V_{\mathrm{oc}}$ 为 $0.90 \mathrm{~V}, J_{\mathrm{sc}}$ 为 $23.3 \mathrm{~mA} / \mathrm{cm}^{2}, \mathrm{FF}$ 为 $63.0 \%$, PCE 为 $13.26 \%$.

在 $\mathrm{Y} 1$ 分子结构的基础上, 邹应萍等通过将末端 “A”单元 INCN 进行卤素取代, 以双氟化的 INCN (2FIC) 作为末端 “ $A$ ” 单元合成了 $Y 1-4 F(Y 3)\left(\right.$ 图 21e) ${ }^{[138]}$, 其吸 收边界红移至 $953 \mathrm{~nm}, E_{\mathrm{LUMO}}$ 与 $E_{\mathrm{HOMO}}$ 也明显降低, 基 于 PBDB-T-F/Y $1-4 \mathrm{~F}(w / w, 1: 1,0.5 \mathrm{vol} \% \mathrm{CN}, \approx 110 \mathrm{~nm})$ 器件的 $V_{\mathrm{oc}}$ 为 $0.83 \mathrm{~V}, J_{\mathrm{sc}}$ 为 $25.2 \mathrm{~mA} / \mathrm{cm}^{2}, \mathrm{FF}$ 为 $68.5 \%$, PCE 为 $14.80 \%$. 同样的, 在 Y9 分子结构的基础上, 对 末端 “A” 单元进行氟化, 邹应萍等合成了双氟取代的
$\mathrm{Y} 11$ (图 21f ${ }^{[139]}$ 和单氟取代的 Y14(图 21g) ${ }^{[140]}$. 基于 PM6/Y11(w/w, 1: 1, 0.5 vol\% DPE, $130 \mathrm{~nm})$ 器件的 $V_{\mathrm{oc}}$ 为 $0.83 \mathrm{~V}, J_{\mathrm{sc}}$ 为 $26.7 \mathrm{~mA} / \mathrm{cm}^{2}, \mathrm{FF}$ 为 $74.3 \%, \mathrm{PCE}$ 为 $16.54 \%$, 且 $E_{\mathrm{loss}}$ 均仅为 $0.43 \mathrm{eV}$. 基于 PBDB-T/Y14(w/w, $1: 1,1.0 \mathrm{vol} \% \mathrm{CN}, 100 \mathrm{~nm}$ )反向器件的 $V_{\mathrm{oc}}$ 为 $0.80 \mathrm{~V}, J_{\mathrm{sc}}$ 为 $26.2 \mathrm{~mA} / \mathrm{cm}^{2}, \mathrm{FF}$ 为 $71.5 \%$, PCE 为 $14.92 \%$, 且所制备 的透过率为 $23.69 \%$ 的半透明器件的 PCE 仍可达到 $12.67 \%$; 同样, 他们又以双氯化的 INCN 作为末端 “A” 单元, 在 Y9 分子结构的基础上合成了 $\mathrm{Y} 15$ (图 21h) ${ }^{[141]}$, 基于 PM6/Y $15(w / w, 1: 1.8,0.3 \mathrm{vol} \% \mathrm{DIO})$ 器件的 $V_{\mathrm{oc}}$ 为 $0.87 \mathrm{~V}, J_{\mathrm{sc}}$ 为 $23.8 \mathrm{~mA} / \mathrm{cm}^{2}, \mathrm{FF}$ 为 $68.5 \%$, PCE 为 $14.13 \%$. 通过在 Y 16 末端引入氟原子, 邹应萍等 ${ }^{[142]}$ 合成了 $\mathrm{Y} 18$ (图 21i), 基于 PM6/Y18(w/w, $1: 1.5,0.5 \mathrm{vol} \% \mathrm{CN}$ ) 器件的 $V_{\mathrm{oc}}$ 为 $0.84 \mathrm{~V}, J_{\mathrm{sc}}$ 为 $25.7 \mathrm{~mA} / \mathrm{cm}^{2}, \mathrm{FF}$ 为 $76.5 \%$, $\mathrm{PCE}$ 为 $16.52 \%$, 且 $E_{\mathrm{loss}}$ 均仅为 $0.53 \mathrm{eV}$, 添加 $7.4 \mathrm{wt} \%$

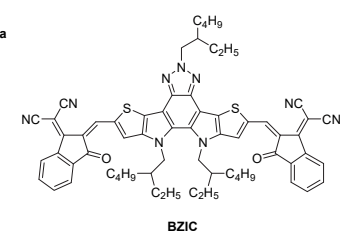

BzIC
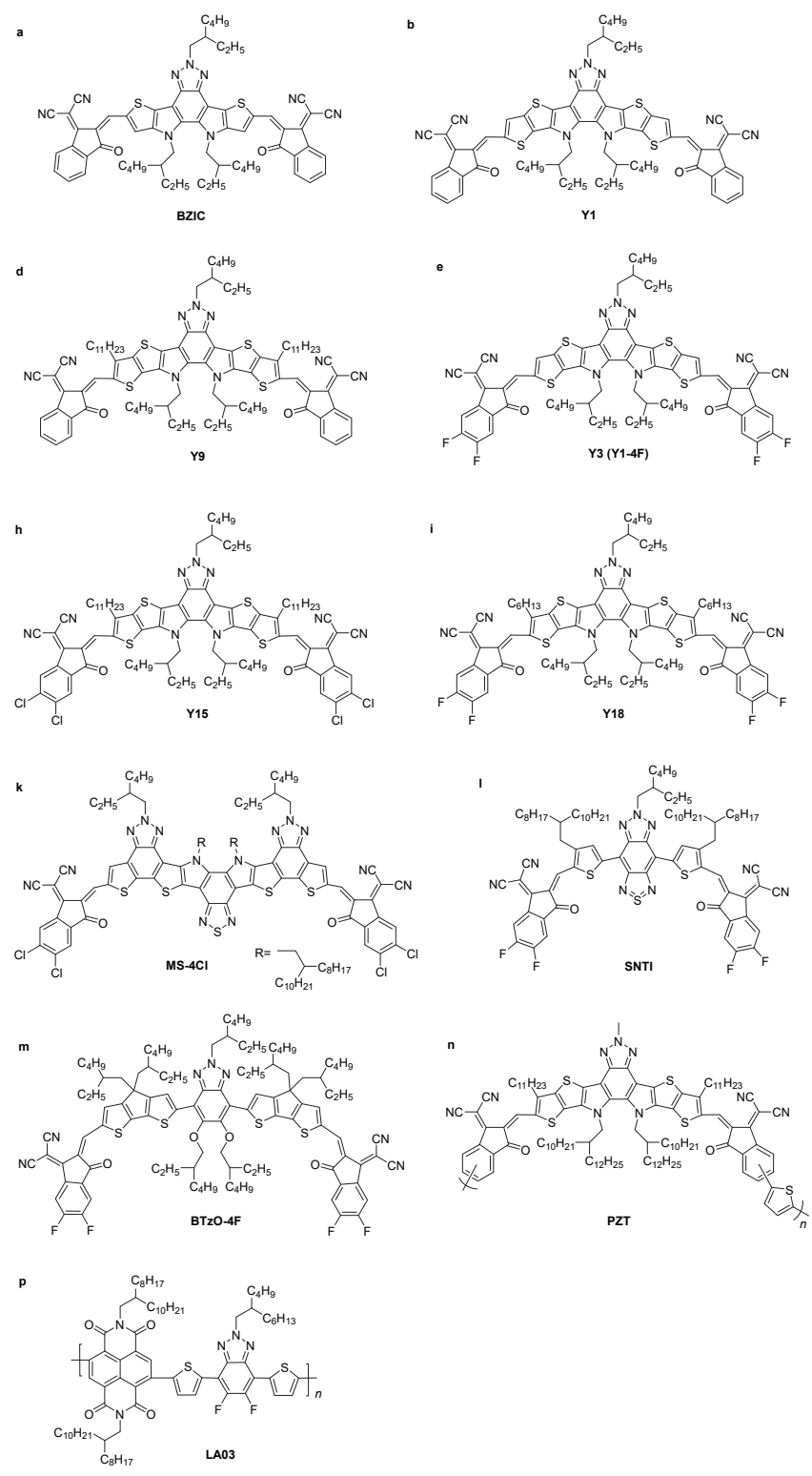

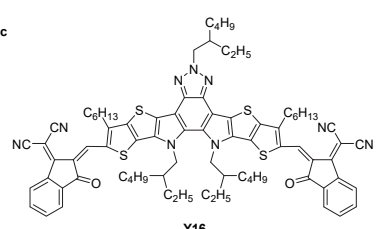

Y16
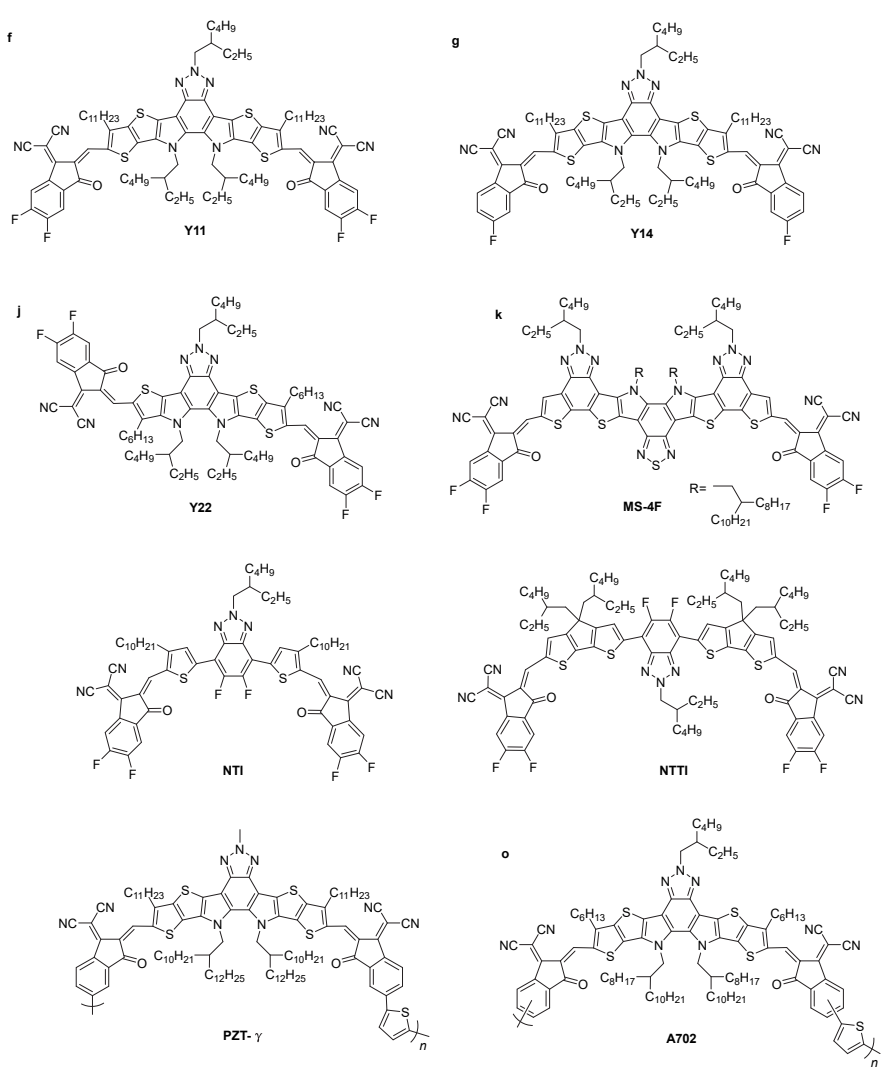

图 21 基于三氮唑单元的 $\mathrm{Y}$ 系列受体材料

Figure 21 Y series acceptor materials based on BTA units 
$\mathrm{PC}_{71} \mathrm{BM}$ 作为第三组分制备的三元器件的 $\mathrm{PCE}$ 可达到 $17.11 \%$. 通过对比 Y3、Y18 和 $\mathrm{Y} 11^{[143]}$, 可以看出 $\beta$ 位 不同长度的烷基侧链的引入, 除了可以增强分子的结晶 性, 改善相分离状态, 得到更为有序的分子堆叠之外, 还可以增加 TT-2FIC 结构扭转的能量势垒, 进而降低分 子骨架的无序度, 有利于促进电荷在给受体间的快速传 输. 在此基础上, 邹应萍等 ${ }^{[144]}$ 进一步对 “DAD” 核心单 元进行调控, 合成了具有不对称的六元稠环核心结构的 Y22(图 21j), 相比于具有对称核心结构的 Y 18, 其 $E_{\mathrm{LUMO}}$ 与 $E_{\mathrm{HOMO}}$ 略有降低, 吸收边界轻微蓝移, 与 PM6 的共混 薄膜同样具有较高的空穴和电子迁移率。基于 $\mathrm{PM} 6 / \mathrm{Y} 22\left(w / w, 1: 1.2,0.3 \mathrm{vol} \% \mathrm{CN}\right.$ )器件的 $V_{\mathrm{oc}}$ 为 $0.85 \mathrm{~V}$, $J_{\mathrm{sc}}$ 为 $24.4 \mathrm{~mA} / \mathrm{cm}^{2}, \mathrm{FF}$ 为 $74.1 \%$, PCE 达到了 $15.40 \%$.

2020 年, 黄飞、胡志诚等 ${ }^{[145]}$ 以苯并三氮唑和苯并 噻二唑单元构建多缺电子单元的稠核, 设计合成了 MS-4F、MS-4Cl(图 21k), 具有不同卤素取代末端的两种 材料均表现出强吸收、窄带隙以及良好的载流子迁移率. 基于 PBDB-T/MS-4F 和 PBDB-T/MS-4Cl 的器件均表现 出较好的 $\mathrm{PCE}(11.75 \% 、 11.79 \%)$.

以上小分子受体材料主要基于稠环单元, 然而这类 材料的合成路线一般较为复杂, 产率较低、成本较高. 而非稠环受体材料则具有反应路线短的优势, 可以显著 降低合成成本.

2020 年, 陈红征等 ${ }^{[146]}$ 设计合成了基于 BTA 单元的 非稠环受体材料 SNTI、NTI 和 NTTI(图 211), 探讨了具 有醌式效应的吸电子性苯并唑类稠环结构对受体材料 的稳定性以及光伏性能的影响. 研究表明受体分子的吸 收、能级和光热稳定性都与其醌式效应的强度密切相关. 基于 PBDB-T/NTTI $(w / w, 1: 1,0.5 \mathrm{wt} \% \mathrm{CN})$ 的器件的 $V_{\text {oc }}$ 为 $0.77 \mathrm{~V}, J_{\text {sc }}$ 为 $17.7 \mathrm{~mA} / \mathrm{cm}^{2}, \mathrm{FF}$ 为 $56.0 \%, \mathrm{PCE}$ 为 $7.62 \%$.

2020 年，黄辉等 ${ }^{[147]}$ 采用非共价 “构象锁” 概念，增 强分子内部的共平面性, 设计合成了含有 “ $\mathrm{S} \cdots \mathrm{O}$ ” 构象 锁的非稠环受体材料 $\mathrm{BTzO}-4 \mathrm{~F}$ (图 21m). 基于 PBDB-T/BTzO-4F $(w / w, 1: 1,0.5 \mathrm{wt} \% \mathrm{CN})$ 的器件的 $V_{\mathrm{oc}}$ 为 $0.84 \mathrm{~V}, J_{\mathrm{sc}}$ 为 $23.6 \mathrm{~mA} / \mathrm{cm}^{2}, \mathrm{FF}$ 为 $69.7 \%, \mathrm{PCE}$ 为 $13.80 \%$.

同时，李永舫、张志国提出的 “小分子受体聚合物 化” (polymerized small molecule acceptors, PSMAs)的概 念 ${ }^{[148]}$ 也被应用在基于 BTA 单元的聚合物受体材料的构
建上. 2020 年，任广禹等 ${ }^{[149]}$ 设计合成了基于 BTA 单元 的窄带隙聚合物受体 PZT(图 21n), 并采用重结晶方法 得到高纯的 IC-Br- $\gamma$ 末端，继而合成了区域规整的 PZT- $\gamma$ (图 13m), 以解决 PZT 的异构问题. 相比于 PZT, 区域规整性的调控使得 PZT- $\gamma$ 的吸收边界进一步红移, 且分子主链方向的堆积增强. 基于 PBDB-T/PZT- $\gamma(w / w$, $2: 1,1 \mathrm{wt} \% \mathrm{CN})$ 的全聚合物太阳能电池器件的 $V_{\mathrm{oc}}$ 为 $0.90 \mathrm{~V}, J_{\mathrm{sc}}$ 为 $24.7 \mathrm{~mA} / \mathrm{cm}^{2}, \mathrm{FF}$ 为 $71.3 \%$, $\mathrm{PCE}$ 为 $15.80 \%$. 2021 年, 周二军等 ${ }^{[150]}$ 设计合成了基于 BTA 单元的聚合 物受体 A702(图 210), 基于 PBDB-T/A702(w/w, 2: 1, 1 $\mathrm{wt} \% \mathrm{CN}$ )的全聚合物太阳能电池器件的 $V_{\mathrm{oc}}$ 为 $0.90 \mathrm{~V}, J_{\mathrm{sc}}$ 为 $21.9 \mathrm{~mA} / \mathrm{cm}^{2}, \mathrm{FF}$ 为 $60.0 \%$, PCE 为 $11.84 \%$.

将噻吩偶联的 BTA 单元与芳香亚胺单元, 如葈酰 亚胺(naphthalenediimide, NDI)单元共聚, 也是一种构筑 高性能聚合物受体的策略. 基于该策略, 2019 年, 李永 舫、霍立军等 ${ }^{[151]}$ 设计合成了 LA03(图 21p). LA03 的分 子结构可以视为在聚合物受体材料 N2200 的两个噻吩 单元间插入 BTA 单元，相比于 N2200, LA03 的吸收边界 蓝移, $E_{\mathrm{LUMO}}$ 升高, $E_{\mathrm{HOMO}}$ 降低, 带隙明显增大. 基于 PBDB-T/LA03( $w / w, 2: 1,1 \mathrm{wt} \% \mathrm{CN})$ 的全聚合物太阳能 电池器件的 $V_{\mathrm{oc}}$ 为 $0.94 \mathrm{~V}, J_{\mathrm{sc}}$ 为 $11.3 \mathrm{~mA} / \mathrm{cm}^{2}, \mathrm{FF}$ 为 $61.3 \%$, $\mathrm{PCE}$ 为 $6.49 \%, \mathrm{PCE}$ 高于基于 $\mathrm{N} 2200 / \mathrm{PBDB}-\mathrm{T}(w / w, 2: 1)$ 器件( $\mathrm{PCE}$ 为 $5.85 \%$ ).

为了更直观地表现分子结构的改变对材料的 $E_{\mathrm{LUMO}}$ 和 $E_{\mathrm{HOMO}}$ 的影响, 我们将以上材料的分子能级图进行对 比，如图 22 所示. 相关受体材料的电化学性质及相应的 有机太阳能电池器件性能指标如表 9 所示.

\section{4 总结与展望}

在过去的 20 年间, 有机太阳能电池发展迅速, 其能 量转换效率从不到 $5 \%$ 突破至 $18 \%$, 这主要得益于各种 新型给体和受体材料的研发. 在这些有机光伏材料中, 三氮唑作为一种经典的缺电子型五元杂环单元, 得到了 广泛的研究. 基于三氮唑单元的聚合物给体材料、小分 子给体材料以及非富勒烯小分子和聚合物受体被不断 地设计合成出来，特别是基于苯并三氮唑单元构筑的 $\mathrm{J}$ 系列聚合物给体材料和 Y 系列受体材料，以其优异的光 伏性能，近年来受到广泛关注. 与此同时，相关的给受 体分子设计策略也在不断地更新与完善, 从分子结构上

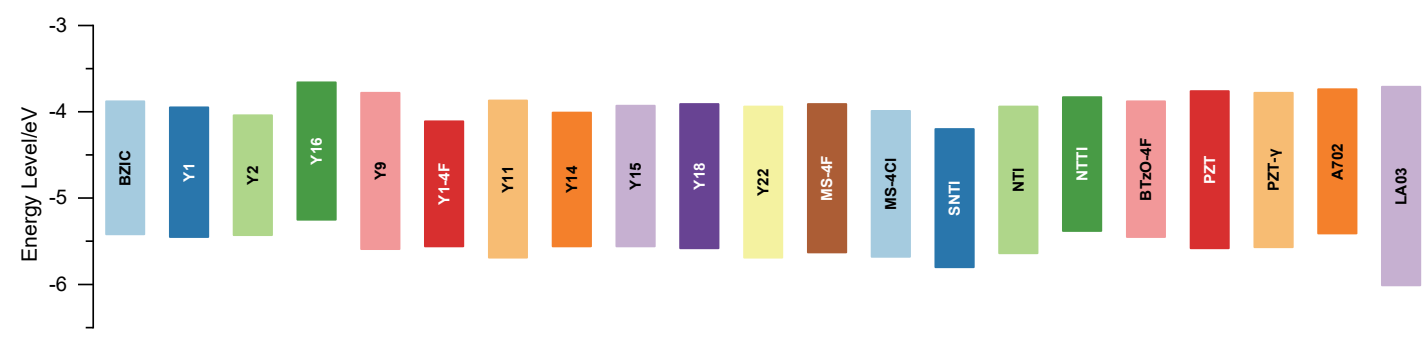

图 22 基于三氮唑单元的 $\mathrm{Y}$ 系列受体材料的能级示意图

Figure 22 Energy level diagram of $Y$ series acceptor materials based on BTA units 
表 9 基于三氮唑单元的 $\mathrm{Y}$ 系列受体材料的电化学性质及相应的有机太阳能电池器件性能指标

Table 9 The electrochemical properties of Y series acceptor materials based on BTA units and the photovoltaic characteristics of the corresponding solar cells

\begin{tabular}{|c|c|c|c|c|c|c|c|c|c|c|}
\hline \multirow[b]{2}{*}{ Acceptor } & \multicolumn{4}{|c|}{ Optical and electrochemical property } & \multicolumn{5}{|c|}{ Photovoltaic characteristics of corresponding OSCs device } & \multirow[b]{2}{*}{ Ref. } \\
\hline & $E_{\mathrm{g}}$ opt $a / \mathrm{eV}$ & $\mathrm{HOMO} / \mathrm{eV}$ & $\mathrm{LUMO} / \mathrm{eV}$ & $E_{\mathrm{g}}{ }^{\mathrm{ec} b} / \mathrm{eV}$ & Donor & $V_{\mathrm{oc}} / \mathrm{V}$ & $\begin{array}{c}J_{\mathrm{sc}} / \\
\left(\mathrm{mA} \cdot \mathrm{cm}^{-2}\right)\end{array}$ & $\mathrm{FF} / \%$ & $\mathrm{PCE} / \%$ & \\
\hline BZIC & 1.45 & -5.42 & -3.88 & 1.54 & HFQx-T & 0.84 & 12.7 & 59.0 & 6.30 & [134] \\
\hline Y1 & 1.37 & -5.45 & -3.95 & 1.50 & PBDB-T & 0.87 & 22.4 & 69.1 & 13.42 & [135] \\
\hline $\mathrm{Y} 2$ & 1.34 & -5.43 & -4.04 & 1.39 & PBDB-T & 0.82 & 23.6 & 69.4 & 13.40 & [135] \\
\hline Y16 & $\approx 1.36$ & -5.25 & -3.66 & 1.59 & PBDB-T & 0.91 & 21.3 & 66.7 & 13.00 & [136] \\
\hline Y9 & 1.36 & -5.59 & -3.78 & 1.81 & PBDB-T & 0.90 & 23.3 & 63.0 & 13.26 & [137] \\
\hline Y1-4F (Y3) & 1.31 & -5.56 & -4.11 & 1.45 & PBDB-T-F & 0.83 & 25.2 & 68.5 & 14.80 & [138] \\
\hline Y11 & 1.31 & -5.69 & -3.87 & 1.82 & PM6 & 0.83 & 26.7 & 74.3 & 16.54 & [139] \\
\hline Y14 & 1.30 & -5.56 & -4.01 & 1.55 & PBDB-T & 0.80 & 26.2 & 71.5 & 14.92 & [140] \\
\hline Y15 & 1.30 & -5.56 & -3.93 & 1.63 & PM6 & 0.87 & 23.8 & 68.5 & 14.13 & [141] \\
\hline Y18 & 1.31 & -5.58 & -3.91 & 1.67 & PM6 & 0.84 & 25.7 & 76.5 & 16.52 & [142] \\
\hline $\mathrm{Y} 22$ & 1.36 & -5.69 & -3.94 & 1.75 & PM6 & 0.85 & 24.4 & 74.1 & 15.40 & [144] \\
\hline $\mathrm{MS}-4 \mathrm{~F}$ & 1.41 & -5.63 & -3.91 & 1.72 & PBDB-T & 0.85 & 19.6 & 70.6 & 11.75 & [145] \\
\hline $\mathrm{MS}-4 \mathrm{Cl}$ & 1.37 & -5.68 & -3.99 & 1.69 & PBDB-T & 0.81 & 20.3 & 71.2 & 11.79 & [145] \\
\hline SNTI & 1.22 & -5.80 & -4.20 & 1.60 & PM6 & 0.47 & 2.1 & 43.0 & 0.42 & [146] \\
\hline NTI & 1.68 & -5.64 & -3.94 & 1.70 & PBDB-T & 0.72 & 1.88 & 33.0 & 0.45 & [146] \\
\hline NTTI & 1.45 & -5.38 & -3.83 & 1.55 & PBDB-T & 0.80 & 17.1 & 63.0 & 8.61 & {$[146]$} \\
\hline $\mathrm{BTzO}-4 \mathrm{~F}$ & $\approx 1.38$ & -5.45 & -3.88 & 1.57 & PBDB-T & 0.84 & 23.6 & 69.7 & 13.80 & [147] \\
\hline PZT & 1.39 & -5.58 & -3.76 & 1.82 & PBDB-T & 0.91 & 23.2 & 68.6 & 14.50 & [149] \\
\hline PZT- $\gamma$ & 1.36 & -5.57 & -3.78 & 1.79 & PBDB-T & 0.90 & 24.7 & 71.3 & 15.80 & [149] \\
\hline A702 & 1.39 & -5.41 & -3.74 & 1.67 & PBDB-T & 0.90 & 21.9 & 60.0 & 11.84 & [150] \\
\hline LA03 & 1.64 & -6.01 & -3.71 & 2.30 & PBDB-T & 0.94 & 11.3 & 61.3 & 6.49 & [151] \\
\hline
\end{tabular}

${ }^{a}$ Optical bandgap calculated from the absorption edge (onset) of the polymer films: $E_{\mathrm{g}}{ }^{\text {opt }}=1240 / \lambda_{\text {edge }}{ }^{b}$ Electrochemical bandgap obtained from: $E_{\mathrm{g}}{ }^{\text {ec }}=E_{\mathrm{LUMO}}-$ Eномо.

来看, 分子设计策略主要包括以下两个方面:

(1)主链结构. D-A 共轭策略仍然是目前最有效的策 略, 即将给体 “ $\mathrm{D}$ ” 单元和受体 “ $\mathrm{A}$ ” 单元交替连接或稠 合构筑分子主链. 给体分子设计中, 常用的策略是 $D-A 、 D-\pi-A-\pi 、 D-A-D-A-D$ 型等, 受体分子设计中为 A-D-A、A- $\pi-D-\pi-A 、 A-D A D-A$ 型等. 基于 BTA 及其衍 生物的有机光伏材料中, “ $\mathrm{D}$ ” 单元通常为苯并二噻吩、 苯并二呋喃、引达省并二噻吩、噻咯并二噻吩、噻吩等, “ $\pi$ ” 桥通常为噻吩、并噻吩等单元. 通过调整主链结构, 可以很好地调整分子的吸收谱带、能级、共混薄膜的形 貌及载流子迁移率等相关性能, 而位于给体单元和受体 单元之间的 “ $\pi$ ” 桥, 也可以降低二者之间的空间位阻, 改善分子的平面性.

(2)侧链工程. 引入功能性侧链如柔性侧链(烷基侧 链、烷氧基侧链、烷硫基侧链、硅烷基侧链等), 共轭侧 链(取代噻吩、取代苯环等), 以及吸电子基团(氟原子、 氯原子、丙二腈基等)等, 可以对材料性质进一步调控.

尽管基于三氮唑单元的有机光伏材料已历经数十 年的发展, 构筑了结构种类丰富的给受体光伏材料, 目 前其仍具有广阔的研究前景, 特别是基于三氮唑单元的 非富勒烯型受体材料. 今后, 进一步探索更深层次的分 子设计机理, 从而系统性地指导分子设计, 也是尤为重 要的研究工作. 为了进一步推动有机光伏领域的发展, 拓展应用场景(例如叠层器件、半透明器件、室内低功 率器件等), 在继续探索并设计新型的有机光伏材料的 同时, 也需要从器件整体的角度, 如与界面层材料、电 极材料、器件工艺等协同优化, 致力于从多角度优化并
提升器件性能. 提高材料的环境(光、氧气、水分等)稳 定性，降低材料的合成工序和生产成本，降低大面积制 备过程中能量转换效率的损失等是今后研究中需要重 点关注的问题，以推动有机光伏领域早日走向商业化应 用.

\section{作者简介}

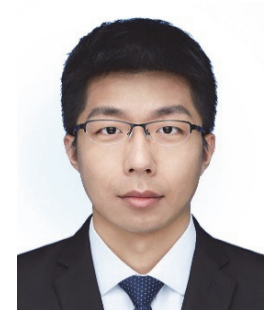

白阳, 2014 年和 2019 年于北京化工大学材料科学与工程 学院获得学士学位和硕士学位, 目前师从张志国教授, 攻读 博士学位, 研究方向为有机光电功能材料.

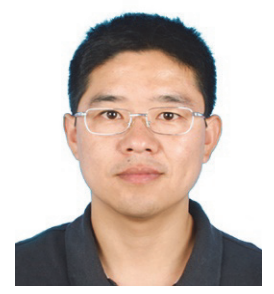

薛灵伟博士, 北京化工大学材料科学与工程学院博士后, 2017 年于北京科技大学获得博士学位, 期间于中国科学院化 学研究所联合培养, 师从李永舫院士. 研究方向为有机光电 功能材料. 


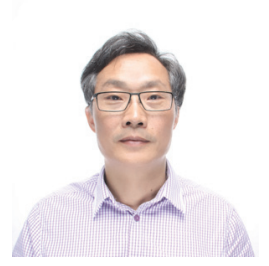

王海侨, 北京化工大学教授、博士生导师, 北京市水性聚 合物合成与应用工程技术研究中心主任. 华中科技大学学士、 硕士、博士, 清华大学化工系博士后. 主要从事光电功能高分 子材料和水性环保材料方面的研究. 发表学术论文 170 余篇, 申请国家发明专利 20 余项。

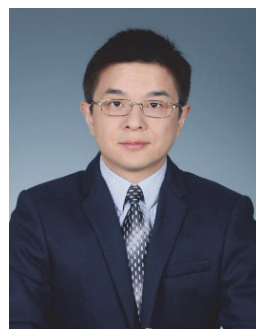

张志国博士, 北京化工大学材料科学与工程学院教授, 博士生导师. 2009 年于武汉大学获得博士学位, 期间参加 “国 家公派博士生联合培养项目”在新加坡学习 2 年. 2009 年在中 国科学院化学所跟随李永舫院士从事博士后研究, 2012 年 3 月 晋升副研究员, 2018 年 5 月调到北京化工大学工作, 组建光伏 材料与器件实验室. 近年紧密围绕活性层材料和界面层材料 的设计和制备, 开展了系统的工作, 并多次获得世界领先的 光伏效率. 2017 年获得国家基金委优秀青年基金资助, 2018 2020 连续 3 年入选 Clarivate Analytics “全球高被引科学家” 名单.

\section{References}

[1] National Renewable Energy Laboratories Best Research-Cell Efficiencies. https://www.nrel.gov/pv/cell-efficiency.html.

[2] (a) Chen, J.; Cao, Y. Acc. Chem. Res. 2009, 42, 1709; (b) Li, Y. Acc. Chem. Res. 2012, 45, 723; (c) Roncali, J. Acc. Chem. Res. 2009, 42, 1719; (d) Fu, H.; Wang, Z.; Sun, Y. Angew. Chem. Int. Ed. 2019, 58, 4442; (e) An, C.; Zheng, Z.; Hou, J. Chem. Commun. 2020, 56, 4750; (f) Cheng, Y.-J.; Yang, S.-H.; Hsu, C.-S. Chem. Rev. 2009, 109, 5868; (g) Fan, Q.; Mendez-Romero, U. A.; Guo, X.; Wang, E.; Zhang, M.; Li, Y. Chem. - Asian J. 2019, 14, 3085; (h) Cheng, P.; Li, G.; Zhan, X.; Yang, Y. Nat. Photonics 2018, 12, 131; (i) Li, G.; Chang, W.-H.; Yang, Y. Nat. Rev. Mater. 2017, 2, 17043; (j) Gao, C.; Wang, L.; Li, X.; Wang, H. Polym. Chem. 2014, 5, 5200; (k) Chochos, C. L.; Tagmatarchisc, N.; Gregoriou, V. G. RSC Adv. 2013, 3, 716; (1) Chamberlain, G. A. Solar Cells 1983, 8, 47; (m) Huang, F.; Bo, Z.-S.; Geng, Y.-H.; Wang, X.-H.; Wang, L.-X.; Ma, Y.-G.; Hou, J.-H.; Hu, W.-P.; Pei, J.; Dong, H.-L.; Wang, S.; Li, Z.; Shuai, Z.-G.; Li, Y.-F.; Cao, Y. Acta Polym. Sinica 2019, 50, 988 (in Chinese). (黄飞, 薄志山, 耿延候, 王献红, 王利祥, 马於光, 侯剑 辉, 胡文平, 裴坚, 董焕丽, 王树, 李振, 帅志刚, 李永舫, 曹镛, 高分子学报, 2019, 50, 988.); (n) Wang, W.-X.; Wang, J.-Q.; Zheng, Z.; Hou, J.-H. Acta Chim. Sinica 2020, 78, 382 (in Chinese). (王文 璇, 王建邱, 郑众, 侯剑辉, 化学学报, 2020, 78, 382.); (o) Zheng, B.; Huo, L.; Li, Y. NPG Asia Mater. 2020, 12, 3; (p) Xu, X.; Li, K.; Wei, Q.; Yuan, J.; Zou, Y. Prog. Chem. 2021, 33, 165; (q) Li, W.-w. Acta Polym. Sinica 2019, 50, 209; (r) Liu, B.; Xu, Y.; Xia, D.; Xiao, C.; Yang, Z.; Li, W. Acta Phys.-Chim. Sinica 2021, 37, 2009056; (s) Lv, M.; Zhou, R.; Lu, K.; Wei, Z. Acta Chim. Sinica 2021, 79, 284 (in Chinese). (吕敏, 周瑞敏, 吕琨, 魏志祥, 化学学报, 2021, 79, 284); (t) Li, T.; Zhan, X. Acta Chim. Sinica 2021, 79, 257 (in Chinese). (李腾飞, 占肖卫, 化学学报, 2021, 79, 257); (u) Zhang, Z.-G.; Chen, Q. J. Funct. Polym. 2020, 33, 415; (v) Zhang, Z.; Zhang, S.; Liu, Z.; Zhang, Z.; Li, Y.; Li, C.; Chen, H. Acta
Phys.-Chim. Sinica 2019, 35, 394.

[3] David, K.; Melvin, C. J. Chem. Phys. 1958, 9, 950.

[4] Tang, C. W. Appl. Phys. Lett. 1986, 48, 183.

[5] Yu, G.; Gao, J.; Hummelen, J. C.; Wudl, F.; Heeger, A. J. Sci. Bull. 1995, 270, 1789.

[6] (a) Coakley, K. M.; McGehee, M. D. Chem. Mater. 2004, 16, 4533; (b) Dou, L.; You, J.; Yang, J.; Chen, C.-C.; He, Y.; Murase, S.; Moriarty, T.; Emery, K.; Li, G.; Yang, Y. Nat. Photonics 2012, 6, 180; (c) Halls, J. J. M.; Walsh, C. A.; Greenham, N. C.; Marseglia, E. A.; Friend, R. H.; Moratti, S. C.; Holmes, A. B. Nature 1995, 376, 498; (d) Kim, J. Y.; Lee, K.; Coates, N. E.; Moses, D.; Nguyen, T. Q.; Dante, M.; Heeger, A. J. Science 2007, 317, 222; (e) Krebs, F. C.; Espinosa, N.; Hosel, M.; Sondergaard, R. R.; Jorgensen, M. Adv. Mater. 2014, 26, 29; (f) Lee, J. K.; Ma, W. L.; Brabec, C. J.; Yuen, J.; Moon, J. S.; Kim, J. Y.; Lee, K.; Bazan, G. C.; Heeger, A. J. J. Am. Chem. Soc. 2008, 130, 3619; (g) Li, G.; Shrotriya, V.; Huang, J.; Yao, Y.; Moriarty, T.; Emery, K.; Yang, Y. Nat. Mater. 2005, 4, 864; (h) Peet, J.; Kim, J. Y.; Coates, N. E.; Ma, W. L.; Moses, D.; Heeger, A. J.; Bazan, G. C. Nat. Mater. 2007, 6, 497; (i) Gunes, S.; Neugebauer, H.; Sariciftci, N. S. Chem. Rev. 2007, 107, 1324; (j) Bessette, A.; Hanan, G. S. Chem. Soc. Rev. 2014, 43, 3342; (k) Winder, C.; Sariciftci, N. S. J. Mater. Chem. 2004, 14, 1077; (1) Beaujuge, P. M.; Frechet, J. M. J. Am. Chem. Soc. 2011, 133, 20009; (m) Zhou, H.; Yang, L.; You, W. Macromolecules 2012, 45, 607; (n) Bloking, J. T.; Giovenzana, T.; Higgs, A. T.; Ponec, A. J.; Hoke, E. T.; Vandewal, K.; Ko, S.; Bao, Z.; Sellinger, A.; McGehee, M. D. Adv. Energy Mater. 2014, 4, 1301426; (o) Yan, Y.; Liu, X.; Wang, T. Adv. Mater. 2017, 29, 1601674; (p) Gan, Q.; Bartoli, F. J.; Kafafi, Z. H. Adv. Mater. 2013, 25, 2385; (q) Li, G.; Zhu, R.; Yang, Y. Nat. Photonics 2012, 6, 153; (r) Dou, L.; Liu, Y.; Hong, Z.; Li, G.; Yang, Y. Chem. Rev. 2015, 115, 12633.

[7] (a) Alvarado, S. F.; Seidler, P. F.; Lidzey, D. G.; Bradley, D. D. C. Phys. Rev. Lett. 1998, 81, 1082; (b) Forrest, S. R. Nature 2004, 428, 911; (c) Halls, J. J. M.; Cornil, J.; Santos, D. A. d.; Silbey, R.; Hwang, D.-H.; Holmes, A. B.; Bredas, J. L.; Friend, R. H. Phys. Rev. B 1999, 60, 5721; (d) PA, H.; Raj, J.; G, L. Chem. Phys. Lett. 2001, 345, 33; (e) Zerza, G.; Brabec, C. J.; Cerullo, G.; De Silvestri, S.; Sariciftci, N. S. Synth. Met. 2001, 119, 637; (f) Wang, R.; Yao, Y.; Zhang, C.; Zhang, Y.; Bin, H.; Xue, L.; Zhang, Z. G.; Xie, X.; Ma, H.; Wang, X.; Li, Y.; Xiao, M. Nat. Commun. 2019, 10, 398.

[8] (a) McGlynn, S. P. Chem. Rev. 1958, 58, 1113; (b) Baran, D.; Kirchartz, T.; Wheeler, S.; Dimitrov, S.; Abdelsamie, M.; Gorman, J.; Ashraf, R. S.; Holliday, S.; Wadsworth, A.; Gasparini, N.; Kaienburg, P.; Yan, H.; Amassian, A.; Brabec, C. J.; Durrant, J. R.; McCulloch, I. Energ. Environ. Sci. 2016, 9, 3783; (c) Janssen, R. A.; Nelson, J. Adv. Mater. 2013, 25, 1847; (d) Li, W.; Hendriks, K. H.; Furlan, A.; Wienk, M. M.; Janssen, R. A. J. Am. Chem. Soc. 2015, 137, 2231; (e) Liu, J.; Chen, S.; Qian, D.; Gautam, B.; Yang, G.; Zhao, J.; Bergqvist, J.; Zhang, F.; Ma, W.; Ade, H.; Inganäs, O.; Gundogdu, K.; Gao, F.; Yan, H. Nat. Energy 2016, 1, 16089; (f) Yao, J.; Kirchartz, T.; Vezie, M. S.; Faist, M. A.; Gong, W.; He, Z.; Wu, H.; Troughton, J.; Watson, T.; Bryant, D.; Nelson, J. Phys. Rev. Appl. 2015, 4, 014020 .

[9] (a) Scharber, M. C.; Sariciftci, N. S. Prog. Polym. Sci. 2013, 38, 1929; (b) Ran, N. A.; Love, J. A.; Takacs, C. J.; Sadhanala, A.; Beavers, J. K.; Collins, S. D.; Huang, Y.; Wang, M.; Friend, R. H.; Bazan, G. C.; Nguyen, T. Q. Adv. Mater. 2016, 28, 1482; (c) Nelson, J. Mater. Today 2011, 14, 462.

[10] (a) Li, Y.; Zou, Y. Adv. Mater. 2008, 20, 2952; (b) Min, J.; Zhang, Z.-G.; Li, Y. Chem. Mater. 2012, 24, 3247; (c) Chang, C. Y.; Cheng, Y. J.; Hung, S. H.; Wu, J. S.; Kao, W. S.; Lee, C. H.; Hsu, C. S. Adv. Mater. 2012, 24, 549; (d) Chen, H.-Y.; Hou, J.; Zhang, S.; Liang, Y.; Yang, G.; Yang, Y.; Yu, L.; Wu, Y.; Li, G. Nat. Photonics 2009, 3, 649; (e) Huo, L.; Zhang, S.; Guo, X.; Xu, F.; Li, Y.; Hou, J. Angew. Chem. Int. Ed. 2011, 50, 9697.

[11] (a) Ingana, O.; Zhang, F.; Andersson, M. R. Acc. Chem. Res. 2009, 42, 1731; (b) Scharber, M. C.; Mühlbacher, D.; Koppe, M.; Denk, P.; Waldauf, C.; Heeger, A. J.; Brabec, C. J. Adv. Mater. 2006, 18, 789; (c) Dennler, G.; Scharber, M. C.; Ameri, T.; Denk, P.; Forberich, K.; Waldauf, C.; Brabec, C. J. Adv. Mater. 2008, 20, 579; (d) Qian, D.; Zheng, Z.; Yao, H.; Tress, W.; Hopper, T. R.; Chen, S.; Li, S.; Liu, J.; Chen, S.; Zhang, J.; Liu, X. K.; Gao, B.; Ouyang, L.; Jin, Y.; Pozina, G.; Buyanova, I. A.; Chen, W. M.; Inganas, O.; Coropceanu, V.; Bredas, J. L.; Yan, H.; Hou, J.; Zhang, F.; Bakulin, A. A.; Gao, F. Nat. Mater. 2018, 17, 703; (e) He, Z.; Zhong, C.; Huang, X.; Wong, W.-Y.; Wu, H.; Chen, L.; Su, S.; Cao, Y. Adv. Mater. 2011, 23, 4636. 
[12] (a) Christian, W. T.; Christensen, C.; Meldal, M. J. Org. Chem. 2002, 67, 3057; (b) Moses, J. E.; Moorhouse, A. D. Chem. Soc. Rev. 2007, 36, 1249; (c) Hein, J. E.; Fokin, V. V. Chem. Soc. Rev. 2010, 39, 1302; (d) Gerard, B.; Ryan, J.; Beeler, A. B.; Porco, J. A. Cheminform 2006, 37, 6405; (e) Zhang, X.; Hsung, R. P.; Li, H. Chem. Commun. 2007, 2420; (f) Wei, F.; Li, H.; Song, C.; Ma, Y.; Zhou, L.; Tung, C. H.; Xu, Z. Org. Lett. 2015, 17, 2860; (g) Zhang, Z.; Zhou, Q.; Ye, F.; Xia, Y.; Wu, G.; Hossain, M. L.; Zhang, Y.; Wang, J. Adv. Synth. Catal. 2015, 357, 2277; (h) Wei, F.; Wang, W.; Ma, Y.; Tung, C.-H.; Xu, Z. Chem. Commun. 2016, 52, 14188; (i) Wang, W. G.; Peng, X. L.; Wei, F.; Tung, C. H.; Xu, Z. H. Angew. Chem. Int. Ed. 2016, 55, 649; (j) Zhou, W.; Zhang, M.; Li, H.; Chen, W. Org. Lett. 2017, 19, 10.

[13] (a) Li, Y. C.; Qi, C.; Li, S. H.; Zhang, H. J.; Sun, C. H.; Yu, Y. Z.; Pang, S. P. J. Am. Chem. Soc. 2010, 132, 12172; (b) Urankar, D.; Pevec, A.; Turel, I.; KosMrlj, J. Cryst. Growth Des. 2010, 10, 4920; (c) Urankar, D.; Pinter, B.; Pevec, A.; De Proft, F.; Turel, I.; Kosmrlj, J. Inorg. Chem. 2010, 49, 4820; (d) Connell, T. U.; White, J. M.; Smith, T. A.; Donnelly, P. S. Inorg. Chem. 2016, 55, 2776.

[14] (a) Cong, B.; Su, Z.; Zhao, Z.; Wang, B. CrystEngComm 2017, 19, 7154; (b) Kan, L.; Cai, J.; Jin, Z.; Li, G.; Liu, Y.; Xu, L. Inorg. Chem. 2018, 58, 391; (c) Wang, X.; Zhang, H.; Wang, X.; Zhang, S.; Liu, J.; Lin, H.; Liu, G. Inorg. Chem. Commun. 2018, 88, 60.

[15] Lau, Y. H.; Rutledge, P. J.; Watkinson, M.; Todd, M. H. Chem. Soc. Rev. 2011, 40, 2848.

[16] (a) Lee, T.; Cho, M.; Ko, S.-Y.; Youn, H.-J.; Baek, D. J.; Cho, W.-J.; Kang, C.-Y.; Kim, S. J. Med. Chem. 2007, 50, 585; (b) Yu, S.; Wang, L.; Wang, Y.; Song, Y.; Cao, Y.; Jiang, Y.; Sun, Q.; Wu, Q. RSC Adv. 2013, 3, 13486; (c) Yu, S.; Wang, N.; Chai, X.; Wang, B.; Wu, Q. Arch. Pharm. Res. 2013, 36, 13486.

[17] Liu, X.; Cai, P.; Chen, Z.; Zhang, L.; Zhang, X.; Sun, J.; Wang, H.; Chen, J.; Peng, J.; Chen, H.; Cao, Y. Polymer 2014, 55, 1707.

[18] (a) Banal, J. L.; Subbiah, J.; Graham, H.; Lee, J.-K.; Ghiggino, K. P.; Wong, W. W. H. Polym. Chem. 2013, 4, 1077; (b) Ghosh, S.; Bedi, A.; Zade, S. S. RSC Adv. 2015, 5, 5312; (c) Zhang, Z.-G.; Bai, Y.; Li, Y. Chin. J. Polym. Sci. 2020, 39, 1.

[19] Cui, C.; Li, Y. Energ. Environ. Sci. 2019, 12, 3225.

[20] Zhang, Z.; Peng, B.; Liu, B.; Pan, C.; Li, Y.; He, Y.; Zhou, K.; Zou, Y. Polym. Chem. 2010, $1,1441$.

[21] Price, S. C.; Stuart, A. C.; Yang, L.; Zhou, H.; You, W. J. Am. Chem. Soc. 2011, 133, 4625.

[22] Tumbleston, J. R.; Stuart, A. C.; Gann, E.; You, W.; Ade, H. Adv. Energy Mater. 2013, 23, 3463.

[23] Chen, D. Y.; Hsu, Y. Y.; Hsu, H. C.; Chen, B. S.; Lee, Y. T.; Fu, H.; Chung, M. W.; Liu, S. H.; Chen, H. C.; Chi, Y. Chem. Commun. 2010, 46, 5256.

[24] Li, W.; Albrecht, S.; Yang, L.; Roland, S.; Tumbleston, J. R.; McAfee, T.; Yan, L.; Kelly, M. A.; Ade, H.; Neher, D.; You, W. J. Am. Chem. Soc. 2014, 136, 15566.

[25] Bauer, N.; Zhang, Q.; Zhu, J.; Peng, Z.; Yan, L.; Zhu, C.; Ade, H.; Zhan, X.; You, W. J. Mater. Chem. A 2017, 5, 22536.

[26] Rech, J. J.; Yan, L.; Peng, Z.; Dai, S.; Zhan, X.; Ade, H.; You, W. Macromolecules 2019, 52, 6523.

[27] (a) Pagliaro, M.; Ciriminna, R. J. Mater. Chem. 2005, 15, 4981; (b) Deng, D.; Zhou, E.; Wei, Z. Acta Phys.-Chim. Sinica 2018, 34, 1239.

[28] Liu, B.; Chen, X.; Zou, Y.; Xiao, L.; Xu, X.; He, Y.; Li, L.; Li, Y. Macromolecules 2012, 45, 6898.

[29] (a) Woo, C. H.; Beaujuge, P. M.; Holcombe, T. W.; Lee, O. P.; Fre'chet, J. M. J. J. Am. Chem. Soc. 2010, 132, 15547; (b) Bin, H.; Zhong, L.; Yang, Y.; Gao, L.; Huang, H.; Sun, C.; Li, X.; Xue, L.; Zhang, Z.-G.; Zhang, Z.; Li, Y. Adv. Energy Mater. 2017, 1700746; (c) Yiu, A. T.; Beaujuge, P. M.; Lee, O. P.; Woo, C. H.; Toney, M. F.; Frechet, J. M. J. Am. Chem. Soc. 2012, 134, 2180.

[30] (a) Huo, L.; Liu, T.; Fan, B.; Zhao, Z.; Sun, X.; Wei, D.; Yu, M.; Liu, Y.; Sun, Y. Adv. Mater. 2015, 27, 6969; (b) Huo, L.; Huang, Y.; Fan, B.; Guo, X.; Jing, Y.; Zhang, M.; Li, Y.; Hou, J. Chem. Commun. 2012, 48, 3318.

[31] Kim, F. S.; Guo, X.; Watson, M. D.; Jenekhe, S. A. Adv. Mater. 2010, 22, 478.

[32] Li, K.; Li, Z.; Feng, K.; Xu, X.; Wang, L.; Peng, Q. J. Am. Chem. Soc. 2013, 135, 13549.

[33] (a) Lee, D.; Stone, S. W.; Ferraris, J. P. Chem. Commun. 2011, 47, 10987; (b) Sista, P.; Biewer, M.; Stefan, M. Macromol. Rapid Commun. 2012, 33, 9; (c) Lee, D.; Hubijar, E.; Kalaw, G. J. D.; Ferraris, J. P. Chem. Mater. 2012, 24, 2534.
[34] (a) Wang, E.; Ma, Z.; Zhang, Z.; Vandewal, K.; Henriksson, P.; Inganas, O.; Zhang, F.; Andersson, M. R. J. Am. Chem. Soc. 2011, 133, 14244; (b) Qin, R.; Li, W.; Li, C.; Du, C.; Veit, C.; Schleiermacher, H.-F.; Andersson, M.; Bo, Z.; Liu, Z.; Inganas, O.; Wuerfel, U.; Zhang, F. J. Am. Chem. Soc. 2009, 131, 14612; (c) Bijleveld, J. C.; Gevaerts, V. S.; Di Nuzzo, D.; Turbiez, M.; Mathijssen, S. G.; de Leeuw, D. M.; Wienk, M. M.; Janssen, R. A. Adv. Mater. 2010, 22, E242; (d) Su, M. S.; Kuo, C. Y.; Yuan, M. C.; Jeng, U. S.; Su, C. J.; Wei, K. H. Adv. Mater. 2011, 23, 3315.

[35] Kim, J. H.; Song, C. E.; Shin, N.; Kang, H.; Wood, S.; Kang, I. N.; Kim, B. J.; Kim, B.; Kim, J. S.; Shin, W. S.; Hwang, D. H. ACS Appl. Mater. Inter. 2013, 5, 12820.

[36] (a) Bathula, C.; Song, C. E.; Badgujar, S.; Hong, S.-J.; Kang, I.-N.; Moon, S.-J.; Lee, J.; Cho, S.; Shim, H.-K.; Lee, S. K. J. Mater Chem. 2012, 22, 22224; (b) Anthony, J. E. Chem. Rev. 2006, 106, 5028; (c) Shi, Q.; Fan, H.; Liu, Y.; Hu, W.; Li, Y.; Zhan, X. Macromolecules 2011, 44, 9173; (d) Winzenberg, K. N.; Kemppinen, P.; Fanchini, G.; Bown, M.; Collis, G. E.; Forsyth, C. M.; Hegedus, K.; Singh, T. B.; Watkins, S. E. Chem. Mater. 2009, 21, 5701; (e) Anthony, J. E. Angew. Chem. Int. Ed. 2008, 47, 452; (f) Chung, D. S.; Park, J. W.; Yun, W. M.; Cha, H.; Kim, Y. H.; Kwon, S. K.; Park, C. E. ChemSusChem 2010, 3, 742; (g) Park, J. H.; Chung, D. S.; Lee, D. H.; Kong, H.; Jung, I. H.; Park, M. J.; Cho, N. S.; Park, C. E.; Shim, H. K. Chem. Commun. 2010, 46, 1863.

[37] Uy, R. L.; Yan, L.; Li, W.; You, W. Macromolecules 2014, 47, 2289.

[38] (a) Alghamdi, A. A. B.; Watters, D. C.; Yi, H.; Al-Faifi, S.; Almeataq, M. S.; Coles, D.; Kingsley, J.; Lidzey, D. G.; Iraqi, A. J. Mater. Chem. A 2013, 1, 5165; (b) Li, Y.; Pan, Z.; Miao, L.; Xing, Y.; Chen, Y. Polym. Chem. 2014, 5, 330; (c) Shin, S. A.; Park, J. B.; Kim, J. H.; Hwang, D. H. Synth. Met. 2013, 172, 54; (d) Zhou, E.; Cong, J.; Hashimoto, K.; Tajima, K. Macromolecules 2013, 46, 763.

[39] Wood, S.; Kim, J.-H.; Hwang, D.-H.; Kim, J.-S. Chem. Mater. 2015, $27,4196$.

[40] Bin, H.; Zhong, L.; Zhang, Z.-G.; Gao, L.; Yang, Y.; Xue, L.; Zhang, J.; Zhang, Z.; Li, Y. Sci. China Chem. 2016, 59, 1317.

[41] Yan, T.; Bin, H.; Sun, C.; Zhang, Z. G.; Li, Y. Org. Electron. 2018, $55,106$.

[42] Ye, L.; Xiong, Y.; Chen, Z.; Zhang, Q.; Fei, Z.; Henry, R.; Heeney, M.; O'Connor, B. T.; You, W.; Ade, H. Adv. Mater. 2019, 31, 1808153.

[43] Kim, J.-H.; Kim, H. U.; Song, C. E.; Kang, I.-N.; Lee, J.-K.; Shin, W. S.; Hwang, D.-H. Sol. Energy Mater. Sol. Cells 2013, 108, 113.

[44] Gao, L.; Zhang, Z. G.; Xue, L.; Min, J.; Zhang, J.; Wei, Z.; Li, Y. Adv. Mater. 2016, 28, 1884.

[45] Gao, L.; Zhang, Z. G.; Bin, H.; Xue, L.; Yang, Y.; Wang, C.; Liu, F.; Russell, T. P.; Li, Y. Adv. Mater. 2016, $28,8288$.

[46] Bin, H.; Zhang, Z.-G.; Gao, L.; Chen, S.; Zhong, L.; Xue, L.; Yang, C.; Li, Y. J. Am. Chem. Soc. 2016, 138, 4657.

[47] Yang, Y.; Zhang, Z.-G.; Bin, H.; Chen, S.; Gao, L.; Xue, L.; Yang, C.; Li, Y. J. Am. Chem. Soc. 2016, 138, 15011.

[48] Bin, H.; Gao, L.; Zhang, Z. G.; Yang, Y.; Zhang, Y.; Zhang, C.; Chen, S.; Xue, L.; Yang, C.; Xiao, M.; Li, Y. Nat. Commun. 2016, 7, 13651.

[49] Yan, T.; Bin, H.; Yang, Y.; Xue, L.; Zhang, Z.-G.; Li, Y. Sci. China Chem. 2017, 60, 537.

[50] Huang, H.; Bin, H.; Peng, Z.; Qiu, B.; Sun, C.; Liebman-Pelaez, A.; Zhang, Z.-G.; Zhu, C.; Ade, H.; Zhang, Z.; Li, Y. Macromolecules 2018, 51, 6028 .

[51] Bin, H.; Yang, Y.; Peng, Z.; Ye, L.; Yao, J.; Zhong, L.; Sun, C.; Gao, L.; Huang, H.; Li, X.; Qiu, B.; Xue, L.; Zhang, Z.-G.; Ade, H.; Li, Y. Adv. Energy Mater. 2017, 1702324.

[52] Fan, Q.; Su, W.; Meng, X.; Guo, X.; Li, G.; Ma, W.; Zhang, M.; Li, Y. Solar RRL 2017, 1, 1700020 .

[53] Su, W.; Meng, Y.; Guo, X.; Fan, Q.; Zhang, M.; Jiang, Y.; Xu, Z.; Dai, Y.; Xie, B.; Liu, F.; Zhang, M.; Russell, T. P.; Li, Y. J. Mater. Chem. A 2018, 6, 16403.

[54] Xue, L.; Yang, Y.; Xu, J.; Zhang, C.; Bin, H.; Zhang, Z. G.; Qiu, B.; Li, X.; Sun, C.; Gao, L.; Yao, J.; Chen, X.; Yang, Y.; Xiao, M.; Li, Y. Adv. Mater. 2017, 1703344.

[55] Su, W.; Li, G.; Fan, Q.; Zhu, Q.; Guo, X.; Chen, J.; Wu, J.; Ma, W.; Zhang, M.; Li, Y. J. Mater. Chem. A 2019, 7, 2351.

[56] (a) Li, Y.; Lin, J. D.; Che, X.; Qu, Y.; Liu, F.; Liao, L. S.; Forrest, S. R. J. Am. Chem. Soc. 2017, 139, 17114; (b) Zhang, H.; Yao, H.; Hou, J.; Zhu, J.; Zhang, J.; Li, W.; Yu, R.; Gao, B.; Zhang, S.; Hou, J. Adv. Mater. 2018, 30, e1800613; (c) Tang, M. L.; Oh, J. H.; 
Reichardt, A. D.; Bao, Z. J. Am. Chem. Soc. 2009, 131, 3733.

[57] Yan, T.; Bin, H.; Sun, C.; Zhang, Z.-G.; Li, Y. Org. Electron. 2018, $57,255$.

[58] Pan, F.; Sun, C.; Bin, H.; Angunawela, I.; Lai, W.; Meng, L.; Ade, H.; Li, Y. Org. Electron. 2020, 78, 105603.

[59] Fan, B.; Ying, L.; Zhu, P.; Pan, F.; Liu, F.; Chen, J.; Huang, F.; Cao, Y. Adv. Mater. 2017, 29, 1703906.

[60] Zhong, L.; Bin, H.; Angunawela, I.; Jia, Z.; Qiu, B.; Sun, C.; Li, X.; Zhang, Z.; Ade, H.; Li, Y. Macromolecules 2019, 52, 4776.

[61] Wang, T.; Sun, R.; Xu, S.; Guo, J.; Wang, W.; Guo, J.; Jiao, X.; Wang, J.; Jia, S.; Zhu, X.; Li, Y.; Min, J. J. Mater. Chem. A 2019, 7, 14070.

[62] Qiu, B.; Chen, S.; Li, H.; Luo, Z.; Yao, J.; Sun, C.; Li, X.; Xue, L.; Zhang, Z.-G.; Yang, C.; Li, Y. Chem. Mater. 2019, 31, 6558.

[63] Tang, A.; Song, W.; Xiao, B.; Guo, J.; Min, J.; Ge, Z.; Zhang, J.; Wei, Z.; Zhou, E. Chem. Mater. 2019, 31, 3941.

[64] Liu, X.; Li, X.; Zheng, N.; Gu, C.; Wang, L.; Fang, J.; Yang, C. ACS Appl. Mater. Inter. 2019, 11, 43433.

[65] Tang, A.; Zhang, Q.; Du, M.; Li, G.; Geng, Y.; Zhang, J.; Wei, Z.; Sun, X.; Zhou, E. Macromolecules 2019, 52, 6227.

[66] Liu, B.; Chen, X.; He, Y.; Li, Y.; Xu, X.; Xiao, L.; Li, L.; Zou, Y. J. Mater. Chem. A 2013, 1, 570.

[67] Zhong, W.; Xiao, J.; Sun, S.; Jiang, X.-F.; Lan, L.; Ying, L.; Yang, W.; Yip, H.-L.; Huang, F.; Cao, Y. J. Mater. Chem. C 2016, 4, 4719.

[68] Li, Z.; Xie, R.; Zhong, W.; Fan, B.; Ali, J.; Ying, L.; Liu, F.; Li, N.; Huang, F.; Cao, Y. Solar RRL 2018, 2, 1800196.

[69] Li, Z.; Ying, L.; Xie, R.; Zhu, P.; Li, N.; Zhong, W.; Huang, F.; Cao, Y. Nano Energy 2018, 51, 434

[70] Fan, B.; Zhu, P.; Xin, J.; Li, N.; Ying, L.; Zhong, W.; Li, Z.; Ma, W.; Huang, F.; Cao, Y. Adv. Energy Mater. 2018, 8, 1703085.

[71] Fan, B.; Zhong, W.; Ying, L.; Zhang, D.; Li, M.; Lin, Y.; Xia, R.; Liu, F.; Yip, H. L.; Li, N.; Ma, Y.; Brabec, C. J.; Huang, F.; Cao, Y. Nat. Commun. 2019, 10, 4100.

[72] Duan, C.; Li, Z.; Pang, S.; Zhu, Y. L.; Lin, B.; Colberts, F. J. M.; Leenaers, P. J.; Wang, E.; Sun, Z. Y.; Ma, W.; Meskers, S. C. J.; Janssen, R. A. J. Solar RRL 2018, 2, 1800247.

[73] Liao, Z.; Xie, Y.; Chen, L.; Tan, Y.; Huang, S.; An, Y.; Ryu, H. S.; Meng, X.; Liao, X.; Huang, B.; Xie, Q.; Woo, H. Y.; Sun, Y.; Chen, Y. Adv. Funct. Mater. 2019, 29, 1808828.

[74] Li, X.; Weng, K.; Ryu, H. S.; Guo, J.; Zhang, X.; Xia, T.; Fu, H.; Wei, D.; Min, J.; Zhang, Y.; Woo, H. Y.; Sun, Y. Adv. Energy Mater. 2019, 1906809.

[75] Tang, A.; Xiao, B.; Chen, F.; Zhang, J.; Wei, Z.; Zhou, E. Adv. Energy Mater. 2018, 8, 1801582.

[76] Li, Z.; Xu, X.; Zhang, G.; Yu, T.; Li, Y.; Peng, Q. Solar RRL 2018, 2, 1800186.

[77] Chen, W.; Huang, G.; Li, X.; Li, Y.; Wang, H.; Jiang, H.; Zhao, Z.; Yu, D.; Wang, E.; Yang, R. ACS Appl. Mater. Inter. 2019, 11, 33173.

[78] Wang, X.; Han, J.; Jiang, H.; Liu, Z.; Li, Y.; Yang, C.; Yu, D.; Bao, X.; Yang, R. ACS Appl. Mater. Inter. 2019, 11, 44501.

[79] Chao, P.; Liu, L.; Zhou, J.; Qu, J.; Mo, D.; Meng, H.; Xie, Z.; He, F.; Ma, Y. ACS Appl. Energy Mater. 2018, 1, 6549.

[80] Gao, Y.; Shen, Z.; Tan, F.; Yue, G.; Liu, R.; Wang, Z.; Qu, S.; Wang, Z.; Zhang, W. Nano Energy 2020, 76, 104964.

[81] Xue, X.; Zheng, B.; Zhang, Y.; Zhang, M.; Wei, D.; Liu, F.; Wan, M.; Liu, J.; Chen, G.; Huo, L. Adv. Energy Mater. 2020, 10 , 2002142.

[82] Zhang, Y.; Wang, Y.; Ma, R.; Luo, Z.; Liu, T.; Kang, S.-H.; Yan, H.; Yuan, Z.; Yang, C.; Chen, Y. Chin. J. Polym. Sci. 2020, 38, 797.

[83] Li, Z.; Lin, H.; Jiang, K.; Carpenter, J.; Li, Y.; Liu, Y.; Hu, H.; Zhao, J.; Ma, W.; Ade, H.; Yan, H. Nano Energy 2015, 15, 607.

[84] Lin, H.; Chen, S.; Li, Z.; Lai, J. Y.; Yang, G.; McAfee, T.; Jiang, K.; Li, Y.; Liu, Y.; Hu, H.; Zhao, J.; Ma, W.; Ade, H.; Yan, H. Adv. Mater. 2015, 27, 7299 .

[85] Li, Z.; Jiang, K.; Yang, G.; Lai, J. Y.; Ma, T.; Zhao, J.; Ma, W.; Yan, H. Nat. Commun. 2016, 7, 13094.

[86] Chen, S.; Zhang, L.; Ma, C.; Meng, D.; Zhang, J.; Zhang, G.; Li, Z.; Chow, P. C. Y.; Ma, W.; Wang, Z.; Wong, K. S.; Ade, H.; Yan, H. Adv. Energy Mater. 2018, 8, 1702427.

[87] Chen, S.; Liu, Y.; Zhang, L.; Chow, P. C. Y.; Wang, Z.; Zhang, G.; Ma, W.; Yan, H. J. Am. Chem. Soc. 2017, 139, 6298.

[88] He, M.; Li, W.; Tian, H.; Tong, H.; Zhang, J.; Liu, J.; Xie, Z.; Geng, Y.; Wang, F. Org. Electron. 2019, 65, 31.

[89] Qi, F.; Song, J.; Xiong, W.; Huo, L.; Sun, X.; Sun, Y. Dyes Pigm. 2018, 155, 126.

[90] Guo, H.; Huang, B.; Zhang, L.; Chen, L.; Xie, Q.; Liao, Z.; Huang,
S.; Chen, Y. ACS Appl. Mater. Inter. 2019, 11, 15853.

[91] Xie, Q.; Liu, Y.; Liao, X.; Cui, Y.; Huang, S.; Hu, L.; He, Q.; Chen, L.; Chen, Y. Macromol. Rapid Commun. 2020, 41, 2000454.

[92] Zhang, L.; He, C.; Chen, J.; Yuan, P.; Huang, L.; Zhang, C.; Cai, W.; Liu, Z.; Cao, Y. Macromolecules 2010, 43, 9771.

[93] Min, J.; Zhang, Z.-G.; Zhang, S.; Zhang, M.; Zhang, J.; Li, Y. Macromolecules 2011, 44, 7632 .

[94] (a) Chu, T. Y.; Lu, J.; Beaupre, S.; Zhang, Y.; Pouliot, J. R.; Wakim, S.; Zhou, J.; Leclerc, M.; Li, Z.; Ding, J.; Tao, Y. J. Am. Chem. Soc. 2011, 133, 4250; (b) Hou, J.; Chen, H.; Zhang, S.; Li, G.; Yang, Y. J. Am. Chem. Soc. 2008, 130, 16144.

[95] Wang, K.; Zhao, Y.; Tang, W.; Zhang, Z.-G.; Fu, Q.; Li, Y. Org. Electron. 2014, 15, 818 .

[96] Deng, M.; Xu, X.; Lee, Y. W.; Woo, H. Y.; Bi, Z.; Ma, W.; Li, Y.; Peng, Q. ACS Appl. Mater. Inter. 2018, 11, 3308.

[97] Weng, C.; Wang, W.; Liang, J.; Wang, G.; Tan, S.; Shen, P. J. Polym. Sci., Part A: Polym. Chem. 2018, 56, 2330.

[98] Li, F.; Tang, A.; Zhang, B.; Zhou, E. ACS Macro Lett. 2019, 8, 1599.

[99] Ma, S.; Song, Y.; Wang, Z.; He, B.; Yang, X.; Li, L.; Xu, B.; Zhang, J.; Huang, F.; Cao, Y. Polymer 2019, 179, 121580.

[100] Dong, Y.; Cai, W.; Hu, X.; Zhong, C.; Huang, F.; Cao, Y. Polymer 2012, 53, 1465 .

[101] Dong, Y.; Cai, W.; Wang, M.; Li, Q.; Ying, L.; Huang, F.; Cao, Y. Org. Electron. 2013, 14, 2459

[102] Dong, Y.; Hu, X.; Duan, C.; Liu, P.; Liu, S.; Lan, L.; Chen, D.; Ying, L.; Su, S.; Gong, X.; Huang, F.; Cao, Y. Adv. Mater. 2013, 25, 3683.

[103] Lan, L.; Zhang, G.; Dong, Y.; Ying, L.; Huang, F.; Cao, Y. Polymer 2015, 67, 40 .

[104] Feng, K.; Yuan, J.; Bi, Z.; Ma, W.; Xu, X.; Zhang, G.; Peng, Q. iScience 2019, 12, 1 .

[105] Lan, L.; Chen, Z.; Hu, Q.; Ying, L.; Zhu, R.; Liu, F.; Russell, T. P.; Huang, F.; Cao, Y. Adv. Sci. 2016, 3, 1600032.

[106] (a) Nielsen, C. B.; Ashraf, R. S.; Treat, N. D.; Schroeder, B. C.; Donaghey, J. E.; White, A. J.; Stingelin, N.; McCulloch, I. Adv. Mater. 2015, 27, 948; (b) Li, H.; Sun, S.; Mhaisalkar, S.; Zin, M. T.; Lam, Y. M.; Grimsdale, A. C. J. Mater. Chem. A 2014, 2, 17925; (c) Wang, L.; Cai, D.; Zheng, Q.; Tang, C.; Chen, S.-C.; Yin, Z. ACS Macro Lett. 2013, 2, 605.

[107] Fan, B.; Zhang, K.; Jiang, X. F.; Ying, L.; Huang, F.; Cao, Y. Adv Mater. 2017, 1606396.

[108] Fan, B.; Ying, L.; Wang, Z.; He, B.; Jiang, X.-F.; Huang, F.; Cao, Y. Energ. Environ. Sci. 2017, 10, 1243.

[109] Zhong, W.; Li, K.; Cui, J.; Gu, T.; Ying, L.; Huang, F.; Cao, Y. Macromolecules $\mathbf{2 0 1 7}, 50,8149$.

[110] Li, Z.; Zhong, W.; Ying, L.; Liu, F.; Li, N.; Huang, F.; Cao, Y. Nano Energy 2019, 64, 103931.

[111] Zheng, N.; Mahmood, K.; Zhong, W.; Liu, F.; Zhu, P.; Wang, Z.; Xie, B.; Chen, Z.; Zhang, K.; Ying, L.; Huang, F.; Cao, Y. Nano Energy 2019, 58, 724.

[112] Fan, B.; Du, X.; Liu, F.; Zhong, W.; Ying, L.; Xie, R.; Tang, X.; An, K.; Xin, J.; Li, N.; Ma, W.; Brabec, C. J.; Huang, F.; Cao, Y. Nat. Energy 2018, 3, 1051

[113] Fan, B.; Zhang, D.; Li, M.; Zhong, W.; Zeng, Z.; Ying, L.; Huang, F.; Cao, Y. Sci. China Chem. 2019, 62, 746.

[114] Fan, B.; Zeng, Z.; Zhong, W.; Ying, L.; Zhang, D.; Li, M.; Peng, F.; Li, N.; Huang, F.; Cao, Y. ACS Energy Lett. 2019, 4, 2466.

[115] Fan, B.; Li, M.; Zhang, D.; Zhong, W.; Ying, L.; Zeng, Z.; An, K.; Huang, Z.; Shi, L.; Bazan, G. C.; Huang, F.; Cao, Y. ACS Energy Lett. 2020, 2087.

[116] Li, W.; Yan, L.; Zhou, H.; You, W. Chem. Mater. 2015, 27, 6470.

[117] Chen, Y.; Jiang, X.; Chen, X.; Zhou, J.; Tang, A.; Geng, Y.; Guo, Q.; Zhou, E. Macromolecules 2019, 52, 8625.

[118] Jiang, X.; Wang, J.; Wang, W.; Yang, Y.; Zhan, X.; Chen, X. Dyes Pigm. 2019, 166, 381 .

[119] Liu, B.; Zou, Y.-p.; Long, M.; He, Y.-h.; Zhong, H.; Li, Y.-f. Synth. Met. 2012, 162, 630.

[120] (a) Roncali, J.; Leriche, P.; Cravino, A. Adv. Mater. 2007, 19, 2045 ; (b) Zhao, G.; Wu, G.; He, C.; Bai, F.-Q.; Xi, H.; Zhang, H.-X.; Li, Y. J. Mater. Chem. C 2009, 113, 2636.

[121] Chen, Y.; Du, Z.; Chen, W.; Liu, Q.; Sun, L.; Sun, M.; Yang, R. Org. Electron. 2014, 15, 405.

[122] Bin, H.; Yang, Y.; Zhang, Z. G.; Ye, L.; Ghasemi, M.; Chen, S.; Zhang, Y.; Zhang, C.; Sun, C.; Xue, L.; Yang, C.; Ade, H.; Li, Y. J. Am. Chem. Soc. 2017, 139, 5085.

[123] Guo, J.; Bin, H.; Wang, W.; Chen, B.; Guo, J.; Sun, R.; Zhang, Z.-G.; Jiao, X.; Li, Y.; Min, J. J. Mater. Chem. A 2018, 6, 15675. 
[124] Gu, H.; Qin, Y.; Dai, W.; Zhou, D.; Xie, Y. Synth. Met. 2019, 251, 95.

[125] (a) Yue, Q.; Liu, W.; Zhu, X. J. Am. Chem. Soc. 2020, 142, 11613; (b) Zhong, Y.; Causa, M.; Moore, G. J.; Krauspe, P.; Xiao, B.; Gunther, F.; Kublitski, J.; Shivhare, R.; Benduhn, J.; BarOr, E.; Mukherjee, S.; Yallum, K. M.; Rehault, J.; Mannsfeld, S. C. B.; Neher, D.; Richter, L. J.; DeLongchamp, D. M.; Ortmann, F.; Vandewal, K.; Zhou, E.; Banerji, N. Nat. Commun. 2020, 11, 833; (c) Zhang, J.; Liu, W.; Zhou, G.; Yi, Y.; Xu, S.; Liu, F.; Zhu, H.; Zhu, X. Adv. Energy Mater. 2019, 10, 1903298; (d) Chen, S.; Wang, Y.; Zhang, L.; Zhao, J.; Chen, Y.; Zhu, D.; Yao, H.; Zhang, G.; Ma, W.; Friend, R. H.; Chow, P. C. Y.; Gao, F.; Yan, H. Adv. Mater. 2018, 30, e1804215; (e) Li, S.; Zhan, L.; Sun, C.; Zhu, H.; Zhou, G.; Yang, W.; Shi, M.; Li, C. Z.; Hou, J.; Li, Y.; Chen, H. J. Am. Chem. Soc. 2019, 141, 3073; (f) Han, G.; Yi, Y. J. Phys. Chem. Lett. 2019, 10, 2911; (g) Han, G.; Guo, Y.; Song, X.; Wang, Y.; Yi, Y. J. Mater. Chem. C 2017, 5, 4852; (h) Li, S.; Li, C.-Z.; Shi, M.; Chen, H. ACS Energy Lett. 2020, 5, 1554; (i) Xue, L.-W.; Yang, Y.-X.; Li, Y.-F. Sci. Sinica Chim. 2016, 46, 623 (in Chinese). (薛灵伟, 杨运旭, 李永舫, 中国 科学: 化学, 2016, 46, 623.)

[126] Gwinner, M. C.; Brenner, T. J. K.; Lee, J.-K.; Newby, C.; Ober, C. K.; McNeill, C. R.; Sirringhaus, H. J. Mater. Chem. 2012, 22, 4436.

[127] Xiao, B.; Tang, A.; Zhang, J.; Mahmood, A.; Wei, Z.; Zhou, E. Adv. Energy Mater. 2017, 7, 1602269.

[128] Xiao, B.; Tang, A.; Yang, J.; Wei, Z.; Zhou, E. ACS Macro Lett. 2017, 6,410 .

[129] Tang, A.; Xiao, B.; Wang, Y.; Gao, F.; Tajima, K.; Bin, H.; Zhang, Z. G.; Li, Y.; Wei, Z.; Zhou, E. Adv. Funct. Mater. 2017, 28, 1704507.

[130] Wen, X.; Xiao, B.; Tang, A.; Hu, J.; Yang, C.; Zhou, E. Chin. J. Chem . 2018, 36, 392.

[131] Zhang, Q.; Xiao, B.; Du, M.; Li, G.; Tang, A.; Zhou, E. J. Mater. Chem. C 2018, 6, 10902.

[132] Xiao, B.; Du, M.; Wang, X.; Xiao, Z.; Li, G.; Tang, A.; Ding, L.; Geng, Y.; Sun, X.; Zhou, E. ACS Appl. Mater. Inter. 2019, 12, 1094.

[133] Wang, X.; Tang, A.; Yang, J.; Du, M.; Li, J.; Li, G.; Guo, Q.; Zhou, E. Sci. China Chem. 2020, 63, 1666.

[134] Feng, L.; Yuan, J.; Zhang, Z.; Peng, H.; Zhang, Z.-G.; Xu, S.; Liu, Y.; Li, Y.; Zou, Y. ACS Appl. Mater. Inter. 2017, 9, 31985.

[135] Yuan, J.; Huang, T.; Cheng, P.; Zou, Y.; Zhang, H.; Yang, J. L.;
Chang, S.-Y.; Zhang, Z.; Huang, W.; Wang, R.; Meng, D.; Gao, F.; Yang, Y. Nat. Commun. 2019, 10, 570 .

[136] Ma, X.; Luo, M.; Gao, W.; Yuan, J.; An, Q.; Zhang, M.; Hu, Z.; Gao, J.; Wang, J.; Zou, Y.; Yang, C.; Zhang, F. J. Mater. Chem. A 2019, 7, 7843.

[137] Luo, M.; Zhou, L.; Yuan, J.; Zhu, C.; Cai, F.; Hai, J.; Zou, Y. J. Energy Chem. 2020, 42, 169

[138] Wang, R.; Yuan, J.; Wang, R.; Han, G.; Huang, T.; Huang, W.; Xue, J.; Wang, H. C.; Zhang, C.; Zhu, C.; Cheng, P.; Meng, D.; Yi, Y.; Wei, K. H.; Zou, Y.; Yang, Y. Adv. Mater. 2019, 31, e1904215.

[139] Liu, S.; Yuan, J.; Deng, W.; Luo, M.; Xie, Y.; Liang, Q.; Zou, Y.; He, Z.; Wu, H.; Cao, Y. Nat. Photonics 2020, 14, 300.

[140] Luo, M.; Zhao, C.; Yuan, J.; Hai, J.; Cai, F.; Hu, Y.; Peng, H.; Bai, Y.; Tan, Z. a.; Zou, Y. Mater. Chem. Front. 2019, 3, 2483.

[141] Luo, M.; Zhu, C.; Yuan, J.; Zhou, L.; Keshtov, M. L.; Godovsky, D. Y.; Zou, Y. Chin. Chem. Lett. 2019, 30, 2343.

[142] Zou, Y.; Zhu, C.; Yuan, J.; Cai, F.; Meng, L.; Zhang, H.; Chen, H.; Li, J.; Qiu, B.; Peng, H.; Chen, S.; Hu, Y.; Yang, C.; Gao, F.; Li, Y. Energ. Environ. Sci. 2020, 13, 2459.

[143] Yuan, J.; Zhang, C.; Chen, H.; Zhu, C.; Cheung, S. H.; Qiu, B.; Cai, F.; Wei, Q.; Liu, W.; Yin, H.; Zhang, R.; Zhang, J.; Liu, Y.; Zhang, H.; Liu, W.; Peng, H.; Yang, J.; Meng, L.; Gao, F.; So, S.; Li, Y.; Zou, Y. Sci. China Chem. 2020, 63, 1159.

[144] Cai, F.; Peng, H.; Chen, H.; Yuan, J.; Hai, J.; Lau, T.-K.; Wang, J.; Hu, Y.; Liu, W.; Lu, X.; Zou, Y. J. Mater. Chem. A 2020, 8, 15984.

[145] Ma, S.; Feng, H.; Liu, X.; Hu, Z.; Yang, X.; Liang, Y.; Zhang, J.; Huang, F.; Cao, Y. ChemSusChem 2021, DOI: 10.1002/cssc. 202100592.

[146] Lv, R.; Geng, S.; Li, S.; Wu, F.; Li, Y.; Andersen, T. R.; Li, Y.; Lu, X.; Shi, M.; Chen, H. Solar RRL 2020, 4, 2000286.

[147] Liu, X.; Wei, Y.; Zhang, X.; Qin, L.; Wei, Z.; Huang, H. Sci. China Chem. 2020, 64, 228.

[148] Zhang, Z. G.; Li, Y. Angew. Chem. Int. Ed. 2021, 60, 4422.

[149] Fu, H.; Li, Y.; Yu, J.; Wu, Z.; Fan, Q.; Lin, F.; Woo, H. Y.; Gao, F.; Zhu, Z.; Jen, A. K. J. Am. Chem. Soc. 2021, 143, 2665.

[150] Zhang, B.; Li, J.; Tang, A.; Geng, Y.; Guo, Q.; Zhou, E. ACS Appl. Energy Mater. 2021, 4, 4217.

[151] Ma, Q.; Xue, X.; Zhong, L.; Angunawela, I.; Chen, S.; Ade, H.; Huo, L.; Zhang, Z.; Li, Y. J. Mater. Chem. C 2019, 7, 9031.

(Cheng, B.) 